NUREG/CR-6530

SAND94-1676

\title{
Deliberate Ignition of Hydrogen-Air-Steam Mixtures in Condensing Steam Environments
}

\section{DISCLAIMER}

This report was prepared as an account of work sponsored by an agency of the United States Government. Neither the United States Government nor any agency thereof, nor any of their bility for the accuracy warranty, express or implied, or assumes any legal liability or responsibility for the accuracy, completeness, or usefulness of any information, apparatus, product, or

Manuscript Completed: April 1997

Date Published: May 1997 process disclosed, or represents that its use would not infringe privately owned rights. Refermanufacturer, or otherwise commercial product, process, or service by trade name, trademark, mendation, or farity constitute or imply its endorsement, recomand opinions of authors expressed States Government or any agency thereof. The views Prepared by United States Government or any agency thereof.

T. K. Blanchat, Sandia National Laboratories

D. W. Stamps, University of Evansville

\section{MASTER}

Sandia National Laboratories

Albuquerque, NM 87185-1139

University of Evansville

1800 Lincoln Ave.

Evansville, IN 47722

\section{A. Malliakos, NRC Project Manager}

\section{Prepared for}

Division of Systems Technology

Office of Nuclear Regulatory Research

U.S. Nuclear Regulatory Commission

Washington, DC 20555-0001

NRC Job Code L2443
DISTRIBUTION OF THIS DOCUMENT IS UNLIMITED 



\section{DISCLAMMER}

Portions of this document may be illegible in electronic image products. Images are produced from the best available original doccument. 


\begin{abstract}
Large scale experiments were performed at the Surtsey Test Facility for the Nuclear Regulatory Commission to determine the effectiveness of thermal glow plug igniters to burn hydrogen in a condensing steam environment due to the presence of water sprays. The experiments were designed to determine if a detonation or an accelerated flame could occur in a hydrogen-air-steam mixture which was initially nonflammable due to steam dilution but was subsequently rendered flammable by rapid condensation of steam due to water sprays. Eleven Hydrogen Igniter Tests were conducted in the Surtsey test vessel. The Surtsey vessel was instrumented with pressure transducers, thermocouple rakes, gas grab sample bottles, hydrogen microsensors, and cameras. The Surtsey vessel contained two prototypic engineered systems: 1) a deliberate hydrogen ignition system and 2) a water spray system. The experiments were conducted under conditions scaled to be nearly prototypic of those expected in Advanced Light Water Reactors (such as the Combustion Engineering (CE) System $80+$ ), with prototypic spray drop diameter, spray mass flux, steam condensation rates, hydrogen injection flow rates, and using the actual proposed plant igniters. The lack of any significant pressure increase during the majority of the burn and condensation events, signified that localized, benign hydrogen deflagration(s) occurred with no significant pressure load on the Surtsey containment vessel. Igniter location did not appear to be a factor in the open geometry. Initially stratified tests with a stoichiometric mixture in the top showed that the water spray effectively mixes the initially stratified atmosphere prior to the deflagration event. All of the tests demonstrated that thermal glow plugs ignite hydrogen-airsteam mixtures under conditions with water sprays near the flammability limits previously determined for hydrogen-air-steam mixtures under quiescent conditions. This report describes these experiments, gives the experimental results, and provides interpretation of the results.
\end{abstract}





\section{Contents}

$\underline{\text { Page }}$

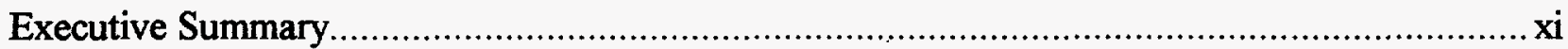

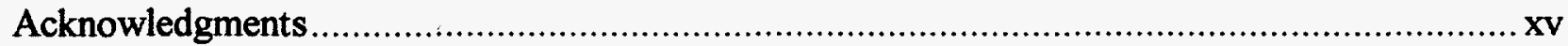

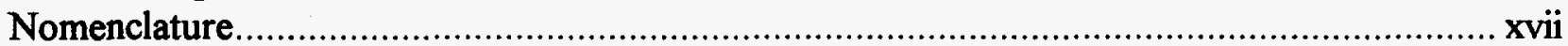

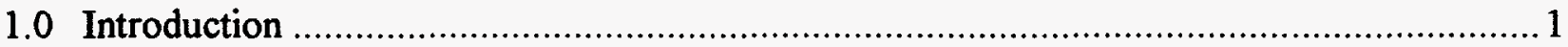

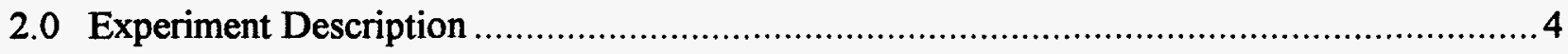

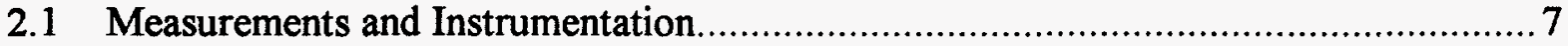

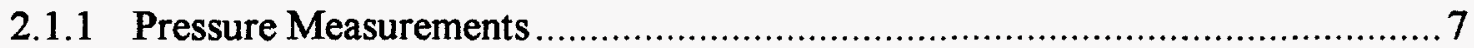

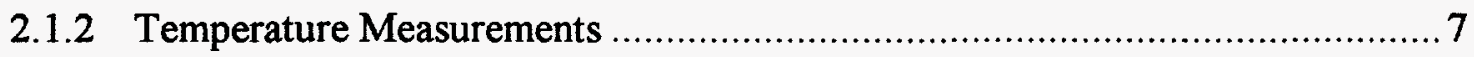

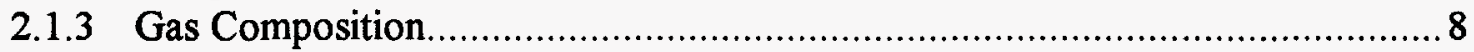

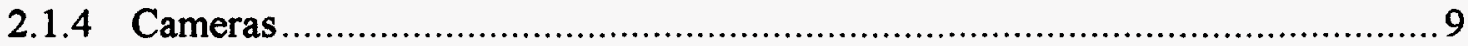

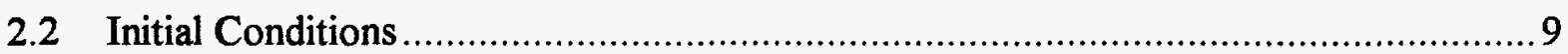

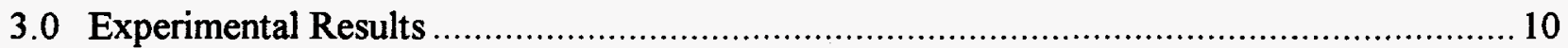

3.1 HIT-1 Pressure, Temperature, and Spray Flow Measurements............................... 11

3.2 HIT-2 Pressure, Temperature, and Spray Flow Measurements................................ 12

3.3 HIT-3 Pressure, Temperature, and Spray Flow Measurements ............................... 13

3.4 HIT-4 Pressure, Temperature, and Spray Flow Measurements ............................... 14

3.5 HIT-5 Pressure, Temperature, and Spray Flow Measurements ................................. 14

3.6 HIT-6 Pressure, Temperature, and Spray Flow Measurements ................................. 15

3.7 HIT-7 Pressure, Temperature, and Spray Flow Measurements ................................ 17

3.8 HIT-8 Pressure, Temperature, and Spray Flow Measurements ................................ 18

3.9 HIT-9 Pressure, Temperature, and Spray Flow Measurements ................................ 19

3.10 HIT-10 Pressure, Temperature, and Spray Flow Measurements .............................22

3.11 HIT-11 Pressure, Temperature, and Spray Flow Measurements ..............................20

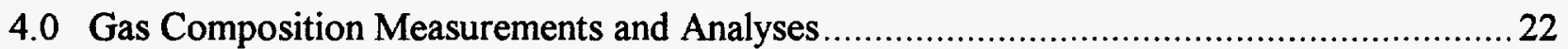

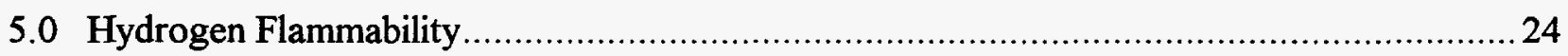

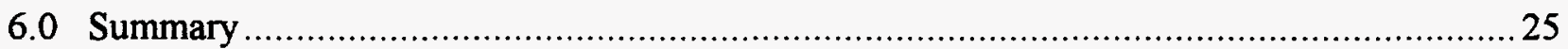

7.0 References 


\section{Figures}

Figure

Page

1. Location of the HIT experiments in the Surtsey vessel...............................................45

2. HIT instrumentation, mixing fans, hydrogen injectors, and spray nozzle .......................46

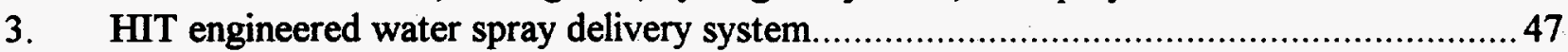

4. Thermal glow plug, glow plug mount, and spray shield ..............................................48 48

5. Location of the HIT instrumentation and systems in the Surtsey vessel..........................49

6. Identification of the Surtsey vessel wall and array thermocouples ................................50

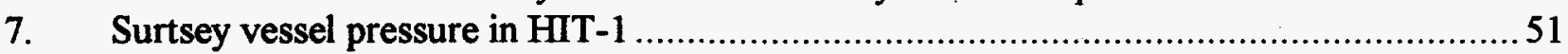

8. Surtsey vessel gas temperature from thermocouple array A in HIT-1...........................51

9. Surtsey vessel gas temperature from thermocouple array B in HIT-1 ...........................51

10. Surtsey vessel gas temperature from thermocouple array $\mathrm{C}$ in HIT-1 .........................51

11. Surtsey vessel gas temperature from thermocouple array $D$ in HIT-1.........................51

12. Surtsey vessel gas temperature from thermocouple array $\mathrm{E}$ in HIT-1 .........................51

13. Surtsey vessel average gas temperature in HIT-1.................................................52

14. Surtsey vessel dome, wall, and floor temperatures in HIT-1 …...............................52

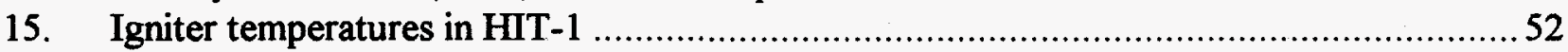

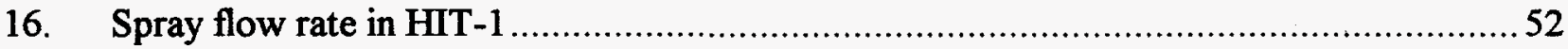

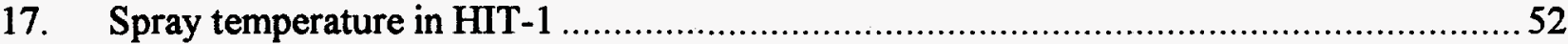

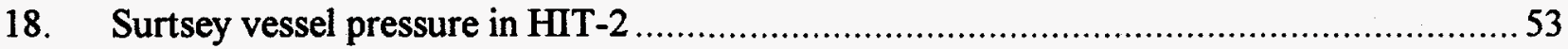

19. Surtsey vessel gas temperature from thermocouple array A in HIT-2 ...........................53

20. Surtsey vessel gas temperature from thermocouple array B in HIT-2 .........................53

21. Surtsey vessel gas temperature from thermocouple array C in HIT-2 …......................53

22. Surtsey vessel gas temperature from thermocouple array $D$ in HIT-2 ...........................53

23. Surtsey vessel gas temperature from thermocouple array E in HIT-2 ............................5 53

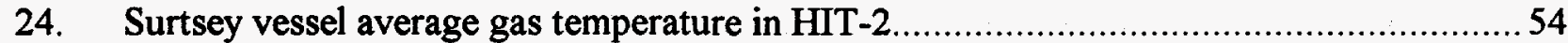

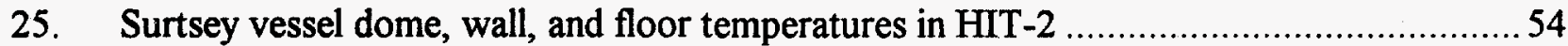

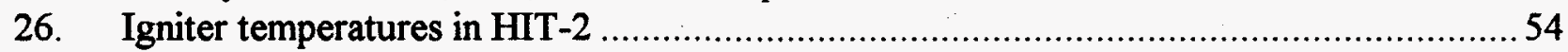

27. Spray flow rate in HIT-2

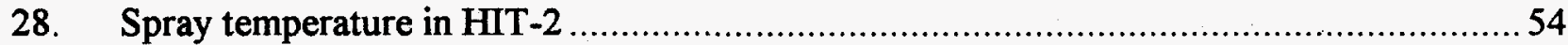

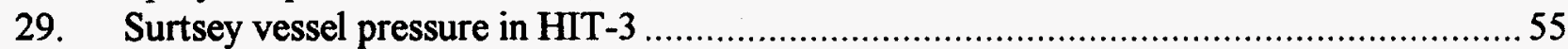

30. Surtsey vessel gas temperature from thermocouple array A in HIT-3 ...........................55

31. Surtsey vessel gas temperature from thermocouple array B in HIT-3 ............................55

32. Surtsey vessel gas temperature from thermocouple array $C$ in HIT-3 ….......................55

33. Surtsey vessel gas temperature from thermocouple array D in HIT-3 ..........................55

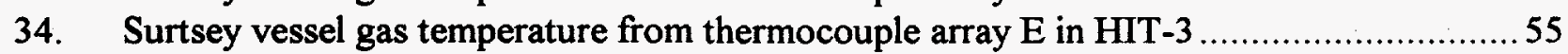

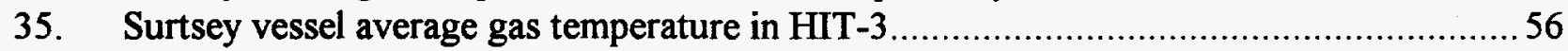

36. Surtsey vessel dome, wall, and floor temperatures in HIT-3 ..................................56

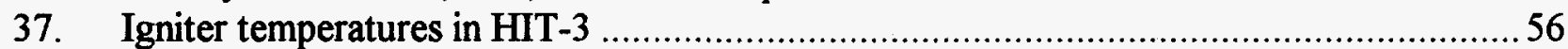

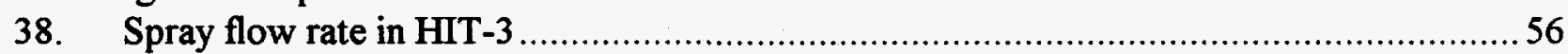

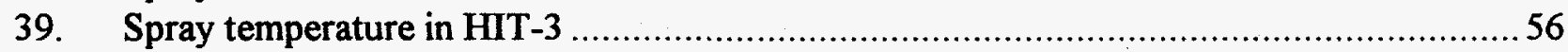

40. Surtsey vessel pressure in HIT-4

41. Surtsey vessel gas temperature from thermocouple array A in HIT-4 ……....................57 


\section{Figures (continued)}

Figure

Page

42. Surtsey vessel gas temperature from thermocouple array B in HIT-4 ..........................57

43. Surtsey vessel gas temperature from thermocouple array $\mathrm{C}$ in HIT-4 ........................5 57

44. Surtsey vessel gas temperature from thermocouple array $D$ in HIT-4 ......................57

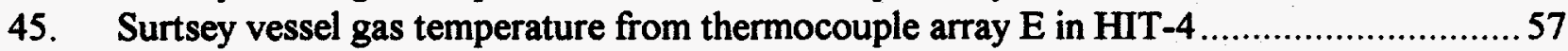

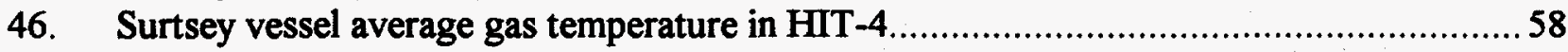

47. Surtsey vessel dome, wall, and floor temperatures in HIT-4 …................................. 58

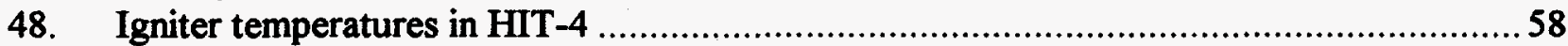

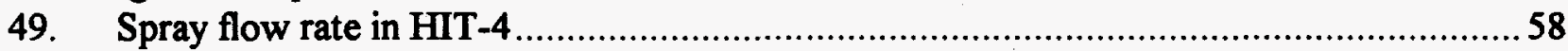

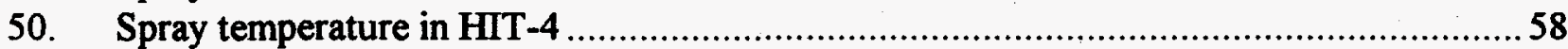

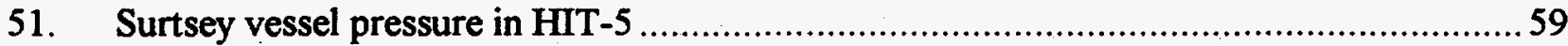

52. Surtsey vessel gas temperature from thermocouple array A in HIT-5........................ 59

53. Surtsey vessel gas temperature from thermocouple array B in HIT-5 .......................... 59

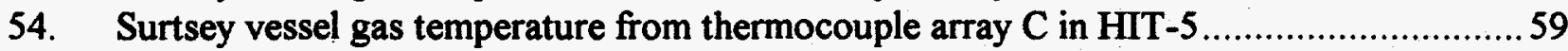

55. Surtsey vessel gas temperature from thermocouple array $D$ in HIT-5.........................59

56. Surtsey vessel gas temperature from thermocouple array $E$ in HIT-5 .........................59

57. Surtsey vessel average gas temperature in HIT-5............................................60

58. Surtsey vessel dome, wall, and floor temperatures in HIT-5 .................................60

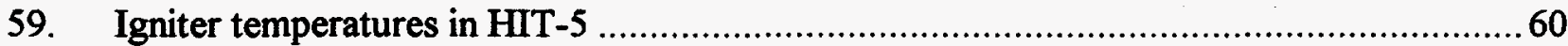

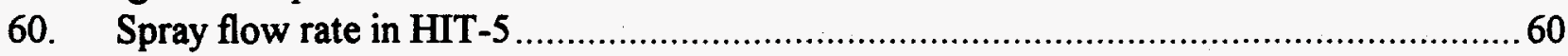

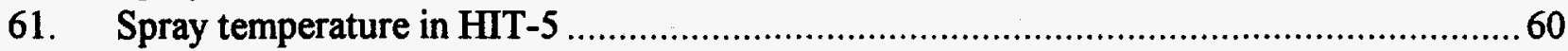

62. Hydrogen concentration measurements by microsensors and gas grab samples

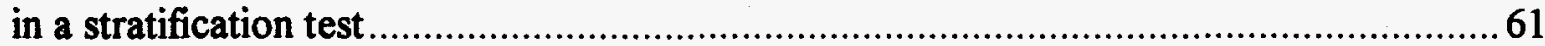

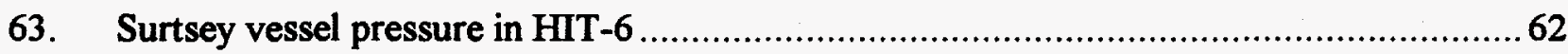

64. Surtsey vessel gas temperature from thermocouple array A in HIT-6.........................62

65. Surtsey vessel gas temperature from thermocouple array B in HIT-6..........................62

66. Surtsey vessel gas temperature from thermocouple array $\mathrm{C}$ in HIT-6........................62

67. Surtsey vessel gas temperature from thermocouple array D in HIT-6..........................6. 62

68. Surtsey vessel gas temperature from thermocouple array $\mathrm{E}$ in HIT-6.......................6. 62

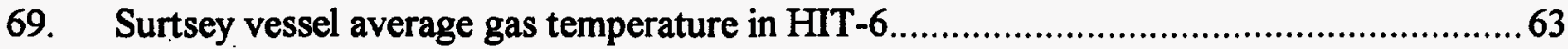

70. Surtsey vessel dome, wall, and floor temperatures in HIT-6 ..................................63

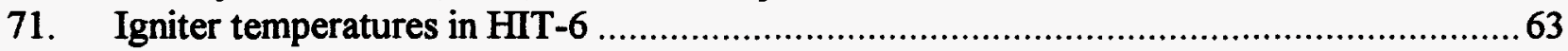

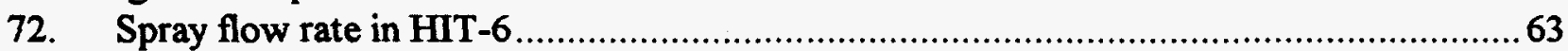

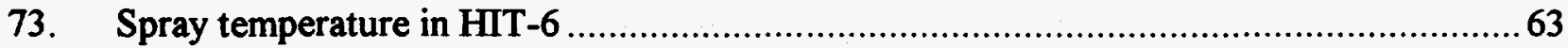

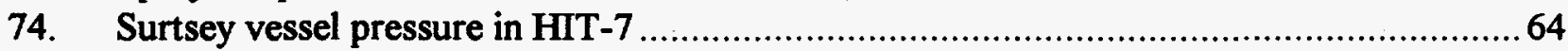

75. Surtsey vessel gas temperature from thermocouple array A in HIT-7 .........................64

76. Surtsey vessel gas temperature from thermocouple array B in HIT-7 ...........................64

77. Surtsey vessel gas temperature from thermocouple array $\mathrm{C}$ in HIT-7 .......................64

78. Surtsey vessel gas temperature from thermocouple array $\mathrm{D}$ in HIT-7.......................6 64

79. Surtsey vessel gas temperature from thermocouple array E in HIT-7 ..........................6 64

80. Surtsey vessel average gas temperature in HIT-7 ................................................65

81. Surtsey vessel dome, wall, and floor temperatures in HIT-7 .................................65 


\section{Figures (continued)}

Figure

$\underline{\text { Page }}$

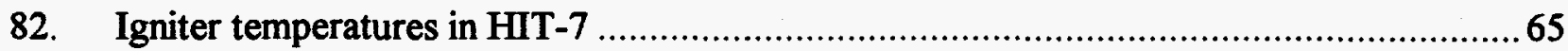

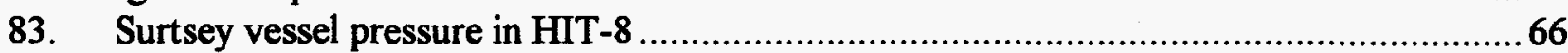

84. Surtsey vessel gas temperature from thermocouple array A in HIT-8 .......................66

85. Surtsey vessel gas temperature from thermocouple array B in HIT-8 ........................66

86. Surtsey vessel gas temperature from thermocouple array $\mathrm{C}$ in HIT-8 .........................66

87. Surtsey vessel gas temperature from thermocouple array D in HIT-8..........................66

88. Surtsey vessel gas temperature from thermocouple array $\mathrm{E}$ in HIT-8 ..........................66

89. Surtsey vessel average gas temperature in HIT-8 ...........................................67

90. Surtsey vessel dome, wall, and floor temperatures in HIT-8 ..................................67

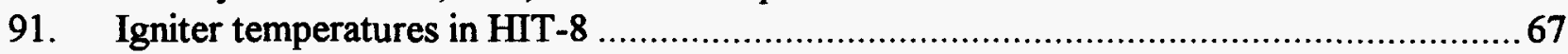

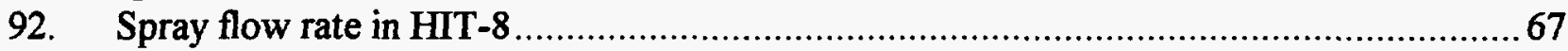

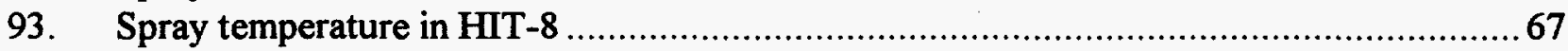

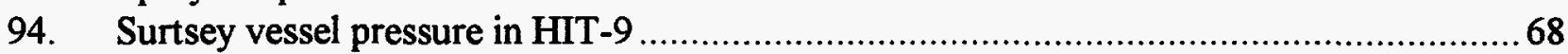

95. Surtsey vessel gas temperature from thermocouple array A in HIT-9.........................68

96. Surtsey vessel gas temperature from thermocouple array B in HIT $-9 . \ldots \ldots \ldots \ldots \ldots \ldots \ldots \ldots . . . \ldots 6$

97. Surtsey vessel gas temperature from thermocouple array $\mathrm{C}$ in HIT-9.........................68

98. Surtsey vessel gas temperature from thermocouple array D in HIT-9..........................68

99. Surtsey vessel gas temperature from thermocouple array $\mathrm{E}$ in HIT-9 .........................68

100. Surtsey vessel average gas temperature in HIT-9................................................69

101. Surtsey vessel dome, wall, and floor temperatures in HIT-9 ..................................69

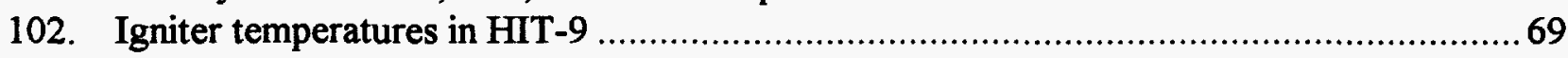

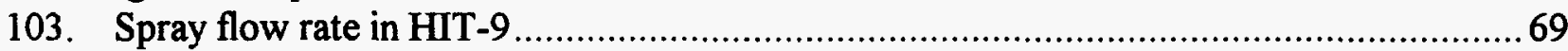

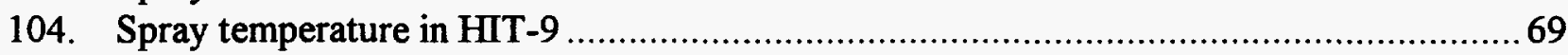

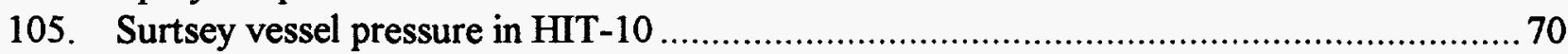

106. Surtsey vessel gas temperature from thermocouple array A in HIT-10....................... 70

107. Surtsey vessel gas temperature from thermocouple array B in HIT-10 ...................... 70

108. Surtsey vessel gas temperature from thermocouple array $\mathrm{C}$ in HIT-10...................... 70

109. Surtsey vessel gas temperature from thermocouple array D in HIT-10 ......................70

110. Surtsey vessel gas temperature from thermocouple array $E$ in HIT-10 ..................... 70

111. Surtsey vessel average gas temperature in HIT-10 ............................................. 71

112. Surtsey vessel dome, wall, and floor temperatures in HIT-10 ................................ 71

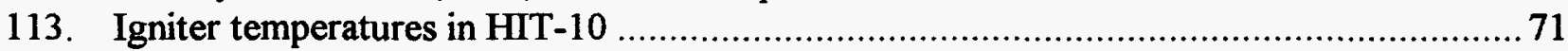

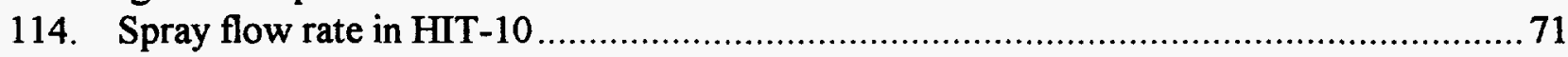

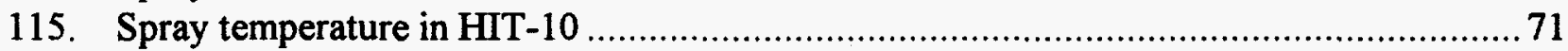

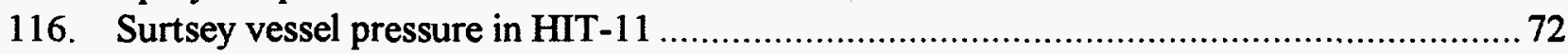

117. Surtsey vessel gas temperature from thermocouple array A in HIT-11 ...................... 72

118. Surtsey vessel gas temperature from thermocouple array B in HIT-11 ......................72

119. Surtsey vessel gas temperature from thermocouple array $\mathrm{C}$ in HIT-11 ......................72

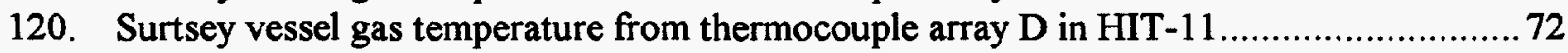

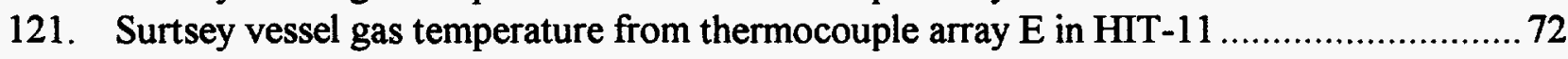

122. Surtsey vessel average gas temperature in HIT-11 .......................................... 73 
Figures (concluded)

Figure $\quad$ Page

123. Surtsey vessel dome, wall, and floor temperatures in HIT-11 ...................................73

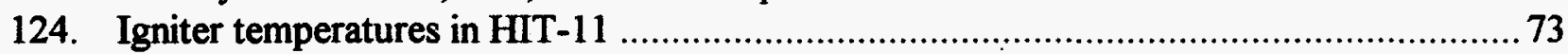

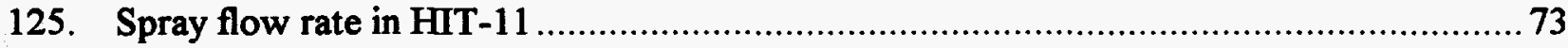

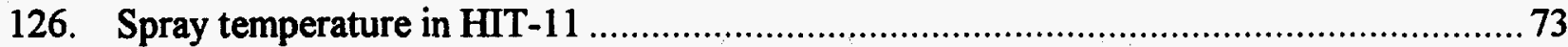

127. Comparison of experimental results with flammability limits data obtained for quiescent hydrogen-air-steam mixtures 


\section{Tables}

Table $\underline{\text { Page }}$

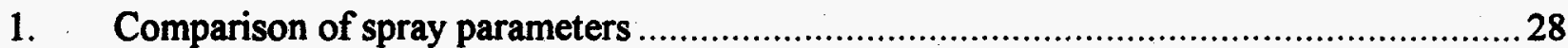

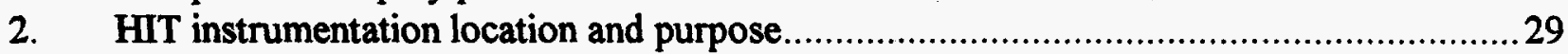

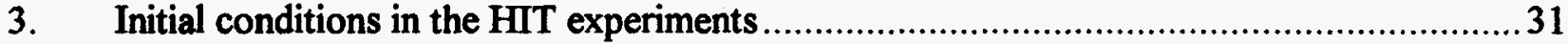

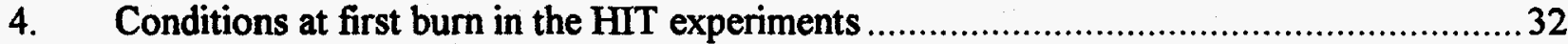

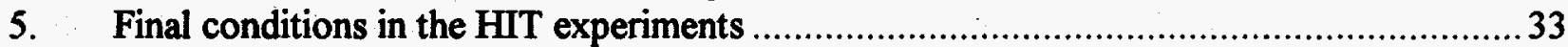

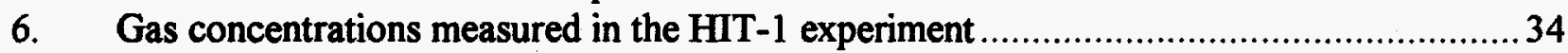

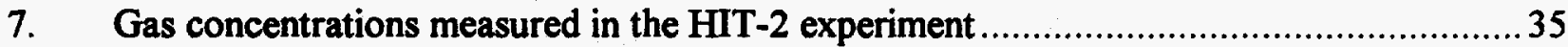

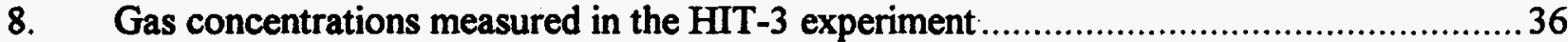

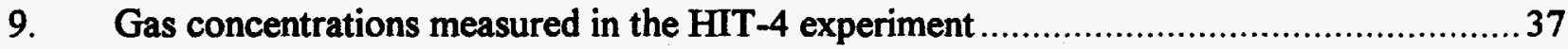

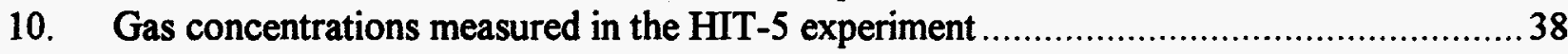

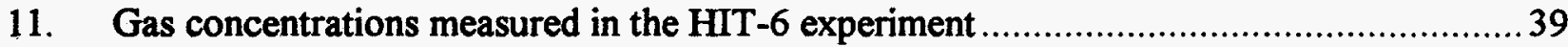

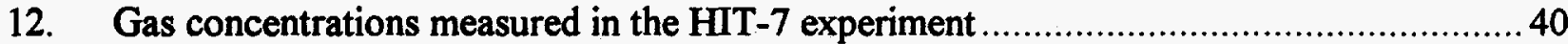

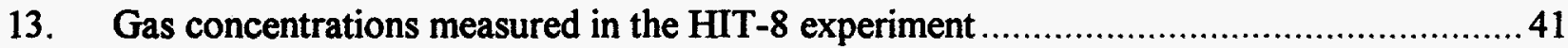

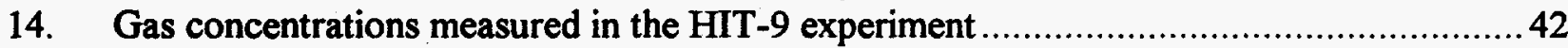

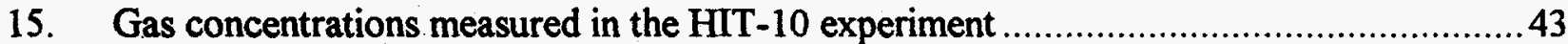

16. Gas concentrations measured in the HIT-11 experiment .............................................4 


\section{Executive Summary}

A hydrogen-air-steam mixture that is initially nonflammable because it is diluted by steam may be rendered flammable when water sprays cause rapid condensation of steam. If the condensation process is sufficiently rapid, then a question arises as to whether a detonation or an accelerated flame could occur in such mixtures if thermal glow plugs were active during the operation of the water sprays. Detonations or accelerated flames may be possible if: (1) ignition by thermal glow plugs is delayed until enough steam has been removed to make the mixture intrinsically detonable or (2) ignition occurs early near the flammability limits but the time for the entire mixture to burn is so long that any unburned mixture can be made intrinsically detonable by the action of the water sprays before the burn is complete.

The effect of water sprays on the combustion of hydrogen-air-steam mixtures was investigated in a 2048-cubic meter $\left(\mathrm{m}^{3}\right)$ spherical vessel [Ratzel, 1985]. Unlike the scenario described earlier, however, the water sprays and the combustible gas mixture were at the same temperature so that there was no steam condensation. Since the steam concentration did not change, the chemical sensitivity of the flammable mixture was fixed prior to activation of the igniters. Similar experiments were also performed using water sprays with hydrogen-air mixtures [Nelson, 1985; Shebeko et al., 1990]. In all of these experiments, the mixtures were flammable prior to the activation of the igniters. These experiments did not address the issue of mixtures becoming more reactive by the removal of steam during the same time the igniters were active. This issue was investigated for hydrogen-air-steam mixtures without water sprays in a 17-liter quasi-spherical vessel [Tamm et al., 1987]. By using water-cooled coils around the outside of the vessel, the steam condensation time could be reduced to less than 10 minutes. However, the condensation time can be significantly shorter when the steam is condensed by internal water sprays. Furthermore, the effect of the spray-generated turbulence on the combustion behavior was not investigated. The purpose of the current set of experiments was to investigate the combustion behavior of initially nonflammable mixtures that rapidly became flammable through the action of water sprays when the igniters were activated the entire time.

Depending on the location and the conditions under which hydrogen is released into the containment, the hydrogen may be either stratified or well mixed. Under stratified conditions, the hydrogen is concentrated in the upper part of the containment. If steam were absent, these mixtures would be more sensitive to detonation than if the same quantity of hydrogen was released at a low location and well mixed throughout the entire containment. For the CE System $80+$ containment, the well-mixed concentration of hydrogen is approximately 13.6 percent (\%) on a dry basis assuming 100\% zirconium-water reaction of the active cladding [CESSAR, 1993]. Hypothetically, if all of this hydrogen accumulates above the operating deck, the average concentration in that region would be approximately $19.3 \%$. The ability of water sprays to mix stratified mixtures is an important factor in determining the resulting combustion mode.

The combustion mode that results when initially nonflammable mixtures are rendered flammable by rapid condensation of steam caused by water sprays depends on the competition among three processes: (1) the removal of steam by water sprays, (2) the consumption of hydrogen by chemical reaction, and (3) for stratified mixtures, the mixing of hydrogen by water sprays. If the 


\section{Executive Summary}

time required to remove steam is slow relative to the other time scales, then combustion can be initiated as the mixture first becomes flammable and a slowly propagating flame will result.

The objectives of this program were developed to cover the conditions of well-mixed or stratified hydrogen-air-steam mixtures prior to the operation of the water sprays. The program objectives were to determine: (1) if detonations or other forms of energetic combustion (i.e., accelerated flames) are possible when originally nonflammable mixtures are rendered flammable by water sprays, (2) the effectiveness of water sprays in mixing hydrogen-stratified mixtures, and (3) the effect of hydrogen stratification on the maximum combustion pressure.

Experiments were conducted in the modified Surtsey vessel shown in Figure 1. The vessel is a domed cylinder $3.6 \mathrm{~m}$ in diameter, $5.6 \mathrm{~m}$ high, and has a volume of $56.7 \mathrm{~m}^{3}$. The vessel was instrumented with pressure transducers, gas grab sample bottles, hydrogen microsensors, thermocouple rakes, and cameras. A deliberate ignition system was installed which was composed of actual plant igniters (GM AC7G thermal glow plugs) at three locations. The effect of igniter location was tested using one or more igniters at these three locations. For most tests, the target water spray mass flux was scaled to one spray train at runout flow in the CE System $80+$ standard design. Owing to the characteristics of the nozzle used in the tests, the spray mass flux was the same as for the CE System $80+$ but the volumetric condensation rate for the tests was 1.63 times the CE System $80+$ rate. For these tests, a full-cone spray nozzle (Lechler model 461.148 having a $120^{\circ}$ nozzle spray angle) was installed at the top of the dome. When the water spray mass flux was scaled to the operation of both CE System 80+ independent spray trains, a high-capacity full-cone spray nozzle (Lechler model 461.206 having a $90^{\circ}$ nozzle spray angle) was installed at the top of the dome.

The experiments were conducted under conditions scaled to be nearly prototypical of those expected in hypothetical severe accidents typical to CE System 80+ containments. The quantities that were scaled included the spray mass flux (Table 1) and hydrogen mass flow rates for stratified tests.

Eleven combustion tests were conducted: 8 were well-mixed tests and 3 were stratified tests. The main parameters that were tested in these experiments were hydrogen concentration, steam condensation rate as determined by the water spray flow rate, and igniter location. Table 3 shows the initial conditions of the tests; Table 4 shows the conditions at the first burn; and Table 5 shows the conditions at the end of the tests after the water sprays were turned off. The first test, HIT-1, was performed to collect data and test gas grab sample techniques and igniter design. After test HIT-1, the time to purge gas sample lines was increased and gas sample data were considered more accurate. Results for HIT-7 were influenced by a small leak $(\sim 0.03$ megapascal/hour $(\mathrm{MPa} / \mathrm{hr})$ ) in the facility since the test was conducted over a long (23-hour) period. This leak did not have any significant influence on the results of the other tests because the test times were short ( 20 minutes). Results from HIT-7 were analyzed assuming the steam was saturated and that the remaining constituents leaked out in proportion to their composition in the facility. A steam condensation experiment was conducted before the combustion tests to determine the steam condensation rate due to water sprays in a nonflammable helium-air-steam mixture. Three 
mixing tests were performed at ambient conditions to determine if stratified conditions could be created for the combustion tests and to measure the mixing time with the water sprays.

In all of the combustion tests, one or more relatively slow deflagrations were recorded; no detonations were observed. The combustion behavior of the well-mixed tests can be loosely categorized into one of two types: (1) multiple deflagrations with relatively small pressure rises, and (2) a single deflagration with a pressure rise greater than those observed in the multiple deflagrations but lower than (about $70 \%$ ) the theoretical adiabatic constant volume value. The combustion behavior of the stratified tests using sprays was similar to that of the well-mixed tests. This is because the sprays were very effective in mixing the hydrogen before the mixture became flammable.

One stratified test was performed without using the spray system. As the steam condensed due to natural cool down of the vessel, the vessel pressure and temperature decreased slowly over time. Localized, benign hydrogen deflagrations (small temperature spikes with no associated pressure increases) occurred during the test. Gas grab samples taken at the end of the test indicated that the vessel had become well-mixed.

For mixture compositions that have directionally dependent flammability limits where the extent of combustion is controlled by hydrogen concentration, multiple deflagrations with relatively small pressure rises were observed. Within the range of experimental uncertainty, these mixtures lie below the downward flammability limit (below the "nose" of the curve, Figure 127). Combustion behavior was not dependent on igniter location. Since these mixtures have directionally dependent flammability limits (upward, horizontal, and downward propagation criteria), the upward propagation criterion was satisfied first and a marginal burn occurred. The combustion was incomplete and the pressure rise was small (1-10 kilopascal ( $\mathrm{kPa})$ ). The partial burn temporarily inerted the mixture, which did not become flammable again until additional steam was condensed by the water sprays. The partial burns were responsible for the multiple deflagrations. This behavior is illustrated in Figure 18, which shows the results of HIT-2, a well-mixed test with $13.6 \%$ hydrogen on a dry basis. The pressure rises were larger (up to $30 \mathrm{kPa}$ ) in the well-mixed tests with $13.8 \%$ hydrogen on a dry basis but having larger steam condensation rates. Multiple deflagrations, however, were again observed. This behavior is illustrated in Figure 105, which shows the results of HIT-10, a well-mixed test with $13.8 \%$ hydrogen on a dry basis and a spray flow rate nominally twice that of test HIT-2.

For mixture compositions that do not have directionally dependent flammability limits, a single deflagration with a pressure rise greater than those observed in the multiple deflagrations but lower than the theoretical adiabatic constant volume value was observed. Once these mixtures were rendered flammable by the water sprays, the flame could propagate in all directions, which consumed nearly all of the hydrogen. This resulted in a single deflagration with a pressure rise of about $70 \%$ of the adiabatic constant volume value. The increase in pressure did not achieve peak theoretical values because of heat losses from the relatively slow deflagration near the flammability limit. The single deflagration behavior is illustrated in Figure 29, which shows the results of HIT-3, a well-mixed test with a stoichiometric mixture $(29.7 \%$ hydrogen on a dry basis). 


\section{Executive Summary}

Three stratified tests were conducted with different spray flow rates but all having a near stoichiometric mixture in the upper part of the vessel. The target condition for each test was a stratified mixture with $29.5 \%$ hydrogen (dry basis) in the upper part of the vessel but having an equivalent well-mixed concentration of $13.5 \%$ hydrogen (dry basis). Different spray flow rates were used: 0.0 kilogram $(\mathrm{kg}) / \mathrm{second}$ (i.e., no sprays were used), $1.35 \mathrm{~kg} / \mathrm{second}$, and 3.17 $\mathrm{kg} / \mathrm{second}$. The behavior of these tests was similar to that of the comparable well-mixed tests with $\sim 13.5 \%$ hydrogen. This behavior is illustrated in Figure 63 , which shows the results of HIT6 , a stratified test with approximately $24 \%$ hydrogen (dry basis) in the upper part of the vessel. The sprays rapidly mixed the hydrogen in the vessel prior to the mixture becoming flammable so that the hydrogen was essentially uniform at $13.5 \%$ (dry basis) before ignition.

The mixing time was determined using newly developed hydrogen microsensors which provided spatially resolved real-time continuous output of hydrogen concentrations. A stratified test was conducted at ambient conditions with approximately $19 \%$ hydrogen (dry basis) in the upper part of the vessel. The hydrogen was mixed by water sprays with a flow rate of $1.58 \mathrm{~kg} / \mathrm{second}$. As shown in Figure 62, the mixing time was approximately 20 seconds for most of the vessel and less than 1 minute even for the lowest levels.

Multiple deflagrations with relatively small pressure rises or single deflagrations with pressure rises greater than those observed in the multiple deflagrations but lower than the theoretical adiabatic constant volume values were observed when igniters were on during the entire experiment. This is because ignition occurred near the flammability limit and the combustion time was fast relative to the time to condense steam. Detonations or other forms of energetic combustion (flame acceleration or DDT) were not observed in hydrogen-air-steam mixtures which were initially nonflammable owing to steam dilution but were rendered flammable by steam condensation caused by water sprays. Mixtures with hydrogen concentrations above approximately $24 \%$ (dry basis) exhibited a single deflagration with a relatively large pressure rise. Mixtures with these large hydrogen concentrations cannot exist under globally well-mixed conditions applicable to ALWR containments. These containments will have approximately $13.5 \%$ hydrogen (dry basis) on a well-mixed basis, assuming a $100 \%$ zirconium-water reaction of the active cladding. Hypothetically, if the hydrogen accumulates above the operating deck level, the concentration could be as high as $19.3 \%$ (dry basis) on a well-mixed basis above the floor of the operating deck. Tests were performed with $19.3 \%$ hydrogen to provide experimental data points between the $13.5 \%$ and the $29.7 \%$ hydrogen concentration data. Mixtures having $19.3 \%$ hydrogen or less exhibited multiple deflagrations with relatively small pressure rises.

Thermal glow plugs functioned as intended: ignition occurred near the flammability limits. The flammability limits for mixtures with water sprays were similar to previously obtained flammability limits for quiescent hydrogen-air-steam mixtures. Stratified mixtures and well-mixed mixtures yielded similar combustion pressures owing to the effective mixing by water sprays. Stratified hydrogen in the Surtsey vessel was made essentially uniform by the water sprays in less than one minute. 


\section{Acknowledgments}

The authors would like to thank M.D. Allen and M.M. Pilch for their useful discussions during the experimental program. The authors express their gratitude to R.T. Nichols, the lead mechanical engineer and site manager; to M.S. Oliver and T.F. Thornhill, who were the electronics and instrumentation engineers; to J. Ross and T.T. Covert, who were the mechanical technicians; and R. Hudgens and J.C. Andazola, who provided technical support during the experiments. The gas mass spectrometry technical assistance and analyses were provided by S.M. Thornberg and S.D. Reber. D.C. Williams, J.H. Bentz, and A. Malliakos reviewed the report, providing numerous helpful comments. M.L. Garcia typed, compiled, and edited the manuscript.

This work was supported by the U.S. Nuclear Regulatory Commission and was performed at Sandia National Laboratories, which is operated for the U.S. Department of Energy under Contract No. DE-AC04-94AL85000. The support and guidance of the NRC program managers A. Malliakos and C.G. Tinkler is gratefully acknowledged. 



\section{Nomenclature}

\begin{tabular}{|c|c|}
\hline $\begin{array}{l}\mathrm{CE} \\
\mathrm{CCD}\end{array}$ & $\begin{array}{l}\text { Combustion Engineering } \\
\text { charge coupled device }\end{array}$ \\
\hline HIT & hydrogen igniter test \\
\hline HVAC & heating, ventilation, and air-conditioning \\
\hline RCB & reactor containment building \\
\hline $\mathbf{f}_{\mathrm{NC}}$ & noncondensible gas fraction \\
\hline $\mathbf{f}_{\mathrm{NC}}^{0}$ & initial noncondensible gas fraction \\
\hline $\begin{array}{l}\mathrm{N}_{\mathrm{IC}} \\
\mathrm{N}_{\mathrm{N2}}^{0}\end{array}$ & $\begin{array}{l}\text { hydrogen gas moles injected into the Surtsey vessel } \\
\text { pretest moles of } \mathrm{N}_{2}\end{array}$ \\
\hline $\begin{array}{l}\mathrm{N}^{0} \mathrm{Total}^{\mathrm{t}} \\
\mathrm{N}_{\mathrm{H} \text {, burmed }}^{t}\end{array}$ & $\begin{array}{l}\text { total pretest moles of gas including steam and noncondensible gases } \\
\text { moles of } \mathrm{H}_{2} \text { burned at time } \mathrm{t}\end{array}$ \\
\hline $\mathrm{N}_{\mathrm{N} 2}^{t}$ & moles of $\mathrm{N}_{2}$ at time $\mathrm{t}$ \\
\hline$P_{\text {final }}$ & hydrogen manifold final pressure \\
\hline $\mathbf{P}_{\text {manifold, initial }}$ & hydrogen manifold initial pressure \\
\hline $\mathbf{R}$ & universal gas constant $(8.314 \mathrm{e}-6 \mathrm{MPa} \mathrm{m} / \mathrm{g} \cdot$ mole $\mathrm{K})$ \\
\hline $\mathbf{T}_{\text {manifold,final }}$ & hydrogen manifold final temperature \\
\hline$T_{\text {manifold,initial }}$ & hydrogen manifold initial temperature \\
\hline $\mathrm{V}$ & volume of a standard $44 \mathrm{~L}$ gas cylinder $\left(0.044 \mathrm{~m}^{3}\right)$ \\
\hline $\mathbf{X}_{\mathbf{i}}^{0}$ & initial (pretest) mole fraction of species $i$ at time $t=0$ \\
\hline $\mathbf{X}_{\mathbf{i}}^{t}$ & mole fraction of species $i$ at time $t$ \\
\hline$\tau_{b}$ & time to consume all of the hydrogen in the mixture \\
\hline & time required to condense the steam by water spray \\
\hline
\end{tabular}




\subsection{Introduction}

For some severe accident scenarios, it has been proposed that large quantities of hydrogen may be released into the containment when sufficient quantities of steam are present in the atmosphere to render the subsequent hydrogen/air/steam mixture nonflammable during the entire injection period. In the proposed Combustion Engineering (CE) System 80+ reactor containment buildings (RCB), igniters will be operated during the entire accident sequence. The hydrogen above the injection point may be either stratified or well-mixed depending upon the injection conditions, i.e., elevation of the injection point or injection flow rate. The maximum amount of hydrogen that can be injected in the CE System $80+$ containment equals a globally well-mixed concentration of approximately 13.5 percent (\%) in dry air (based upon $100 \%$ zirconium-water reactions). Water sprays located at the top of the dome will be actuated at a specified containment pressure setpoint. The water sprays will condense the steam and eventually form combustible mixtures.

A series of hydrogen igniter tests (HITs) conducted in the Surtsey Test Facility have determined igniter effectiveness in condensing steam environments. These tests were performed by the Severe Accident Phenomenology Department 6422 and the Containment Modeling Department 6429 as part of the United States Nuclear Regulatory Commission's effort on severe accident research. Experiments with both well-mixed and stratified hydrogen were performed. The three objectives of the experiments were to determine: (1) if energetic forms of combustion are possible when originally nonflammable hydrogen/air/steam mixtures are ignited while the mixture is de-inerted by water sprays, (2) the effectiveness of water sprays in mixing hydrogen, and (3) the effect of hydrogen stratification on the maximum combustion pressure.

The main objective of the tests on igniter effectiveness in a condensing steam environment was to determine what form of combustion results when hydrogen/air/steam mixtures are de-inerted by sprays in the presence of activated glow plugs. One of the main parameters influencing the mode of combustion that results is the time required to condense the steam by sprays $\left(\tau_{c}\right)$ relative to the time to consume all of the hydrogen in the mixture $\left(\tau_{b}\right)$. Therefore, when attempting to extrapolate experimental results from Surtsey to full-scale, it is important that the thermodynamic state of the mixture in Surtsey (with time) match that anticipated in the CE System $80+$. For example, one value of interest is the change in the steam concentration with time.

Steam condensation results from the operation of the containment water sprays. Initially, when the sprays are introduced into Surtsey, they are much colder than the surrounding atmosphere (288-323 kelvin (K) versus $413 \mathrm{~K}$ ). As long as the spray drops are not in thermal equilibrium with the containment atmosphere, the volumetric condensation rate is the parameter that governs the steam concentration with time. In this regime, rate processes, like heat and mass transfer, are the governing processes and depend on such physical characteristics as drop diameter and surface area.

Once the drops attain thermal equilibrium, rate processes are no longer governing, and the problem is governed by thermodynamics alone. In the thermodynamic equilibrium 
case, preserving the spray mass flux will preserve $\tau_{d} / \tau_{b}$ (since scale effects cancel out). In this regime, the spray mass flux becomes the parameter that governs the steam concentration with time. The spray mass flux is defined to be spray mass flow rate divided by the spray flow area. Preliminary CONTAIN calculations for the Surtsey test conditions indicate that variations in drop size (from 0.5 millimeter (mm) to $1 \mathrm{~mm}$ ) do not result in any significant variations in the thermodynamic state of the Surtsey mixture with time for a given spray mass flux. These calculations indicate that the spray drops attain thermal equilibrium relatively quickly in the Surtsey vessel and the spray mass flux is the governing parameter. The spray mass fluxes are equal for the Surtsey vessel and the CE System 80+ containment.

Posttest analyses suggest that thermodynamic equilibrium may not have been fully realized in the Surtsey vessel. Thermodynamic equilibrium would likely be achieved in full-scale containments.

However, any potential departure from thermodynamic equilibrium in the tests do not significantly distort $\tau_{\mathrm{c}} / \tau_{\mathrm{b}}$, and therefore do not affect the interpretation of the test results in a practical sense.

Table 1 provides spray nozzle information and lists the values for 1) spray flow rate, 2) spray volumetric density, 3) spray mass flux, 4) drop size, and 5) drop velocity for the CE System 80+ design and the scaled Surtsey experiment. Two columns are listed in Table 1 detailing the Surtsey spray parameters. One column gives the spray values for operation of a single scaled spray train (the normal mode of spray operation). The other column gives the spray parameters assuming both independent spray trains are operating, yielding twice the scaled nominal spray flow rate. The spray volumetric density is defined to be spray mass flux divided by spray settling or droplet terminal velocity. The following scaled experiment to prototypic design ratios were determined; the volumetric density is $0.60: 1$ and the drop surface area is $2.56: 1$. Therefore, assuming the mass transfer coefficient and the relative humidity are similar, the volumetric condensation rate (proportional to the volumetric density times the drop surface area) is $1.63: 1$. This shows that the experiment would have a higher condensation rate than prototypic scale. This should provide a conservative, upper bound on the condensation time scale relative to the combustion time scale.

The hydrogen igniters are located in the CE System $80+$ containment to ensure the earliest possible combustion of hydrogen. The igniters would be turned on at some point early in the severe accident scenario. The design has sixteen igniters placed in the dome and upper inside cranewall regions (two at each of the eight locations for redundancy) to allow for burning of any pockets which may possibly form [System $80+, 1990]$. The remaining 64 igniters are located in various subcompartment areas. The dome region has a sufficient number of igniters (8) to guarantee early combustion of hydrogen. A volume scaling approach was used to determine the number and location of igniters for the scaled test in Surtsey. The volume of the CE System $80+$ dome region is roughly half of the total containment volume $\left(94,449\right.$ cubic meters $\left.\left(\mathrm{m}^{3}\right)\right)$, or about $47,224 \mathrm{~m}^{3}$. This gives about one igniter location for every $5903 \mathrm{~m}^{3}$. The Surtsey volume is $56.7 \mathrm{~m}^{3}$. Therefore, with the Surtsey volume about $1 / 100$ that of the CE System $80+$ dome volume, no pockets of hydrogen are expected (certainly in the wellmixed cases), and one igniter location should be sufficient. Thus, it was recommended 
that one igniter location be used with two igniters operating at that location to ensure that a burn will occur even if one igniter fails. Furthermore, the location should be centrally located high in the Surtsey vessel to approximate those igniters in the dome region. It was also recommended that igniters be installed at two additional locations: low in the vessel along the central axis, and about vessel midplane near the wall. These locations would approximate those igniter locations in the HVAC and subcompartment regions. These igniters would be used to verify that igniter location has no effect on the results. Note that these experiments were intended to simulate the dome only and the effects of compartmentalization (with structures) were not included. 


\subsection{Experiment Description}

Figure 1 is a isometric view of the Surtsey vessel and the instrumentation and equipment in the HIT experiments. The Surtsey vessel is an ASME-approved steel pressure vessel with an internal volume of $103 \mathrm{~m}^{3}$, which makes it slightly over-scaled (for a 1:10 linear scale) compared to most nuclear RCBs. It has a cylindrical shape with removable, dished heads attached to both ends and is $3.6 \mathrm{~m}$ in diameter by $10.3 \mathrm{~m}$ high. The Surtsey vessel has a maximum allowable working pressure of 1 megapascal $(\mathrm{MPa})$ at 260 kelvin (K), but has a burst diaphragm installed to limit the pressure in the vessel to less than $0.9 \mathrm{MPa}$. It is supported approximately $2 \mathrm{~m}$ off the ground by a structural steel framework with its longitudinal axis oriented vertically. A total of twenty 30.5 -centimeter $(\mathrm{cm})(12 \mathrm{inch})$ and $61-\mathrm{cm}(24$ inch) instrument penetration ports exist at six different levels around the perimeter of the vessel. The vessel walls and heads are $9.5 \mathrm{~cm}$ thick and covered with at least $100 \mathrm{~cm}$ of fiberglass insulation or equivalent material.

A false floor was installed in the middle of Surtsey between levels 3 and 4 . The false floor was constructed using steel plate welded to the vessel walls and supported with I-beams mounted vertically in the vessel. The distance from the false floor to the dome is about $5.5 \mathrm{~m}$. The free board volume above the false floor was $56.7 \mathrm{~m}^{3}$. The HIT experiments were performed in this volume (Figure 2). The false floor was designed for $1.03 \mathrm{MPa}$ at $260 \mathrm{~K}$ with a safety factor of 4 . The false floor was not insulated, but was externally heated (see below). Numerous flanges on the vessel have been modified to allow steam, noncondensible gas, water, electrical, and video service into the vessel.

Figure 3 shows the spray system. A 1893 liter (L) tank (rated for 1.72 MPa) was filled with water. The water tank was pressurized to $1.4 \mathrm{MPa}$ using ten full $44 \mathrm{~L}$ compressed air cylinders installed on a regulated air manifold. A pressure regulator at the discharge of the water tank maintained nozzle pressure at about $0.83 \mathrm{MPa}$. This provided about $0.34 \mathrm{MPa}$ differential pressure across the spray nozzle which provided the nominal desired flow rate. Remotely operated valves controlled the air pressurization and the water discharge. The water tank pressure, nozzle pressure, spray flow rate, and water temperature were continuously monitored and recorded. One test required hot spray water. Electric heaters installed in the insulated water tank heated the water. A recirculation loop heated and maintained the spray header and tank at the desired temperature. The spray nozzle was located at the Surtsey vessel centerline at the top of the dome.

In the majority of the tests, a low capacity spray nozzle (Lechler 461.148 ) with a $120^{\circ}$ spray angle was used. The sprayed volume was $55.7 \mathrm{~m}^{3}$. The un-sprayed volume (a small portion of the upper dome not covered by the $120^{\circ}$ spray angle) was $3.4 \mathrm{~m}^{3}$. This gave a spray coverage of $94 \%$ in the Surtsey vessel. In HIT-9, HIT-10, and HIT-11, a high capacity spray nozzle (Lechler 461.206 ) with a nozzle spray angle is $90^{\circ}$ was used. The sprayed volume was $50.3 \mathrm{~m}^{3}$. The unsprayed volume was $8.8 \mathrm{~m}^{3}$. This gave a spray coverage of $85.1 \%$ in the Surtsey vessel for the high capacity spray nozzle. 
A shakedown test of the spray system was performed. The 461.148 spray nozzle was mounted on a frame over the Surtsey vessel at the correct height. Tarps were hung over the tent-like framework to provide an enclosed volume since the Surtsey upper head was not yet installed. The water tank was full (1893 L) and the water temperature was $323 \mathrm{~K}$. All six igniters were turned on. The spray header was pressurized to about $0.45 \mathrm{MPa}$ and spray was initiated. The flow rate was $1.58 \mathrm{kilogram} / \mathrm{second}(\mathrm{kg} / \mathrm{s})$. The vessel was sprayed for about 21 minutes, until the tank emptied. Visual observations in the vessel during the test showed the spray hitting the vessel walls just below the upper flange. The spray coverage throughout the vessel appeared to be uniform, as expected with a axial, full cone nozzle. All igniters glowed during the 21 minute spray test; the igniter shields were effective in keeping the spray off of the plugs. Buckets were placed on the false floor in an ' $X$ ' pattern. Water filled the buckets during the spray test. Relatively flat distributions of water were obtained which verified that a uniform spatial pattern across the circular area was achieved.

The igniter hardware for the Surtsey experiment is exactly the same as the proposed CE System $80+$ design. The igniter is an AC-7G cylindrical glow plug and it is powered with a 14 VAC transformer (Dongan Electric). The igniters were located at three elevations above the false floor; $1.09 \mathrm{~m}$ (along the vessel centerline), $3.72 \mathrm{~m}$ ( $0.305 \mathrm{~m}$ from the vessel wall), and $4.42 \mathrm{~m}$ (along the vessel centerline). Two igniters were placed at each location. A rain shield was placed over each igniter to ensure nominal operation during the entire water spray. Figure 4 shows the igniter mount and rain shield. Many igniters failed during initial tests of the igniter hardware. It was determined that an igniter 'break in' procedure was required. The procedure consisted of powering an igniter at successively higher currents over a series of intervals (two amp increment after each two hour interval), starting at 6 amps and ending at 14 amps. Igniters that continued to function after the 10 hour procedure were very reliable. The igniters reached a steadystate temperature value of $\sim 1300 \mathrm{~K}$ in about $40 \mathrm{~s}$, as measured with a type- $K$ thermocouple wired to the tip of the glow plug. Igniter current was also continuously monitored during the experiments. A visual inspection showed that all igniters glowed 'red-hot' at the final steady-state temperature.

During HIT-1, it was noted that the all of the igniter temperatures had become seriously degraded. Therefore, in HIT-2 through HIT-6, new igniters were placed into the vessel through vessel port flanges. The experiment test matrix was temporarily suspended after HIT- 6 to remove the upper vessel head and inspect/replace damaged equipment and instrumentation. Inspection of the igniter system showed the fault. The igniter power lead was fed through the vessel inside conduit, with the igniter ground being the conduit itself. Galvanic corrosion of the conduit coupling nuts in the steam environment increased the resistance in the electrical path due to coupling nut disintegration. The problem was solved simply by replacing the conduit and coupling nuts with stainless steel material and running a separate ground wire inside the conduit. Therefore, in HIT-7 through HIT-11, the original igniters and igniter locations were used.

The air and hydrogen gas were supplied to the vessel from separate manifolds. Standard 44 liter compressed gas cylinders were installed on the manifolds. The gas entering 
the vessel was first routed through a hot-oil heat exchanger that was capable of heating the cold gas to the desired test temperature. This was necessary to prevent condensation of the steam. Three hydrogen injectors $(0.635 \mathrm{~cm}$ nozzle diameter) were placed in the vessel. The locations were $0.305 \mathrm{~m}$ above the floor, $2.70 \mathrm{~m}$ above the floor, and $3.37 \mathrm{~m}$ above the floor. All of the injectors were located along the vessel centerline. The $2.70 \mathrm{~m}$ injector location was based on a $13.5 \%$ stoichiometric hydrogen/air mixture occupying the top $45.7 \%$ of the Surtsey volume. This assumed that all of the injected hydrogen stratified and filled the region above the injection elevation. The $3.37 \mathrm{~m}$ injector placement was based on a $10.0 \%$ stoichiometric hydrogen/air mixture occupying the top $33.9 \%$ of the Surtsey volume. For the HIT experiments, the Surtsey vessel was first heated internally with steam and externally with a liquid propane gas burner (under the non-insulated false floor) to ensure steam pressurization and to minimize steam condensation while setting the initial atmosphere conditions. The portable steam boiler provided a lowpressure, saturated steam heat source (227 $\mathrm{kg} / \mathrm{hr}$ ) into Surtsey. Initially, the steam that entered Surtsey condensed and provided latent heat to the vessel walls and atmosphere. A steam trap installed in the floor removed the condensate without removing gases. As the vessel heated, the steam condensation rate decreased and the vessel began to pressurize. The floor heat up was accomplished with a liquid propane straight fire-sleeve burner, rated at 2,000,000 BTU/hr. The burner directed flames into the lower level of Surtsey below the false floor; this provided some degree of temperature regulation of the gas in the upper level after the steam heat up was completed. The liquid propane gas burner mounted under the dividing floor was controlled to match gas temperatures above and below the floor during the heat up to minimize structural stress and heat loss. The vessel bulk gas and structure heat up was accomplished in about 10 hours.

The general procedure of the experiments was to initially inert the Surtsey vessel with saturated steam during the steam heat up process to ensure a known initial atmosphere condition. A series of vessel fill and vents was performed. The vessel was vented to near atmospheric pressure $(0.103 \mathrm{MPa})$ and then refilled with steam to a pressure of about $0.207 \mathrm{MPa}$. This was performed five to seven times and the entire procedure lasted about two hours. The vessel had a small, known leak rate, about $0.003 \mathrm{MPa} / \mathrm{hr}$. As the vessel was pressurized with steam, small amounts of air and steam leaked out. This small leak rate had minimal impact on the test results.

After heating the vessel, the vessel was pressurized with saturated steam $(413 \mathrm{~K})$ to about $0.36 \mathrm{MPa}$. The propane burner was turned off and the floor condensate trap was isolated. Heated air $(460 \mathrm{~K})$ was then added to increase vessel pressure by about 0.12 $\mathrm{MPa}$. The air concentration was typically $\sim 27 \mathrm{~mole} \%$ (wet basis). In the well-mixed experiments, heated hydrogen $(390 \mathrm{~K})$ was added through the lower injection point with the fans operating until its final concentration was $4-11$ mole\% (wet basis). The gases were mixed using three 1000 SCFM pneumatically operated fans installed inside the Surtsey vessel. The final vessel temperature and pressure prior to operation of the sprays was approximately $415 \mathrm{~K}$ and $0.45 \mathrm{MPa}$. After verifying the glow plug igniters were operating nominally, the water spray was initiated. The target spray nozzle flow rate and the temperature of the spray water ranged from $\sim 1.5$ to $3.0 \mathrm{~kg} / \mathrm{s}$ and from 
288 to $323 \mathrm{~K}$, respectively. The spray was expected to operate up to and after the combustion event. Enough water was available to provide 21 minutes of spray at the nominal spray flow rate.

The procedure for the stratified experiments was nearly identical to the procedure for the well-mixed tests. The main difference was that the stratified hydrogen injection point was located approximately in the middle of the Surtsey vessel and the mixing fans were turned off a few minutes prior to the addition of hydrogen in order to obtain a quiescent atmospheric condition. The target conditions were to have stoichiometric mixtures above the injection point and no hydrogen below. This would result in mixtures with $\sim 8 \mathrm{~mole} \%$ hydrogen (wet basis) above the injection point before the operation of the sprays.

\subsection{Measurements and Instrumentation}

The most significant variables measured in the HIT experiments were (1) the pressure and temperature in the Surtsey vessel, (2) the water spray flow rate and temperature, (3) the igniter temperature, and (4) the number of $\mathrm{g} \cdot \mathrm{moles}$ of hydrogen burned. Figure 5 shows the HIT instrumentation location in the Surtsey vessel. Figure 6 identifies the array, wall, and spray thermocouples. The circled numbers in Figure 6 correspond to the channel numbers in the data acquisition system. Table 2 is a listing of the instrumentation used in the HIT experiments, including channel number, type, purpose, and location. The instrumentation and techniques used to make these measurements are described in the sections below.

\subsubsection{Pressure Measurements}

Four pressure transducers were used to measure the pressure in the Surtsey vessel. Two transducers, channels 31 and 32 , had ranges of $0-1.38 \mathrm{MPa}$. Two transducers, channels 33 and 34, had ranges of $0-2.07$ $\mathrm{MPa}$. The four transducers were mounted in level 6 penetrations in the Surtsey vessel. All of the transducers were metal diaphragm strain gauge-type pressure transducers (Precise Sensor, Inc., Monrovia, CA). The specified accuracy from the manufacturer for the pressure transducers is less than \pm 0.50 percent at full-scale output. The transducer's frequency response is greater than 22 kilohertz (kHz) (16 millisecond (ms) rise time). These instruments are routinely recalibrated at SNL against instruments traceable to the National Institute of Standards and Technology, and accuracies are always within the manufacturer's specifications. The Hewlett Packard AP1000 data acquisition system recorded data at a rate of 30 data points per second per channel from just prior to igniter activation. After 20 minutes, the computer automatically switched to a slow data acquisition mode, acquiring data at a rate of 1 data point per second per channel until test completion.

\subsubsection{Temperature Measurements}

The gas temperature in the Surtsey vessel was measured with thermocouple rakes. Figures 5 and 6 show the 45 gas-measuring thermocouple locations. There were five vertical thermocouple rakes installed in the vessel; three rakes located $0.3 \mathrm{~m}$ from the vessel wall $120^{\circ}$ apart (array $\mathrm{A}$, array $\mathrm{B}$, and array $C$ ), one rake at the vessel centerline (array E), and one rake (array D) between the centerline rake and a wall rake (array $C$ ). Nine equally-spaced type-K thermocouples 
(0.61 m spacing) were located on each rake. The thermocouple elevations were $0.15 \mathrm{~m}$, $0.76 \mathrm{~m}, 1.37 \mathrm{~m}, 1.98 \mathrm{~m}, 2.59 \mathrm{~m}, 3.20 \mathrm{~m}$, $3.81 \mathrm{~m}, 4.42 \mathrm{~m}$, and $5.03 \mathrm{~m}$ above the floor. All type-K thermocouples were made of $0.254-\mathrm{mm}$ wire with a $1.6-\mathrm{mm}$ metal sheath. The temperature range was $273 \mathrm{~K}$ to $1523 \mathrm{~K}$. The maximum error using the manufacturer's calibration is $\pm 9.4 \mathrm{~K}$ at 1523.K. The thermocouples had the sheath removed at the tip, exposing the junction to ensure a fast time response (0.3-s time constant).

Ten type-K thermocouples were installed in the Surtsey vessel steel walls. Two measured dome temperature, two measured dome flange temperature, three measured wall temperature, and three measured floor temperature. A type- $K$ thermocouple also monitored the water spray temperature. In addition, thermocouples measure air and hydrogen manifold temperature and also the temperature of the heated air and hydrogen that was introduced into the Surtsey vessel.

Near the end of the first set of experiments (HIT-1 through HIT-6), some of the array thermocouples had failed. In addition, many array thermocouples showed erratic behavior, especially under the large steam pressure (0.55 MPa) and temperature $(425 \mathrm{~K})$ in the vessel near the end of the heat up period. The problem was traced to the compacted $\mathrm{MgO}$ ceramic insulation (a hygroscopic material that can absorb moisture) that was exposed to the steam when the sheath was removed at the thermocouple tip. All array thermocouples were replaced after HIT-6 with type-K thermocouples that were constructed using $0.127-\mathrm{mm}$ wire with a thin Teflon sheathing. The time constant for these thermocouples is $\sim 0.1 \mathrm{~s}$.

\subsubsection{Gas Composition}

In the HIT experiments, eighteen pre-evacuated $500-\mathrm{cm}^{3}$ gas grab sample bottles were used to collect samples from the vessel, nine samples were taken pretest and nine samples were taken posttest. Five gas grab sample suction lines were attached to thermocouple array $\mathrm{E}$ at $1.22 \mathrm{~m}, 2.13 \mathrm{~m}$, $3.05 \mathrm{~m}, 3.96 \mathrm{~m}$, and $4.88 \mathrm{~m}$ above the floor. Four gas grab sample suction lines were attached to thermocouple array $\mathrm{C}$ at $1.68 \mathrm{~m}$, $2.59 \mathrm{~m}, 3.51 \mathrm{~m}$, and $4.42 \mathrm{~m}$ above the floor. All sample lines were purged prior to filling the gas grab bottles to ensure representative samples. Hydrogen microsensors were installed at the same elevations and locations as the gas grab sample suction lines (see Section 3.6 for details).

All of the gas samples were analyzed using gas mass spectroscopy by the Gas Analysis Laboratory, Department 1823, at SNL. Tests were performed at SNL to measure the fill times of the $500-\mathrm{cm}^{3}$ gas grab sample bottles at three different initial pressures (atmospheric, 0.26 MPa, and 0.43 MPa). An evacuated bottle at $\sim 295 \mathrm{~K}$ was separated from a pressure source by a remotely operated solenoid valve. A pressure transducer was installed downstream of the valve and pressure source, and the fill time was recorded by the data acquisition system. The data indicate that all bottles were filled in less than $2 \mathrm{~s}$, regardless of the upstream pressure.

The results of the gas analysis showed unexpected large deviations in HIT-1 through HIT-3. Also, pretest initial condition measured concentrations did not show good agreement with the calculated amount of gas added to the vessel (Section 2.2). The problem was traced to inadequate purging of the gas grab sample lines. The 
lines were re-engineered and the purge procedure was modified. Thereafter, good agreement was obtained between measured and calculated initial condition concentrations along with small standard deviations between individual samples in HIT-4 through HIT-11.

\subsubsection{Cameras}

In the HIT tests, a high resolution $1 / 2$-inch change-coupled device (CCD) color camera was used. The camera was mounted on either the level 4 port located $0.61 \mathrm{~m}$ above the floor or the level 6 port located $3.05 \mathrm{~m}$ above the floor, viewing the event through a tempered glass window. In addition to the digital camera, an infrared camera was used, also viewing the vessel through the level 6 port located $3.05 \mathrm{~m}$ above the floor. Figure 2 shows the vertical location of the ports at three different levels with the lowest port located just above the floor.

\subsection{Initial Conditions}

To ensure that the initial conditions were met for the hydrogen igniter effectiveness experiments, the calculation below was performed to determine the amount of air and hydrogen to be added to the Surtsey vessel. Air and hydrogen were supplied from standard 44 liter $\left(0.044 \mathrm{~m}^{3}\right)$ compressed gas cylinders. Based on the desired number of gas moles to be added, the number of cylinders installed on a manifold, the cylinder volume, the manifold initial pressure and temperature, and assuming the manifold final temperature at the end of the gas addition, the final manifold pressure can be calculated. The manifold final temperature was assumed to be $273 \mathrm{~K}$. The following equation was used to determine the final manifold pressure at which to stop filling the Surtsey vessel.

Table 3 lists the initial conditions for the HIT experiments. The noncondensible gas and steam fractions at the start of each experiment was calculated using the initial moles of air and hydrogen and the measured pressure and calculated average gas temperature data at time $t=0$ minutes, along with $P, V, T$ ideal-gas law relationships. The actual number of moles of air and hydrogen placed into the Surtsey vessel was based on Equation (2.1) and using measured final manifold temperature. Also listed in Table 3 is vessel temperature, pressure, gas moles and gas concentration (wet and dry basis), time-averaged spray flow rate, spray temperature, and igniter temperature (for the hottest igniter).

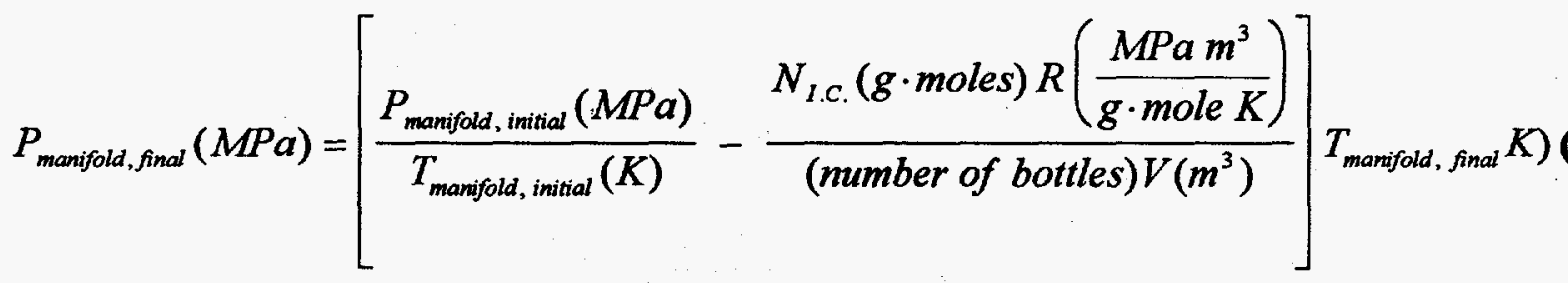




\subsection{Experimental Results}

Some general pretest and posttest observations from the eleven tests are described in the following paragraphs. The specific experimental results and test observations are then presented in the respective test sections.

After the vessel was purged with steam, steam was added to the vessel until pressure reached $0.55 \mathrm{MPa}$. The $15 \mathrm{~K}$ superheat above the target temperature of $410 \mathrm{~K}$ on the vessel walls provided some time margin for cool down during the air and hydrogen addition and pretest gas sampling. After the vessel heat up was completed, steam was released from the vessel until the desired initial pressure was achieved. The use of the steam trap to remove the floor condensate was discontinued after the steam heat up. There usually was a small amount of water on the floor prior to initiating the spray. The water could be seen with the camera mounted on a level 4 port penetration and it is estimated that the water level was about $3-5 \mathrm{~cm}$.

In the well-mixed experiments, the hydrogen was injected through the bottom injector nozzle at elevation $0.3 \mathrm{~m}$ with the mixing fans operating. In all of the stratified tests, the hydrogen was injected through the middle nozzle at elevation $2.7 \mathrm{~m}$, with the mixing fans off for five minutes prior to injection.

The camera view showed what appeared to be a 'light rain' inside the vessel after spray initiation during HIT-1 through HIT-6 and in HIT-8. The vessel pressure and bulk gas temperature steadily decreased during the spray down. Spray flow rate always increased during the spray down due to the decreasing vessel back pressure. The average bulk gas temperature was calculated by averaging the temperature data obtained from the five vertical thermocouple arrays. The bottom thermocouple on each array showed water reaching the $15 \mathrm{~cm}$ level at about 10 minutes after spray initiation. HIT-9, HIT-10, and HIT-11 used the higher capacity spray nozzle; the camera view clearly showed a 'heavy rain' inside the vessel. The air delivery system was modified to provide a higher pressure and flow to the water tank for these last tests. As a result, the spray flow rate was constant during the tests, and the water level reached the bottom thermocouples at about 5 minutes after spray initiation.

The floor thermocouples showed good agreement, indicative of water on the floor. The 'wetted-wall' thermocouple showed lower and more erratic temperatures due to water streaming down the walls as compared to the upper wall thermocouples. These thermocouples were mounted near the upper head flange and were located just above the sprayed-unsprayed transition boundary. The upper wall thermocouples showed good temperature agreement. The dome thermocouple always recorded the highest structure temperature and showed the smallest rate of temperature decrease.

The gas fractions at the time of first recorded burn were calculated using the initial moles of air and hydrogen and the measured pressure and calculated average gas temperature data at time of first burn along with P,V,T ideal-gas law relationships. It was assumed that the air and hydrogen noncondensible gas amounts remained constant at the initial values throughout the 
test until the time of first burn. A timedependent steam fraction in the vessel can be estimated assuming the noncondensible fraction remains constant at the initial value. Note that the assumption breaks down after the first burn. This is expected since the noncondensible moles should decrease due to hydrogen and oxygen combustion. Table 4 lists the vessel conditions at the time of first burn.

Immediately prior to spray initiation, the gas grab sample lines were purged and then the samples were taken. There was considerable deviation between the individual samples and the concentrations added to the vessel in the first three experiments. The problem was caused by an incomplete gas sample line purge, partly due to the construction of the purge system and also due to an underestimate of the time necessary to perform the purge with the new sample system. The problems were corrected prior to HIT-4 and good agreement was then obtained between calculated and measured initial vessel gas concentrations.

At the end of each test (spray completion), the mixing fans were turned on to ensure a well-mixed state, the gas sample lines were purged, and then the posttest gas grab samples were taken. Table 5 summarizes the final conditions and results of the HIT experiments. Tables 6-16 list the pretest and posttest gas concentrations measured in each HIT experiment.

A series of eleven figures is presented for each of the eleven experiments presented below. The first figure in each series shows the pressure in the Surtsey vessel measured by the four transducers. The next five figures show the temperatures recorded by the thermocouples on each of the five thermocouple arrays. An average Surtsey vessel gas temperature is presented next (average of all operating array thermocouples), followed by a figure showing the vessel dome, wall, and floor temperatures. A figure shows the igniter temperatures, along with a time-average temperature of the hottest igniter. The last two figures of each series (with the exception of HIT-7 which did not use the spray system) give the water flow rate and temperature through the spray nozzle, and the corresponding time-averages.

\subsection{HIT-1 Pressure, Temperature, and Spray Flow Measurements}

HIT- 1 was intended to be the baseline test using the maximum credible amounts of hydrogen in the containment (refer to Figures 7-17). The Surtsey vessel was inerted with saturated steam at $0.36 \mathrm{MPa}$. Hot air was then added to a concentration of $27.7 \mathrm{~mole} \%$. Heated hydrogen was added to achieve a concentration of $4.3 \mathrm{~mole} \%$. The gases were well-mixed using fans installed inside the Surtsey vessel. The temperature and pressure prior to operation of the spray nozzle was $416 \mathrm{~K}$ and $0.46 \mathrm{MPa}$. All six glow plug igniters were activated. The hottest igniter averaged $1072 \mathrm{~K}$. The spray system was turned on. The time-averaged mass flow rate and the temperature of the spray water was $1.68 \mathrm{~kg} / \mathrm{s}$ and $332 \mathrm{~K}$. The spray was operated for 18.9 minutes.

Final temperature and pressure in the Surtsey vessel was 372 and $0.17 \mathrm{MPa}$. The pressure curve showed no significant pressure increase during the spray down. Small pressure increases (1 kilopascal $(\mathrm{kPa})$ ) were seen at $t=10.9$ min and $t=16.5 \mathrm{~min}$. Small temperature increases $(10 \mathrm{~K})$ were also seen at the same times, however, the average vessel bulk gas temperature increase was 
Experimental Results

developed at Whiteshell and should be used with caution.

Analysis of posttest gas grab samples showed that hydrogen concentration (on a dry basis) decreased to 0.2 mole $\%$. The gas data, along with the significant pressure increase during the burn event, signified that a complete hydrogen deflagration occurred in the Surtsey containment vessel.

\subsection{HIT-4 Pressure, Temperature, and Spray Flow Measurements}

HIT-4 was intended to be a replicate of HIT2 , except using only one igniter location (refer to Figures 40-50). The Surtsey vessel inerted with saturated steam at $0.38 \mathrm{MPa}$. Heated air and hydrogen gas were then added. On a wet basis, the steam concentration was $66.1 \mathrm{~mole} \%$, the air concentration was $29.3 \mathrm{~mole} \%$, and the hydrogen concentration was $4.6 \mathrm{~mole} \%$. On a dry basis, the air concentration was 86.5 mole\% and the hydrogen concentration was $13.5 \mathrm{~mole} \%$. The steam and noncondensible gases were well-mixed using fans installed inside the Surtsey vessel. The temperature and pressure prior to operation of the spray nozzle were approximately $419 \mathrm{~K}$ and 0.44 $\mathrm{MPa}$, respectively. Two cylindrical glow plug igniters were activated. Both igniters were located $0.5 \mathrm{~m}$ from the wall of the vessel and $3.1 \mathrm{~m}$ above the floor. The average igniter temperature was $1204 \mathrm{~K}$. The spray system was turned on. The average spray flow rate was $1.63 \mathrm{~kg} / \mathrm{s}$ with and average temperature of $289 \mathrm{~K}$. The spray operated for 19.3 minutes. Final temperature and pressure in the Surtsey vessel were approximately $326 \mathrm{~K}$ and 0.13 $\mathrm{MPa}$, respectively.
The pressure curve showed a typical pressure decrease due to steam condensation during the spray down during the first four minutes. At 4.3 minutes after the start of the water spray, and at a steam concentration of $48.6 \mathrm{~mole} \%$ (oxygen and hydrogen concentrations were 9.3 mole\% and 7.0 mole $\%$, respectively), there were indications of a small deflagration in the Surtsey vessel. Pressure rose from $0.269 \mathrm{MPa}$ to 0.283 $\mathrm{MPa}$. Small pressure increases of less than $7 \mathrm{kPa}$ were also seen at 11.5 minutes and at 16 minutes.

The average gas temperature rose about $5 \mathrm{~K}$ during the burn. The bottom thermocouple at elevation $0.15 \mathrm{~m}$ showed that the rising pool of water in the vessel reached this position 11 minutes after the start of the spray.

The lack of any significant pressure increase during the burn and condensation events, signified that localized, benign hydrogen deflagration(s) occurred with no noticeable pressure load on the Surtsey containment vessel.

\subsection{HIT-5 Pressure, Temperature, and Spray Flow Measurements}

HIT-5 used more than the credible amount, but less than a stoichiometric amount of hydrogen (refer to Figures 51-61). The Surtsey vessel inerted with saturated steam at $0.38 \mathrm{MPa}$. Heated air and hydrogen gas were then added. On a wet basis, the steam concentration was $62.2 \mathrm{~mole} \%$, the air concentration was $29.3 \mathrm{~mole} \%$, and the hydrogen concentration was $7.3 \mathrm{~mole} \%$. On a dry basis, the air concentration was 80.1 mole $\%$ and the hydrogen concentration was $19.3 \mathrm{~mole} \%$. The steam and noncondensible gases were well-mixed using fans installed 
Experimental Results

inside the Surtsey vessel. The vessel temperature and pressure prior to operation of the spray nozzle were approximately $411 \mathrm{~K}$ and $0.41 \mathrm{MPa}$, respectively. Two cylindrical glow plug igniters were activated. Both igniters were located $0.5 \mathrm{~m}$ from the wall of the vessel and $3.1 \mathrm{~m}$ above the floor. The igniter temperature averaged $1204 \mathrm{~K}$. The spray system was turned on. The spray flow rate averaged $1.46 \mathrm{~kg} / \mathrm{s}$. The spray temperature was $298 \mathrm{~K}$. The spray operated for 21.5 minutes. Final temperature and pressure in the Surtsey vessel were approximately $344 \mathrm{~K}$ and $0.11 \mathrm{MPa}$, respectively.

The vessel pressure curve showed a typical pressure decrease due to steam condensation during the spray down during the first five minutes. At 5.5 minutes after the start of the water spray, and at a steam concentration of $39.6 \mathrm{~mole} \%$ (oxygen and hydrogen concentrations were $10.2 \mathrm{~mole} \%$ and 11.7 mole $\%$, respectively), there were indications of a small deflagration in the Surtsey vessel. Pressure rose from $0.244 \mathrm{MPa}$ to 0.255 MPa. Small pressure increases of less than $7 \mathrm{kPa}$ were also seen at 18,19 , and 21 minutes.

The average gas temperature rose about $8 \mathrm{~K}$ during the burn. The bottom array thermocouples at elevation $0.15 \mathrm{~m}$ showed that the rising pool of water in the vessel reached this position 12 minutes after the start of the spray.

The lack of any significant pressure increase during the burn and condensation events, signified that localized, benign hydrogen deflagration(s) occurred with no significant pressure load on the Surtsey containment vessel.

\subsection{HIT-6 Pressure, Temperature, and Spray Flow Measurements}

Three scoping tests (ST-1, ST-2 and ST-3) were performed to qualify the method of introducing a stratified hydrogen atmosphere in the Surtsey vessel [Blanchat 1994]. Hydrogen microsensors (including related instrumentation and control equipment) were provided by Microsensor Research and Development Department 1315 and Silicon Technologies Department 1325. The sensors were installed in the Surtsey vessel at the same elevations as the gas grab sample line suction points. The hydrogen microsensors provide a voltage signal proportional to the partial pressure of hydrogen on the surface of the device. A generic calibration curve based on a average of many sensors that converted sensor signal to partial pressure of hydrogen was also provided by the microsensor department.

If the hydrogen was stratifying in the upper volume of the Surtsey vessel above the middle injector nozzle ( $45.7 \%$ of the total volume), the signal from the microsensors in the stratified volume should follow the stratified sensor signal voltage curves for the generic calibration. The microsensors in the lower Surtsey volume should record little or no output. When the vessel is mixed, the upper and lower sensors should both record the same signal.

The concentrations were measured in realtime as the experiment was being performed. In ST-1, the five sensors in the upper volume (at and above the middle nozzle) clearly indicated that hydrogen stratification had occurred, especially when compared to the lower sensors which measure little or no hydrogen. When the mixing fans were turned on, the output from the lower sensors 
increased, and the output from the upper sensors decreased. Similar results were obtained in ST-2. Stratification of hydrogen clearly occurred. The hydrogen microsensors provided immediate feedback that the hydrogen stratification scoping tests were successful.

The mixing time was determined using the newly developed hydrogen microsensors which provided spatially resolved real-time continuous output of hydrogen concentrations. The ST-3 stratified test was conducted at ambient conditions with approximately $19 \%$ hydrogen (dry basis) in the upper part of the vessel. The hydrogen was mixed by water sprays with a flow rate of $1.58 \mathrm{~kg} / \mathrm{second}$. As shown in Figure 62 , the mixing time was approximately 20 seconds for most of the vessel and less than 1 minute even for the lowest levels. The microsensors were then removed from the vessel since they could not survive the hostile steam environment expected in the HIT-6 experiment.

HIT-6 was the first test using a stratified mixture of the maximum credible amount of hydrogen (refer to Figures 63-73). The Surtsey vessel inerted with saturated steam at $0.38 \mathrm{MPa}$. Heated air and hydrogen gas were then added. On a well-mixed wet basis, the steam concentration was 67.6 mole $\%$, the air concentration was 28.0 mole $\%$, and the hydrogen concentration was $4.4 \mathrm{~mole} \%$. On a well-mixed dry basis, the air concentration was $86.5 \mathrm{~mole} \%$ and the hydrogen concentration was $13.5 \mathrm{~mole} \%$.

The steam and air was well-mixed using fans installed inside the Surtsey vessel. After waiting five minutes to obtain a quiescent atmosphere, hydrogen was introduced into the Surtsey vessel to create a stratified atmosphere. Hydrogen was injected into the vessel through the middle nozzle at elevation $2.71 \mathrm{~m}$ to provide a target $29.5 \mathrm{~mole} \%$ (dry basis) stratified hydrogen concentration. The target hydrogen concentration assumed all of the hydrogen was of uniform concentration and stratified in the upper $45.7 \%$ of the Surtsey vessel (the vessel volume above the injection point). The injection rate was $\sim 0.002 \mathrm{~kg} / \mathrm{s}$; this yielded a total injection time of $420 \mathrm{~s}$.

The vessel temperature and pressure prior to operation of the spray nozzle were approximately $416 \mathrm{~K}$ and $0.46 \mathrm{MPa}$, respectively. Two cylindrical glow plug igniters were activated. Both igniters were located $0.3 \mathrm{~m}$ from the wall of the vessel and $3.1 \mathrm{~m}$ above the floor. The average igniter temperature was $1224 \mathrm{~K}$. The spray system was turned on. The spray flow rate was $1.48 \mathrm{~kg} / \mathrm{s}$. The spray temperature was $292 \mathrm{~K}$. The spray operated for 20.9 minutes. Final temperature and pressure in the Surtsey vessel were approximately $338 \mathrm{~K}$ and 0.12 $\mathrm{MPa}$, respectively.

The vessel pressure curve showed a typical pressure decrease due to steam condensation during the spray down during the first few minutes. At 5.8 minutes after the start of the water spray, and at a steam concentration of $48.8 \mathrm{~mole} \%$ (oxygen and hydrogen concentrations were $9.3 \mathrm{~mole} \%$ and 6.9 mole $\%$ on a well-mixed basis, respectively), there were indications of a small deflagration in the Surtsey vessel. Pressure rose from $0.27 \mathrm{MPa}$ to $0.28 \mathrm{MPa}$. A small pressure increase of less than $1 \mathrm{MPa}$ was also seen at 15.5 minutes. Other smaller deflagrations may have occurred, including some before six minutes.

The average gas temperature rose about $4 \mathrm{~K}$ during the initial burn. The bottom array thermocouples showed that the rising pool of 
water in the vessel reached this position 12 minutes after the start of the spray.

The lack of any significant pressure increase during the burn and condensation events, signified that localized, benign hydrogen deflagration(s) occurred with no significant pressure load on the Surtsey containment vessel. The results from this test (initially stratified with a stoichiometric mixture in the top but equivalent to $13.5 \mathrm{~mole} \%$ hydrogen on a well-mixed basis) showed that the water spray effectively mixes the initially stratified atmosphere prior to the deflagration event.

\subsection{HIT-7 Pressure, Temperature, and Spray Flow Measurements}

The seventh test (HIT-7) was performed to examine the combustion of hydrogen-airsteam mixtures with naturally condensing steam due to natural cool down of the vessel (refer to Figures 74-82). The hydrogen concentration conditions closely replicated HIT-6.

The Surtsey vessel was inerted with saturated steam at $0.21 \mathrm{MPa}$. Heated air and hydrogen gas were then added. On a wellmixed wet basis, the steam concentration was $56.2 \mathrm{~mole} \%$, the air concentration was $37.7 \mathrm{~mole} \%$, and the hydrogen concentration was $6.0 \mathrm{~mole} \%$. On a well-mixed dry basis, the air concentration was $86.2 \mathrm{~mole} \%$ and the hydrogen concentration was $13.8 \mathrm{~mole} \%$.

The steam and air were well-mixed using fans installed inside the Surtsey vessel. After waiting five minutes to obtain a quiescent atmosphere, hydrogen was introduced into the Surtsey vessel to create a stratified atmosphere. Hydrogen was injected into the vessel through the middle nozzle to provide an initial target condition of $29.5 \mathrm{~mole} \%$ (dry basis) stratified hydrogen concentration. The injection rate was $\sim 0.002 \mathrm{~kg} / \mathrm{s}$; this yielded a total injection time of $420 \mathrm{~s}$.

The vessel temperature and pressure prior to igniter operation were approximately $401 \mathrm{~K}$ and $0.33 \mathrm{MPa}$, respectively. The spray system was not used. Two cylindrical glow plug igniters were activated. Both igniters were located along the vessel centerline, $1.8 \mathrm{~m}$ from the wall of the vessel and $4.5 \mathrm{~m}$ above the floor. The hottest igniter average temperature was $1290 \mathrm{~K}$.

The test ran for 23 hours. Outside air temperature ranged from 278-293 K. Final temperature and pressure in the Surtsey vessel were approximately $333 \mathrm{~K}$ and 0.11 $\mathrm{MPa}$, respectively.

The pressure and temperature curves showed very slow decreases. The first burn occurred at 8.8 hours. Temperature data from the upper thermocouples on three arrays (A9, B9, and (9) showed about a $5 \mathrm{~K}$ increase. The pressure curve shows no increase, that, along with the temperature data, showed that the burn occurred only in the upper part of the vessel (probably at and above the igniter). The next series of burns occurred at $14.5 \mathrm{hrs}, 15.5 \mathrm{hrs}, 18.1 \mathrm{hrs}$ and $21.2 \mathrm{hrs}$. Similar behavior to the first burn was seen. Small temperature spikes $(5 \mathrm{~K})$ were seen on the top thermocouples on arrays A, B, C, and $D$. The spikes were larger on the array $\mathrm{E}$ top thermocouple $(75 \mathrm{~K})$. However, since no commensurate pressure spikes were seen, it was concluded that the burns were localized to the gas volume near the ignition point.

The computer was stopped for about 35 minutes with the igniters off at $t=9$ hours to backup data. This break in data is shown on the pressure and temperature curves. The 
small pressure drop at $\mathrm{t}=19.5 \mathrm{hrs}$ was due to a gas grab sample line purge.

A total of twenty gas grab samples were taken in the HIT-7 test. Nine pretest samples were taken at elevations $1.22 \mathrm{~m}$, $1.68 \mathrm{~m}, 1.83 \mathrm{~m}, 2.59 \mathrm{~m}, 3.05 \mathrm{~m}, 3.51 \mathrm{~m}$, $3.86 \mathrm{~m}, 4.42 \mathrm{~m}$, and $4.88 \mathrm{~m}$ after the gases were added. An additional nine samples were obtained posttest at the above locations at $\mathrm{t}=19.5 \mathrm{hrs}$. There was no mixing fan operation prior to these 18 gas grab samples. Additionally, at the end of the test $(t=23$ hrs), the mixing fans were turned on and two well-mixed gas grab samples were taken at elevations $1.68 \mathrm{~m}$ and $4.42 \mathrm{~m}$.

The lack of any significant pressure increase during the natural condensation event, along with the localized temperature increases, signified that localized, benign hydrogen deflagrations occurred with no significant pressure load on the Surtsey containment vessel. These localized deflagrations with little associated pressure increases suggested that the initially stratified hydrogen condition no longer existed at the time of the burns. The diffusion time constant for the experiment was estimated to be about nine hours. However, mass diffusion probably was not the dominant mixing force. Note that the initial atmosphere temperature was hot $(-400 \mathrm{~K})$, temperature gradients across the vessel wall (to ambient) likely set up convection loops inside the vessel that enhanced the passive mixing performance.

\subsection{HIT-8 Pressure, Temperature, and Spray Flow Measurements}

The eighth test (HIT-8) was used to examine the combustion of hydrogen-air-steam mixtures with condensing steam due to water sprays. The test was conducted with a hydrogen concentration that corresponds to the location on the flammability curve at the point of maximum steam concentration ("nose of the curve") (refer to Figures 8393). The target concentration was 24.5 mole\%. The test purpose was to improve the predictive capability for different combustion behaviors under these conditions.

The Surtsey vessel was inerted with steam at $0.36 \mathrm{MPa}$. Heated air and hydrogen gas were then added. The steam and noncondensible gases were well-mixed using fans installed inside the Surtsey vessel. On a wet basis, the steam concentration was 64.0 mole $\%$, the air concentration was 27.1 mole $\%$, and the hydrogen concentration was $8.9 \mathrm{~mole} \%$. On a dry basis, the air concentration was $75.3 \mathrm{~mole} \%$ and the hydrogen concentration was 24.7 mole $\%$.

The vessel temperature and pressure just prior to operation of the spray nozzle were approximately $408 \mathrm{~K}$ and $0.46 \mathrm{MPa}$, respectively. Two cylindrical glow plug igniters were activated. The igniters were located $0.5 \mathrm{~m}$ from the wall of the Surtsey vessel and $3.7 \mathrm{~m}$ above the floor. The average igniter temperature was $1235 \mathrm{~K}$. The spray system was turned on. The average spray flow rate was about $1.43 \mathrm{~kg} / \mathrm{s}$. The temperature of the spray water was $289 \mathrm{~K}$. The spray operated for 21.7 minutes. Final temperature and pressure in the Surtsey vessel were approximately $365 \mathrm{~K}$ and 0.17 $\mathrm{MPa}$, respectively.

The vessel pressure initially decreased due to steam condensation caused by the spray. Four minutes after the start of the water spray, there was a large deflagration in the Surtsey vessel. Pressure rose from 0.33 $\mathrm{MPa}$ to $0.85 \mathrm{MPa}$. The average gas temperature rose from $391 \mathrm{~K}$ to $848 \mathrm{~K}$. The 
top thermocouple on array D recorded the highest peak temperature, $1090 \mathrm{~K}$. The bottom thermocouples on all arrays were under water at the beginning of the test due to a partially clogged floor steam trap. The spray flow rate temporarily decreased to $0.57 \mathrm{~kg} / \mathrm{s}$ during the hydrogen burn due to the increased vessel back pressure which reduced the nozzle differential pressure.

Assuming that the number of moles of noncondensible gases remain constant up to the initial burn, a steam fraction prior to the burn can be calculated. It is estimated that the steam concentration was $51.8 \mathrm{~mole} \%$, the oxygen concentration was $7.6 \mathrm{~mole} \%$, and the hydrogen concentration was 11.9 mole\%. The flammability limit based on FITS data [Roller, 1985; Marshall and Ratzel, 1984] is approximately $52 \mathrm{~mole} \%$ steam.

\subsection{HIT-9 Pressure, Temperature, and Spray Flow Measurements}

The ninth test (HIT-9) was used to examine the combustion of hydrogen-air-steam mixtures with condensing steam due to water sprays. The test was conducted with a water spray flow rate scaled to twice the flow expected in the CE System $80+$ standard design, simulating activation and simultaneous operation of the two, independent, redundant trains (refer to Figures 94-104). To achieve the higher flow rate, a new nozzle was placed inside the Surtsey vessel, at the same height as the original nozzle and $0.41 \mathrm{~m}$ from vessel centerline. The axial full cone large capacity nozzle (Lechler 461.206) has a $90^{\circ}$ spray angle and the estimated Sauter mean diameter drop size is $\sim 500 \mathrm{~mm}$. The target for hydrogen concentration was $19.3 \mathrm{~mole} \%$ (initial atmosphere conditions similar to HIT-5).

The Surtsey vessel was inerted with steam at $0.28 \mathrm{MPa}$. Heated air and hydrogen gas were then added. The steam and noncondensible gases were well-mixed using fans installed inside the Surtsey vessel. On a wet basis, the steam concentration was 61.4 mole\%, the air concentration was 30.8 mole $\%$, and the hydrogen concentration was $7.8 \mathrm{~mole} \%$. On a dry basis, the air concentration was $79.8 \mathrm{~mole} \%$ and the hydrogen concentration was 20.2 mole $\%$.

The vessel temperature and pressure just prior to operation of the spray nozzle were approximately $408 \mathrm{~K}$ and $0.40 \mathrm{MPa}$, respectively. Two cylindrical glow plug igniters were activated. Both igniters were at the same location, $0.5 \mathrm{~m}$ from the wall of the Surtsey vessel and $3.7 \mathrm{~m}$ above the floor. The hottest igniter temperature was $1268 \mathrm{~K}$. The spray system was turned on. The average spray flow rate was $3.15 \mathrm{~kg} / \mathrm{s}$. The temperature of the spray water was $289 \mathrm{~K}$. The spray operated for 9.8 minutes. Final temperature and pressure in the Surtsey vessel were $331 \mathrm{~K}$ and $0.12 \mathrm{MPa}$, respectively.

About one minute after the start of the water spray, there was a deflagration in the Surtsey vessel. Pressure rose from $0.31 \mathrm{MPa}$ to about $0.47 \mathrm{MPa}$. The average gas temperature rose from $391 \mathrm{~K}$ to about $573 \mathrm{~K}$. Another five burns (that produced noticeable pressure rises) occurred at regular intervals after the first burn. The differential pressure due to each burn was smaller than the preceding burn. Several additional smaller burns were detected by the thermocouple rakes. 
It is estimated that the steam concentration at the initial deflagration was $51.3 \mathrm{~mole} \%$, the oxygen concentration was $8.1 \mathrm{~mole} \%$, and the hydrogen concentration was 9.8 mole\%. The flammability limit based on FITS data is approximately 51 mole $\%$ steam.

\subsection{HIT-10 Pressure, Temperature, and Spray Flow Measurements}

The tenth test (HIT-10) was used to examine the combustion of hydrogen-air-steam mixtures with condensing steam due to water sprays. The test was conducted with a water spray flow rate scaled to twice the flow expected in the CE System 80+ standard design (refer to Figures 105-115). The target for hydrogen concentration was 13.6 mole\%.

The Surtsey vessel was inerted with steam at $0.28 \mathrm{MPa}$. Heated air and hydrogen gas were then added. The steam and noncondensible gases were well-mixed using fans installed inside the Surtsey vessel. On a wet basis, the steam concentration was 63.1 mole $\%$, the air concentration was 31.8 mole $\%$, and the hydrogen concentration was $5.1 \mathrm{~mole} \%$. On a dry basis, the air concentration was 86.2 mole $\%$ and the hydrogen concentration was $13.8 \mathrm{~mole} \%$.

The vessel temperature and pressure just prior to operation of the spray nozzle were approximately $406 \mathrm{~K}$ and $0.39 \mathrm{MPa}$, respectively. Two cylindrical glow plug igniters were activated. Both igniters were at the same location, $0.5 \mathrm{~m}$ from the wall of the Surtsey vessel and $3.7 \mathrm{~m}$ above the floor. The hottest igniter average temperature was $1251 \mathrm{~K}$. The spray system was turned on. The average spray flow rate was $3.17 \mathrm{~kg} / \mathrm{s}$. The temperature of the spray water was
$291 \mathrm{~K}$. The spray operated for 9.8 minutes. Final temperature and pressure in the Surtsey vessel were $331 \mathrm{~K}$ and $0.12 \mathrm{MPa}$, respectively.

About one minute after the start of the water spray, there was a small deflagration in the Surtsey vessel. Pressure rose from 0.26 $\mathrm{MPa}$ to $0.29 \mathrm{MPa}$. The average gas temperature rose from $384 \mathrm{~K}$ to about 399 K. Several smaller burns were detected either by pressure transducers and/or by thermocouple rakes.

It is estimated that the steam concentration was 48.2 mole\%, the oxygen concentration was $9.4 \mathrm{~mole} \%$, and the hydrogen concentration was 7.1 mole $\%$ immediately prior to the initial deflagration. The flammability limit based on FITS data is approximately 44 mole $\%$ steam.

\subsection{HIT-11 Pressure, Temperature, and Spray Flow Measurements}

The HIT-11 test was intended to replicate the HIT- 6 experiment, with the exception of twice the spray flow rate (refer to Figures 116-126). The target for hydrogen concentration was 29.8 mole $\%$, stratified in the upper Surtsey volume.

The Surtsey vessel was inerted with steam at $0.36 \mathrm{MPa}$. Heated air was added. The steam and air were well-mixed using fans installed inside the Surtsey vessel. The mixing fans were turned off. After a five minute wait, heated hydrogen was added through the middle injector nozzle. Pretest gas grab samples were then taken. Based on actual air and hydrogen gases added, on a well-mixed wet basis, the steam concentration was 66.2 mole $\%$, the air 
concentration was $29.2 \mathrm{~mole} \%$, and the hydrogen concentration was $4.6 \mathrm{~mole} \%$. On a well-mixed dry basis, the air concentration was 86.3 mole\% and the hydrogen concentration was 13.7 mole\%. Assuming that the hydrogen stratified in the upper $45.7 \%$ of the Surtsey vessel (above the injector nozzle), the stratified hydrogen drybasis concentration was $30.0 \mathrm{~mole} \%$.

The vessel temperature and pressure just prior to operation of the spray nozzle were $411 \mathrm{~K}$ and $0.44 \mathrm{MPa}$, respectively. Two cylindrical glow plug igniters were activated. Both igniters were at the same location, $0.5 \mathrm{~m}$ from the wall of the Surtsey vessel and $3.7 \mathrm{~m}$ above the floor. The igniter temperature averaged $1240 \mathrm{~K}$. The spray system was turned on. The average spray flow rate was $3.15 \mathrm{~kg} / \mathrm{s}$. The temperature of the spray water was $291 \mathrm{~K}$. The spray operated for 9.9 minutes. Final temperature and pressure in the Surtsey vessel were $334 \mathrm{~K}$ and $0.12 \mathrm{MPa}$, respectively. Two minutes after the start of the water spray, there was a small deflagration in the Surtsey vessel. Pressure rose from $0.27 \mathrm{MPa}$ to about $0.30 \mathrm{MPa}$. The average gas temperature rose from $385 \mathrm{~K}$ to about $395 \mathrm{~K}$. Several smaller burns were detected either by pressure transducers and/or by thermocouple rakes.

It is estimated that the steam concentration just prior to the initial deflagration was 48.0 mole $\%$, the oxygen concentration was 9.4 mole $\%$, and the hydrogen concentration was $7.1 \mathrm{~mole} \%$. The flammability limit based on FITS data is approximately $44 \mathrm{~mole} \%$ steam. 


\subsection{Gas Composition Measurements and Analyses}

The gas grab samples were taken from an atmosphere containing a mixture of steam and noncondensible gases. If the sample lines, valves, and bottles were heated above saturation temperature, the sample bottles contained a mixture of steam and noncondensible gases when they were filled. If the sample bottles were cold, it was determined experimentally that they would pressurize to vessel pressure with only noncondensible gas. Gas mass spectroscopy was performed on gases from sample bottles at room temperature. Since the steam in the bottle condensed prior to analysis, the measurements are only of noncondensible gases.

One method used to determine the mole percent of the individual gas species requires the use of a posttest noncondensible gas fraction $\left(f_{\mathrm{NC}}\right)$ adjustment to each bottle measurement. However, the need to estimate the posttest noncondensible fraction introduces uncertainty in the calculated amounts of hydrogen (and other gas species).

The nitrogen-ratio method described below does not require an estimate of the posttest noncondensible fraction [Blanchat, 1994]. It does, however, require the pretest noncondensible fraction. The data and assumptions required for the nitrogen-ratio method are listed below:

1. The initial noncondensible fraction, $\mathrm{f}_{\mathrm{NC}}$, must be known.

2. The total pretest moles of gas, $\mathbf{N}_{\text {total, }}^{0}$ including steam and noncondensible gases, must be known.
3. The measured ratios of the pretest and posttest noncondensible gases must be known.

4. It must be assumed that nitrogen is neither produced nor consumed by chemical reactions.

5. It must be assumed that leakage between the time for which the pretest numbers apply and the time of the posttest samples does not change the ratios of the noncondensible gases.

Let $\mathrm{X}^{0}{ }_{\mathrm{i}}$ be the initial (pretest) mole fraction (from Table 3 ) of species $i$ at time $t=0$ in the containment vessel and let $\mathrm{N}_{\text {total }}^{0}$ be the initial number of steam and noncondensible gas moles in the vessel (from Table 3). The initial number of gas moles for all species is

$$
N_{i}^{0}=X_{i}^{0} \quad N_{\text {total }}^{0} .
$$

Let $X_{i}^{t}$ be the mole fraction (from Tables 6-16) of species $i$ at time $t$. For the various posttest times, the number of moles of nitrogen is assumed to be unchanged, and the numbers of moles of the other gases are therefore given by

$$
N_{i}^{t}=N_{N_{2}}^{0} \frac{X_{i}^{t}}{X_{N_{2}}^{t}} .
$$

It is not necessary to know the posttest noncondensible fraction; only the ratio of the posttest gas species mole fractions is needed. Furthermore, provided all noncondensible gases leak in the same proportion, a correction for posttest leakage is not needed. Table 5 gives the final gas concentrations in the Surtsey vessel, based on the calculated noncondensible gas moles and the measured pressure and calculated average gas temperature data at the completion of the 
Gas Composition Measurements and Analyses

spray along with $\mathbf{P}, \mathrm{V}, \mathrm{T}$ ideal-gas law relationships.

Given the pretest moles of $\mathrm{O}_{2}$ and $\mathrm{H}_{2}$ from the noncondensible fraction method and posttest moles of $\mathrm{O}_{2}$ and $\mathrm{H}_{2}$ from the nitrogen-ratio method, the moles $\mathrm{H}_{2}$ burned can be computed from

$$
N_{H 2, \text { burmed }}^{t}=\left(N_{H 2}^{0}-N_{H 2}^{t}\right)=2\left(N_{O 2}^{0}-N_{O 2}^{t}\right) \text {. }
$$

Table 5 also gives the results for the amounts of oxygen and hydrogen burned based on the nitrogen-ratio method. 


\subsection{Hydrogen Flammability}

An important issue is the contribution of hydrogen combustion to the peak containment pressure. Hydrogen combustion will release energy to the atmosphere and could significantly increase the loads on the containment building. The extent of hydrogen combustion can be estimated through comparison of the experimental results with flammability limits data obtained for quiescent hydrogen/air/steam mixtures (Figure 127).

Figure 127 indicates that the initial gas mixture conditions in the HIT experiments are outside the envelope of flammable concentrations. The initial condition steam concentrations were $66.1 \pm 2.4 \mathrm{~mole} \%$ (excluding HIT-7). This implies that combustion of the hydrogen in the containment atmosphere cannot occur without condensation from sprays.
However, the initial conditions in the vessel changed sufficiently after the actuation of the sprays to permit hydrogen combustion. The estimated steam concentrations at the first noted deflagration were $49.2 \pm 4.8 \mathrm{~mole} \%$ (excluding HIT-7).

Lines have been drawn in Figure 127 from the initial ambient conditions in some of the HIT experiments to the point corresponding to the final measured condition. These lines represent the time-dependent gas concentrations in the vessel and clearly indicate the potential for combustion of the steam/hydrogen/air mixture as it passes into the flammable region. The HIT experiments show that ignition of hydrogen/air/steam mixtures having steam condensed by water sprays occurs within the range of uncertainty of experimentally determined flammability limits for quiescent hydrogen/air/steam mixtures. 


\subsection{Summary}

A series of experiments was conducted to determine hydrogen combustion behavior under conditions of condensing steam caused by water sprays. Experiments were conducted in the Surtsey facility under conditions that were nearly prototypical of those that would be expected in a severe accident in the CE System 80+ containment. Mixtures were initially nonflammable owing to dilution by steam. The mixtures were ignited by thermal glow plugs when they became flammable after sufficient steam was removed by condensation caused by water sprays.

Tests with 13.5 mole\% hydrogen were conducted; HIT-1 had three separate igniter locations, HIT-2 had two igniter locations, and HIT-4 had one location. The 13.5 mole $\%$ hydrogen is the maximum concentration of hydrogen that can exist under well-mixed conditions throughout the entire containments of the CE System 80+, assuming $100 \%$ in-vessel zirconium-water reaction. Multiple deflagrations were observed with small pressure rises $(<15 \mathrm{kPa})$ as mixtures became marginally flammable. Igniter location does not appear to be a factor. The HIT-5 test, with 19.3 mole\% hydrogen, showed results very similar to those obtained using $13.5 \mathrm{~mole} \%$ hydrogen.

Two tests were performed with large amounts of well-mixed hydrogen (29.7 mole $\%$ in HIT-3 and 24.7 mole $\%$ in HIT-8 on a dry basis). One large deflagration was observed in each test. In the stoichiometric mixture experiment (HIT-3), the vessel pressure increase was $610 \mathrm{kPa}$ and the temperature increase was $446 \mathrm{~K}$. The burn time was relatively slow (4.3 s) which resulted in a pressure rise of about $70 \%$ of the potential maximum pressure rise.
Detonations or other forms of energetic combustion were not observed in this test which contained the most chemically sensitive mixture. Note that stoichiometric mixtures cannot exist under well-mixed conditions in the CE System 80+ containment.

The results from the HIT-6 test, initially stratified with a stoichiometric mixture in the top $(29.5 \mathrm{~mole} \%$ hydrogen on a dry basis but equivalent to $13.5 \mathrm{~mole} \%$ hydrogen on a well-mixed basis), showed that the water spray effectively mixes the initially stratified atmosphere prior to the deflagration event. Multiple deflagrations were observed with small pressure rises $(<15 \mathrm{kPa})$ similar to those observed in the well-mixed test with $13.5 \mathrm{~mole} \%$ hydrogen (dry basis). If the water sprays had not been effective and the stoichiometric mixture had been rendered flammable before substantial mixing occurred, combustion pressures due to one large deflagration would have resulted.

One stratified test (HIT-7) was performed without using the spray system. As the steam condensed due to natural cool down of the vessel, the vessel pressure and temperature decreased slowly over time. Localized, benign hydrogen deflagrations (small temperature spikes with no associated pressure increases) occurred during the test. Gas grab samples taken at the end of the test indicated that the vessel had become wellmixed.

Tests were conducted with a water spray flow rate scaled to twice the flow expected in the CE System 80+ standard design, simulating activation and simultaneous operation of the two, independent, redundant water spray trains. The results were very 
similar to those obtained with the nominal spray flow rate.

Detonations or accelerated flame propagation were not observed in hydrogen/air/steam mixtures which were initially non-flammable due to steam dilution but were rendered flammable by steam condensation due to water sprays. The HIT experiments show that the thermal glow plugs functioned as intended; ignition of hydrogen/air/steam mixtures having steam condensed by water sprays occurs within the range of uncertainty of experimentally determined flammability limits for quiescent hydrogen/air/steam mixtures. The combustion mode observed for prototypical mixtures was characterized by multiple deflagrations with relatively small pressure rises. The thermal glow plugs were effective in burning hydrogen safely by igniting the gases as the mixtures became marginally flammable. 


\subsection{References}

Blanchat, T.K., M.D. Allen, M.M. Pilch, and R.T. Nichols, "Experiments to Investigate Direct Containment Heating Phenomena With Scaled Models of the Surry Nuclear Power Plant," Sandia National Laboratories, SAND93-2519, NUREG/CR-6152, Albuquerque, NM, 1994.

CESSAR Design Certification, Appendix 19.11K, "Assessment of the System 80+ Hydrogen Mitigation System for Application in a Severe Accident Environment," ABBCombustion, Combustion Engineering, Inc., Windsor Locks, CT, October 1993.

Kumar, R.K., "Flammability Limits of Hydrogen-Oxygen-Diluent Mixtures," Journal of Fire Sciences, Vol. 3, pp. 245262, July/Auigust 1985.

Marshall, B.W. Jr., and Ratzel, A.C., III, "Pressure Measurements in a Hydrogen Combustion Environment: An Evaluation of Three Pressure Transducers," SAND832621, Volume 2 of 2, Sandia National Laboratories, Albuquerque, NM, May 1984.

Marshall, B.W., "Hydrogen-Air-Steam Flammability Limits and Combustion Characteristics in the FITS Vessel," SAND84-0383, NUREG/CR-3468, Sandia National Laboratories, Albuquerque, NM, December 1986.

Nelson, L.S., "Behavior of Hydrogen Igniters During Operation of Water Sprays in Containment," presented at the Twelfth Water Reactor Safety Research Information Meeting, Gaithersburg, MD, October 22-26, 1983, published as an NRC report, NUREG/CP-0058, Vol. 3, pp. 371-387, Washington, DC, January 1985.
Ratzel, A.C., "Data Analyses for Nevada Test Site (NTS) Premixed Combustion Tests," Sandia National Laboratories, SAND85-0135, NUREG/CR-4138, Albuquerque, NM, May 1985.

Roller, S., "Pressure Measurements in a Hydrogen Combustion Environment: Combustion Test Series 1 and 2 in the FITS Tank," SAND83-2621, Volume 1 of 2, Sandia National Laboratories, Albuquerque, NM, March 1985.

Shebeko, Yu. N., Tsarichenko, S.G., Eremenko, O. Ya., Keller, V.D., and Trunev, A.V., "Combustion of Lean Hydrogen-Air Mixtures in an Atomized Water Spray," Fizika Goreniya I Vzryva, Vol. 26, No. 4, pp. 58-61, July-August 1990.

System 80+ Standard Design: CESSAR Design Certification, Combustion Engineering, Windsor, CT, DOE/SF/16564, December 1990.

Tamm, H., Ungurian, M., and Kumar, R.K., "Effectiveness of Thermal Ignition Devices in Rich Hydrogen-Air-Steam Mixtures," Electric Power Research Institute report, EPRI NP-5245, AECL-8363, Palo Alto, CA, July 1987.

Zabetakis, M.G., "Research on the Combustion and Explosion Hazards of Hydrogen-Water Vapor-Air Mixtures," Bureau of Mines Report, AECU-3327, September 1956. 
Tables

Table 1. Comparisons of spray parameters.

\begin{tabular}{|l|c|c|c|}
\hline & $\begin{array}{c}\text { CE System } \\
80+\end{array}$ & Surtsey $^{1}$ & Surtsey $^{2}$ \\
\hline Spray flow rate $(\mathrm{kg} / \mathrm{s})$ & 403.79 & 1.45 & 3.15 \\
\hline Spray flow area $\left(\mathrm{m}^{2}\right)$ & 2918.64 & 10.51 & 10.51 \\
\hline Spray nozzle designation (Lechler) & $1713 \mathrm{~A}$ & 461.148 & 461.206 \\
\hline Spray nozzle types & $\begin{array}{c}\text { Ramp } \\
\text { Bottom } \\
\text { Hollow } \\
\text { Cone }\end{array}$ & $\begin{array}{c}\text { Axial } \\
\text { Full Cone }\end{array}$ & $\begin{array}{c}\text { Axial } \\
\text { Full Cone } \\
\text { Large } \\
\text { Capacity }\end{array}$ \\
\hline Number of nozzles & 658 & 1 & 1 \\
\hline Drop mass median diameter (micron) & 675 & 1080 & 500 \\
\hline Drop surface area $\left(\mathrm{m}^{2} \mathrm{xl0} 0^{-5}\right)$ & 1.43 & 3.66 & 0.78 \\
\hline Drop terminal velocity $(\mathrm{m} / \mathrm{s})^{3}$ & 2.67 & 3.63 & 1.93 \\
\hline Spray mass flux $\left(\mathrm{kg}^{3} \mathrm{~m}^{2} \mathrm{~s}\right)$ & 0.138 & 0.138 & 0.300 \\
\hline Spray volumetric density $\left(\mathrm{kg}^{2} / \mathrm{m}^{3}\right)$ & 0.052 & 0.038 & 0.155 \\
\hline
\end{tabular}

1 Spray nozzle 461.148 was used in HIT-1, HIT-2, HIT-3, HIT-4, HIT-5, HIT-6, and HIT-8. Flow rate scaled to simulate activation of one spray train.

2 Spray nozzle 461.206 was used in HIT-9, HIT-10, and HIT-11.

Flow rate scaled to simulate activation of both spray train.

3 The drop terminal velocity for the CE System 80+ containment was calculated using a 700 micrometer $(\mu \mathrm{m})$ (micron) diameter drop and for the Surtsey ${ }^{1}$ experiment a 1000 micron diameter drop was used. 
Table 2. HIT instrumentation location and purpose.

\begin{tabular}{|c|c|c|c|}
\hline Channel & Instrument* & Location & Purpose \\
\hline $29,1,105$ & Thermocouple & Dome & Measure dome temperature \\
\hline 30 & Thermocouple & Spray nozzle & Measure water temperature \\
\hline 31 & Pressure transducer & Vessel penetration & Measure gas pressure \\
\hline 32 & Pressure transducer & Vessel penetration & Measure gas pressure \\
\hline 33 & Pressure transducer & Vessel penetration & Measure gas pressure \\
\hline 34 & Pressure transducer & Vessel penetration & Measure gas pressure \\
\hline 41 & Thermocouple array-Al & Bottom & Measure gas temperature \\
\hline 42 & Thermocouple array-A2 & & Measure gas temperature \\
\hline 43 & Thermocouple array- $\mathrm{A3}$ & & Measure gas temperature \\
\hline 44 & Thermocouple array-A4 & & Measure gas temperature \\
\hline 45 & Thermocouple array-A5 & & Measure gas temperature \\
\hline 46 & Thermocouple array-A6 & & Measure gas temperature \\
\hline 47 & Thermocouple array-A7 & & Measure gas temperature \\
\hline 48 & Thermocouple array-A8 & & Measure gas temperature \\
\hline 49 & Thermocouple array-A9 & Top & Measure gas temperature \\
\hline 50 & Thermocouple array-B1 & Bottom & Measure gas temperature \\
\hline 51 & Thermocouple array-B2 & & Measure gas temperature \\
\hline 52 & Thermocouple array-B3 & & Measure gas temperature \\
\hline 53 & Thermocouple array-B4 & & Measure gas temperature \\
\hline 54 & Thermocouple array-B5 & & Measure gas temperature \\
\hline 55 & Thermocouple array-B6 & & Measure gas temperature \\
\hline 56 & Thermocouple array-B7 & & Measure gas temperature \\
\hline 57 & Thermocouple array-B8 & & Measure gas temperature \\
\hline 58 & Thermocouple array-B9 & Top & Measure gas temperature \\
\hline 59 & Thermocouple array-C1 & Bottom & Measure gas temperature \\
\hline 60 & Thermocouple array-C2 & & Measure gas temperature \\
\hline 61 & Thermocouple array-C3 & & Measure gas temperature \\
\hline 62 & Thermocouple array-C4 & & Measure gas temperature \\
\hline 63 & Thermocouple array-C5 & & Measure gas temperature \\
\hline 64 & Thermocouple array-C6 & & Measure gas temperature \\
\hline 65 & Thermocouple array-C7 & & Measure gas temperature \\
\hline 66 & Thermocouple array-C8 & & Measure gas temperature \\
\hline 67 & Thermocouple array-C9 & Top & Measure gas temperature \\
\hline 68 & Thermocouple array-D1 & Bottom & Measure gas temperature \\
\hline 69 & Thermocouple array-D2 & & Measure gas temperature \\
\hline 70 & Thermocouple array-D3 & & Measure gas temperature \\
\hline 71 & Thermocouple array-D4 & & Measure gas temperature \\
\hline 72 & Thermocouple array-D5 & & Measure gas temperature \\
\hline 73 & Thermocouple array-D6 & & Measure gas temperature \\
\hline 74 & Thermocouple array-D7 & & Measure gas temperature \\
\hline 75 & Thermocouple array-D8 & & Measure gas temperature \\
\hline 76 & Thermocouple array-D9 & Top & Measure gas temperature \\
\hline 77 & Thermocouple array-El & Bottom & Measure gas temperature \\
\hline 78 & Thermocouple array-E2 & & Measure gas temperature \\
\hline 79 & Thermocouple array-E3 & & Measure gas temperature \\
\hline 81 & Thermocouple array-E4 & & Measure gas temperature \\
\hline 82 & Thermocouple array-E5 & & Measure gas temperature \\
\hline
\end{tabular}


Tables

Table 2. HIT instrumentation location and purpose.

\begin{tabular}{|r|l|l|l|}
\hline Channel & \multicolumn{1}{|c|}{ Lnstrument* } & \multicolumn{1}{|c|}{ Location } & \multicolumn{1}{|c|}{ Purpose } \\
\hline 83 & Thermocouple array-E6 & & Measure gas temperature \\
\hline 84 & Thermocouple array-E7 & & Measure gas temperature \\
\hline 85 & Thermocouple array-E8 & & Measure gas temperature \\
\hline 86 & Thermocouple array-E9 & Top & Measure gas temperature \\
\hline 88 & Thermocouple & Igniter 1 & Measure igniter temperature \\
\hline 90 & Thermocouple & Igniter 2 & Measure igniter temperature \\
\hline 91 & Thermocouple & Igniter 3 & Measure igniter temperature \\
\hline 92 & Thermocouple & Igniter 4 & Measure igniter temperature \\
\hline 93 & Thermocouple & Igniter 5 & Measure igniter temperature \\
\hline 37,101 & Thermocouple & Igniter 6 & Measure igniter temperature \\
\hline 87,102 & Thermocouple & Top flange-south & Measure wall temperature \\
\hline 95,100 & Thermocouple & Top flange-north & Measure wall temperature \\
\hline 99 & Thermocouple & Wall-3.6 m from floor & Measure wall temperature \\
\hline 97 & Thermocouple & Wall-2.4 m from floor & Measure wall temperature \\
\hline 96,94 & Thermocouple & Wall-0.6 m from floor & Measure wall temperature \\
\hline 96 & Thermocouple & Floor-0.3 m from wall & Measure floor temperature \\
\hline 97,95 & Thermocouple & Floor-0.3 m from wall & Measure floor temperature \\
\hline 106 & Thermocouple & Floor-1.8 $\mathrm{m}$ from wall & Measure floor temperature \\
\hline 107 & Thermocouple & Vessel inlet & Measure hot air temperature \\
\hline 116 & Thermocouple & Vessel inlet & $\begin{array}{l}\text { Measure hot hydrogen } \\
\text { temperature }\end{array}$ \\
\hline 117 & Thermocouple & Air manifold & $\begin{array}{l}\text { Measure manifold } \\
\text { temperature }\end{array}$ \\
\hline 118 & Flowmeter & Hydrogen manifold & $\begin{array}{l}\text { Measure manifold } \\
\text { temperature }\end{array}$ \\
\hline G1-G18 & Gas grab sample & Spray line & Measure spray flow rate \\
\hline & & Various & $\begin{array}{l}\text { Measure gas composition } \\
\text { prior to and after HPME }\end{array}$ \\
\hline & &
\end{tabular}

* All thermocouples were type-K. 
Table 3. Initial conditions in the HIT experiments.

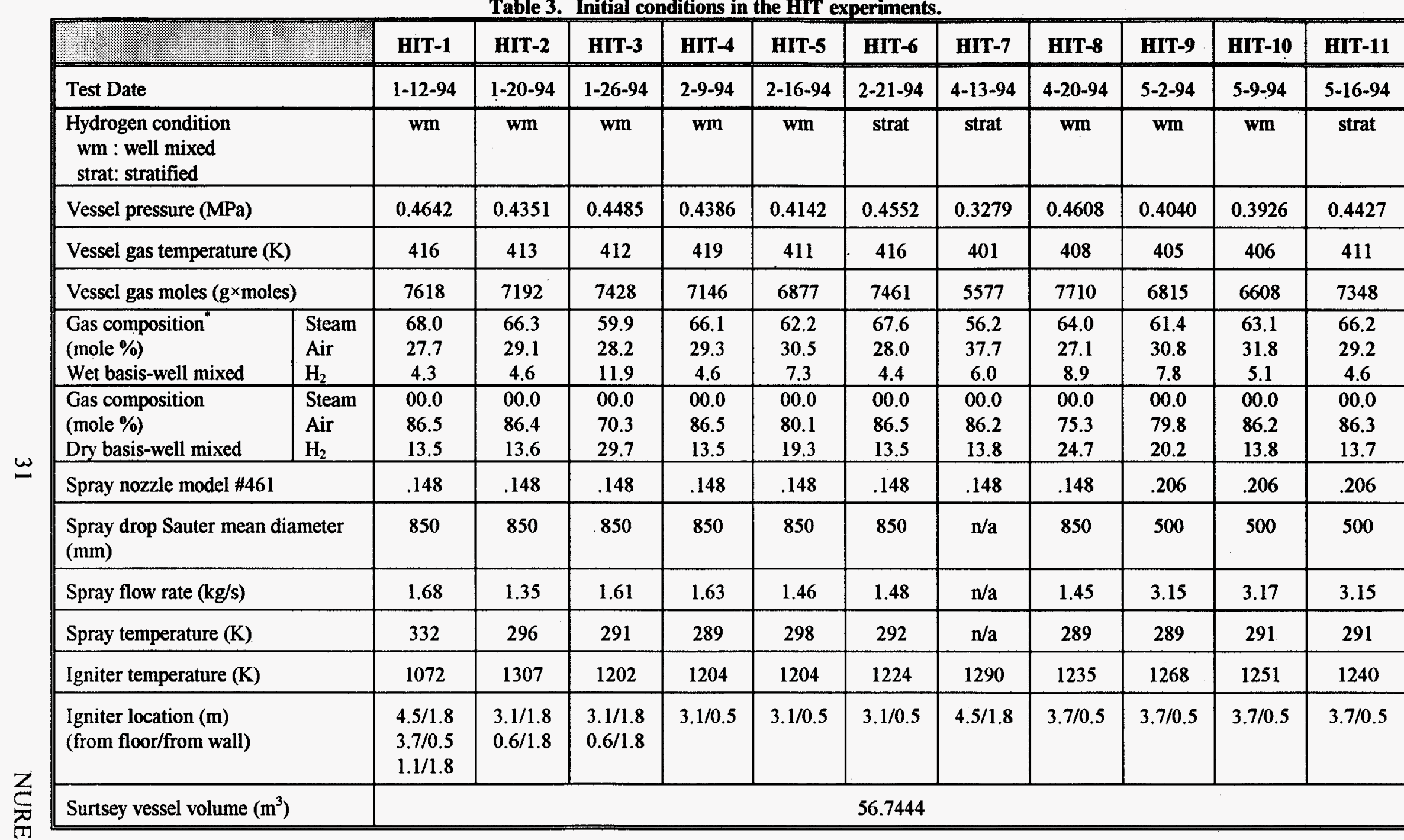

Gas concentrations at initial conditions are based on the calculated amounts of air and hydrogen gases that were added. Steam concentrations are based on ideal gas law. 
Table 4. Conditions at first burn in the HIT experiments.

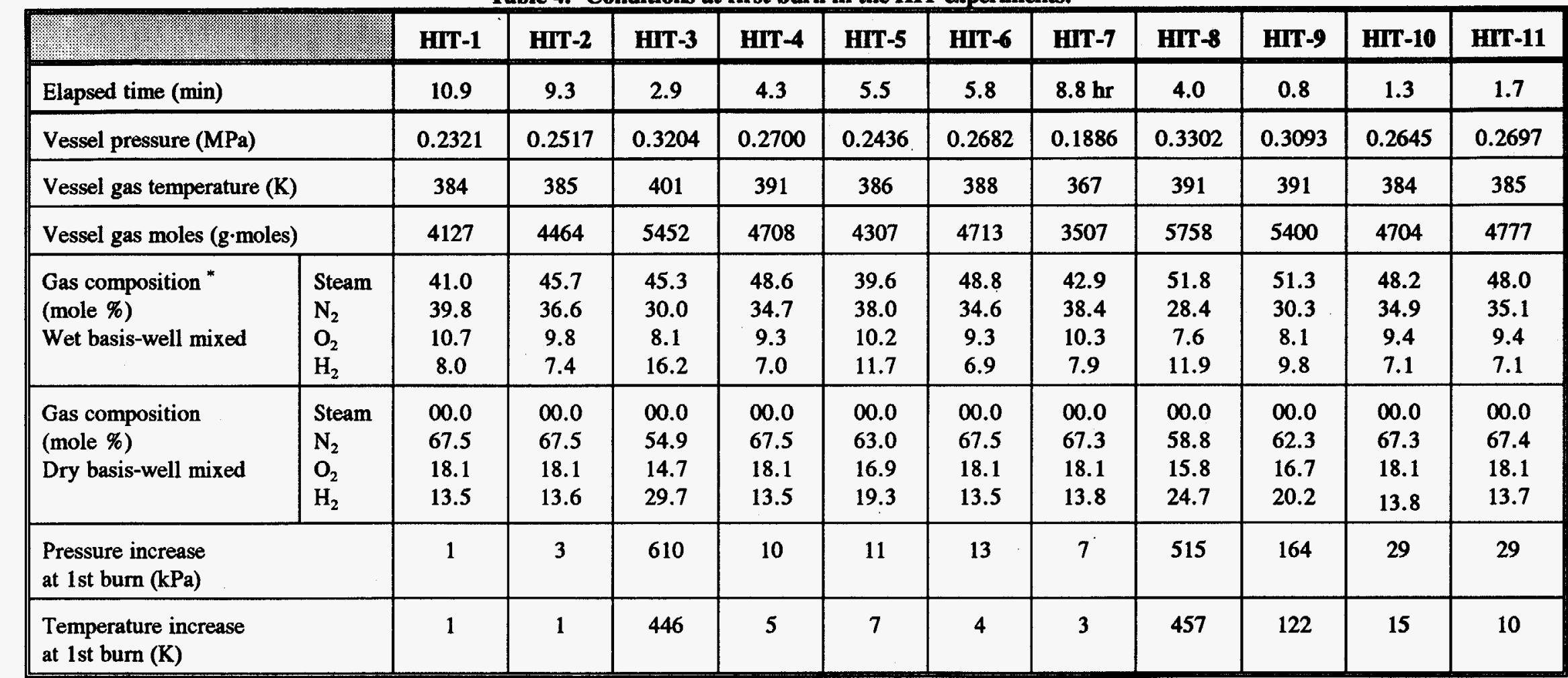

Gas concentrations at first bum conditions are based on assuming that the noncondensible gas moles remain constant at their initial values and steam concentrations are based on the ideal gas law. Wet basis concentrations for HIT-7 were estimated assuming saturated steam conditions. For details on HIT-7, see text in Program Description section. Gas compositions do not include trace air constituents. 
Table 5. Final conditions in the HIT experiments.

\begin{tabular}{|c|c|c|c|c|c|c|c|c|c|c|c|c|}
\hline & HIT-1 & HIT-2 & HIT-3 & HIT-4 & HIT-5 & HIT-6 & HIT-7 & HIT-8 & HIT-9 & HIT-10 & HIT-11 \\
\hline \multicolumn{2}{|l|}{ Elapsed time (min) } & 18.9 & 23.7 & 18.5 & 19.3 & 21.5 & 20.9 & $23(\mathrm{hr})$ & 21.7 & 9.8 & 9.8 & 9.9 \\
\hline \multicolumn{2}{|l|}{ Vessel pressure (MPa) } & 0.1697 & 0.1227 & 0.1070 & 0.1261 & 0.1080 & 0.1225 & 0.1083 & 0.1728 & 0.1150 & 0.1198 & 0.1212 \\
\hline \multicolumn{2}{|c|}{ Vessel gas temperature (K) } & 371 & 338 & 346 & 326 & 344 & 338 & 333 & 365 & 330 & 331 & 334 \\
\hline \multicolumn{2}{|c|}{ Vessel gas moles ( $\mathrm{g} \cdot \mathrm{moles})$} & 3119 & 2480 & 2109 & 2640 & 2143 & 2477 & 2220 & 3232 & 2379 & 2472 & 2476 \\
\hline $\begin{array}{l}\text { Gas composition' } \\
\text { (mole \%) } \\
\text { Wet basis-well mixed }\end{array}$ & $\begin{array}{l}\text { Steam } \\
\mathrm{N}_{2} \\
\mathrm{O}_{2} \\
\mathrm{H}_{2} \\
\end{array}$ & $\begin{array}{c}24.9 \\
52.7 \\
12.7 \\
7.1 \\
\end{array}$ & $\begin{array}{c}13.8 \\
65.9 \\
15.0 \\
4.4 \\
\end{array}$ & $\begin{array}{c}16.8 \\
77.6 \\
4.2 \\
0.2 \\
\end{array}$ & $\begin{array}{l}20.3 \\
61.9 \\
12.7 \\
4.0 \\
\end{array}$ & $\begin{array}{c}3.0 \\
76.5 \\
12.9 \\
5.7 \\
\end{array}$ & $\begin{array}{c}15.9 \\
65.8 \\
13.3 \\
4.2 \\
\end{array}$ & $\begin{array}{l}17.6 \\
58.3 \\
14.9 \\
7.8^{2} \\
\end{array}$ & $\begin{array}{c}45.0 \\
50.4 \\
4.1 \\
0.2\end{array}$ & $\begin{array}{l}17.9 \\
68.9 \\
9.8 \\
3.6 \\
\end{array}$ & $\begin{array}{c}14.8 \\
66.4 \\
13.9 \\
4.0\end{array}$ & $\begin{array}{l}13.6 \\
67.7 \\
13.6 \\
4.1 \\
\end{array}$ \\
\hline $\begin{array}{l}\text { Gas composition } \\
\text { (mole \%) } \\
\text { Dry basis-well mixed }\end{array}$ & $\begin{array}{l}\text { Steam } \\
\mathrm{N}_{2} \\
\mathrm{O}_{2} \\
\mathrm{H}_{2} \\
\end{array}$ & $\begin{array}{c}00.0 \\
70.3 \\
16.9 \\
9.5 \\
\end{array}$ & $\begin{array}{c}00.0 \\
76.5 \\
17.4 \\
5.1 \\
\end{array}$ & $\begin{array}{c}00.0 \\
93.3 \\
5.1 \\
0.2 \\
\end{array}$ & $\begin{array}{c}00.0 \\
77.6 \\
16.0 \\
5.0 \\
\end{array}$ & $\begin{array}{c}0.0 \\
78.8 \\
13.3 \\
5.9 \\
\end{array}$ & $\begin{array}{c}00.0 \\
78.2 \\
15.8 \\
5.0 \\
\end{array}$ & $\begin{array}{l}00.0 \\
70.8 \\
18.1 \\
9.5 \\
\end{array}$ & $\begin{array}{c}00.0 \\
91.8 \\
7.4 \\
0.3\end{array}$ & $\begin{array}{l}00.0 \\
83.8 \\
12.0 \\
4.4 \\
\end{array}$ & $\begin{array}{c}00.0 \\
77.9 \\
16.3 \\
4.7 \\
\end{array}$ & $\begin{array}{l}00.0 \\
78.3 \\
15.7 \\
4.7 \\
\end{array}$ \\
\hline \multicolumn{2}{|l|}{$\begin{array}{l}\text { Oxygen burned }\left(\Delta \mathrm{N}_{\mathrm{O}_{2}}\right) \\
(\mathrm{g} \cdot \mathrm{moles})\end{array}$} & 46 & 67 & 350 & 102 & 164 & 107 & 22 & 307 & 206 & 97 & 113 \\
\hline \multicolumn{2}{|c|}{$\begin{array}{l}\text { Hydrogen burned }\left(\Delta \mathrm{N}_{\mathrm{H} 2}\right) \\
\text { (g.moles) }\end{array}$} & 107 & 220 & 881 & 223 & 380 & 223 & 117 & 680 & 446 & 236 & 239 \\
\hline \multicolumn{2}{|c|}{$2 \times \mathrm{O}_{2}$ burned $/ \mathrm{H}_{2}$ burned } & 0.85 & 0.61 & 0.80 & 0.92 & 0.86 & 0.96 & 0.38 & 0.90 & 0.92 & 0.82 & 0.94 \\
\hline
\end{tabular}

1 Gas concentrations at final conditions are based on the gas grab sample results, steam concentrations are based on the ideal gas law. Gas compositions in HIT-1 were influenced by the gas sample procedure (see text in Program Description section for more details). Wet basis concentrations for HIT-7 were estimated assuming saturated steam conditions. Gas compositions do not include trace air constituents. 
Tables

Table 6. Gas concentrations measured in the HIT-1 experiment.

\begin{tabular}{|c|c|c|c|c|}
\hline \multicolumn{2}{|c|}{ Pretest } & \multicolumn{3}{|c|}{ Species (mole\%) } \\
\hline Label & Location & $\mathbf{N}_{2}$ & $\mathrm{O}_{2}$ & $\mathrm{H}_{2}$ \\
\hline 1 & $4.88 \mathrm{~m}$ & 66.1 & 18.2 & 13.1 \\
\hline 2 & $4.42 \mathrm{~m}$ & 65.0 & 18.0 & 13.5 \\
\hline 3 & $3.96 \mathrm{~m}$ & 66.8 & 18.5 & 11.9 \\
\hline 4 & $3.51 \mathrm{~m}$ & - & - & - \\
\hline 5 & $3.05 \mathrm{~m}$ & 65.3 & 18.0 & 13.5 \\
\hline 6 & $2.59 \mathrm{~m}$ & 66.4 & 18.1 & 13.7 \\
\hline 7 & $2.13 \mathrm{~m}$ & 69.7 & 19.5 & 8.9 \\
\hline 8 & $1.68 \mathrm{~m}$ & 65.5 & 18.30 & 13.7 \\
\hline 9 & $1.22 \mathrm{~m}$ & 69.7 & 19.6 & 8.4 \\
\hline \multicolumn{2}{|c|}{$\begin{array}{l}\text { Pretest Mean } \\
\text { Standard Deviation }\end{array}$} & $\begin{array}{l}66.8 \\
\pm 1.9\end{array}$ & $\begin{array}{l}18.5 \\
\pm 0.7\end{array}$ & $\begin{array}{l}12.1 \\
\pm 2.2\end{array}$ \\
\hline \multicolumn{2}{|c|}{ Posttest } & \multicolumn{3}{|c|}{ Species (mole\%) } \\
\hline Label & Location & $\mathbf{N}_{2}$ & $\mathrm{O}_{2}$ & $\mathrm{H}_{2}$ \\
\hline 10 & $4.88 \mathrm{~m}$ & 69.2 & 17.5 & 10.6 \\
\hline 11 & $4.42 \mathrm{~m}$ & 69.0 & 16.8 & 9.6 \\
\hline 12 & $3.96 \mathrm{~m}$ & 71.2 & 17.8 & 7.6 \\
\hline 13 & $3.51 \mathrm{~m}$ & - & - & - \\
\hline 14 & $3.05 \mathrm{~m}$ & 70.4 & 16.9 & 9.4 \\
\hline 15 & $2.59 \mathrm{~m}$ & 70.2 & 16.8 & 9.4 \\
\hline 16 & $2.13 \mathrm{~m}$ & 70.9 & 17.1 & 9.6 \\
\hline 17 & $1.68 \mathrm{~m}$ & 70.8 & 17.0 & 9.5 \\
\hline 18 & $1.22 \mathrm{~m}$ & 70.1 & 16.9 & 9.4 \\
\hline \multicolumn{2}{|c|}{$\begin{array}{l}\text { Posttest Mean } \\
\text { Standard Deviation }\end{array}$} & $\begin{array}{l}70.2 \\
\pm 0.8\end{array}$ & $\begin{array}{l}17.1 \\
\pm 0.4\end{array}$ & $\begin{array}{r}9.4 \\
\pm 0.8\end{array}$ \\
\hline
\end{tabular}


Tables

Table 7. Gas concentrations measured in the HIT-2 experiment.

\begin{tabular}{|c|c|c|c|c|}
\hline \multicolumn{2}{|c|}{ Pretest } & \multicolumn{3}{|c|}{ Species (mole\%) } \\
\hline Label & Location & $\mathbf{N}_{2}$ & $\mathrm{O}_{2}$ & $\mathrm{H}_{2}$ \\
\hline 1 & $4.88 \mathrm{~m}$ & 73.7 & 20.6 & 6.9 \\
\hline 2 & $4.42 \mathrm{~m}$ & 70.1 & 19.2 & 11.1 \\
\hline 3 & $3.96 \mathrm{~m}$ & 71.3 & 19.7 & 7.1 \\
\hline 4 & $3.51 \mathrm{~m}$ & - & - & - \\
\hline 5 & $3.05 \mathrm{~m}$ & - & - & - \\
\hline 6 & $2.59 \mathrm{~m}$ & 71.6 & 18.6 & 9.4 \\
\hline 7 & $2.13 \mathrm{~m}$ & 70.4 & 19.6 & 8.9 \\
\hline 8 & $1.68 \mathrm{~m}$ & 75.4 & 21.2 & 7.6 \\
\hline 9 & $1.22 \mathrm{~m}$ & 71.3 & 20.1 & 7.7 \\
\hline \multicolumn{2}{|c|}{$\begin{array}{l}\text { Pretest Mean } \\
\text { Standard Deviation }\end{array}$} & $\begin{array}{r}72.0 \\
\pm 1.9\end{array}$ & $\begin{array}{l}19.9 \\
\pm 0.9\end{array}$ & $\begin{array}{c}8.4 \\
\pm 1.5\end{array}$ \\
\hline \multicolumn{5}{|c|}{ 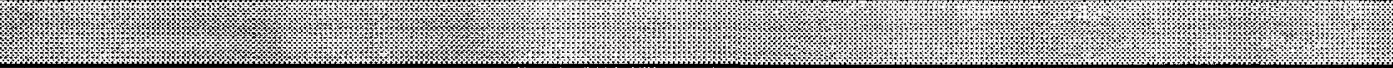 } \\
\hline \multicolumn{2}{|c|}{ Posttest } & \multicolumn{3}{|c|}{ Species (mole\%) } \\
\hline Label & Location & $\mathrm{N}_{2}$ & $\mathrm{O}_{2}$ & $\mathrm{H}_{2}$ \\
\hline 10 & $4.88 \mathrm{~m}$ & 69.9 & 19.3 & 10.1 \\
\hline 11 & $4.42 \mathrm{~m}$ & 77.3 & 17.6 & 5.2 \\
\hline 12 & $3.96 \mathrm{~m}$ & 73.8 & 19.8 & 2.6 \\
\hline 13 & $3.51 \mathrm{~m}$ & - & - & - \\
\hline 14 & $3.05 \mathrm{~m}$ & 75.3 & 17.4 & 5.1 \\
\hline 15 & $2.59 \mathrm{~m}$ & 78.9 & 17.3 & 5.1 \\
\hline 16 & $2.13 \mathrm{~m}$ & 75.7 & 17.4 & 5.1 \\
\hline 17 & $1.68 \mathrm{~m}$ & 75.9 & 17.4 & 4.9 \\
\hline 18 & $1.22 \mathrm{~m}$ & 76.2 & 17.3 & 5.1 \\
\hline \multicolumn{2}{|c|}{$\begin{array}{l}\text { Posttest Mean } \\
\text { Standard Deviation }\end{array}$} & $\begin{array}{l}75.4 \\
\pm 2.7\end{array}$ & $\begin{array}{l}17.9 \\
\pm 1.0\end{array}$ & $\begin{array}{c}5.4 \\
\pm 2.1\end{array}$ \\
\hline
\end{tabular}


Tables

Table 8. Gas concentrations measured in the HIT-3 experiment.

\begin{tabular}{|c|c|c|c|c|}
\hline \multicolumn{2}{|c|}{ Pretest } & \multicolumn{3}{|c|}{ Species (mole\%) } \\
\hline Label & Location & $\mathrm{N}_{2}$ & $\mathrm{O}_{2}$ & $\mathrm{H}_{2}$ \\
\hline 1 & $4.88 \mathrm{~m}$ & 63.9 & 17.8 & 19.1 \\
\hline 2 & $4.42 \mathrm{~m}$ & 58.6 & 16.1 & 25.0 \\
\hline 3 & $3.96 \mathrm{~m}$ & 61.9 & 17.2 & 20.3 \\
\hline 4 & $3.51 \mathrm{~m}$ & - & - & - \\
\hline 5 & $3.05 \mathrm{~m}$ & 62.2 & 17.3 & 20.0 \\
\hline 6 & $2.59 \mathrm{~m}$ & 63.3 & 17.6 & 17.0 \\
\hline 7 & $2.13 \mathrm{~m}$ & 61.8 & 17.2 & 21.8 \\
\hline 8 & $1.68 \mathrm{~m}$ & 68.3 & 17.6 & 17.7 \\
\hline 9 & $1.22 \mathrm{~m}$ & 64.6 & 18.3 & 16.7 \\
\hline \multicolumn{2}{|c|}{$\begin{array}{l}\text { Pretest Mean } \\
\text { Standard Deviation }\end{array}$} & $\begin{array}{l}62.5 \\
\pm 1.8\end{array}$ & $\begin{array}{l}17.4 \\
\pm 0.6\end{array}$ & $\begin{array}{l}19.7 \\
\pm 2.8\end{array}$ \\
\hline \multicolumn{2}{|c|}{ Posttest } & \multicolumn{3}{|c|}{ Species (mole\%) } \\
\hline Label & Location & $\mathbf{N}_{2}$ & $\mathrm{O}_{2}$ & $\mathrm{H}_{2}$ \\
\hline 10 & $4.88 \mathrm{~m}$ & 91.8 & 5.3 & 0.3 \\
\hline 11 & $4.42 \mathrm{~m}$ & 92.9 & 5.4 & 0.6 \\
\hline 12 & $3.96 \mathrm{~m}$ & 89.3 & 5.4 & 0.5 \\
\hline 13 & $3.51 \mathrm{~m}$ & - & - & - \\
\hline 14 & $3.05 \mathrm{~m}$ & 93.7 & 5.0 & 0.1 \\
\hline 15 & $2.59 \mathrm{~m}$ & 91.7 & 7.0 & 1.0 \\
\hline 16 & $2.13 \mathrm{~m}$ & 90.2 & 5.4 & 1.1 \\
\hline 17 & $1.68 \mathrm{~m}$ & 91.7 & 7.0 & 1.0 \\
\hline 18 & $1.22 \mathrm{~m}$ & 87.7 & 5.2 & 1.1 \\
\hline \multicolumn{2}{|c|}{$\begin{array}{l}\text { Posttest Mean } \\
\text { Standard Deviation }\end{array}$} & $\begin{array}{l}91.1 \\
\pm 2.0\end{array}$ & $\begin{array}{c}5.7 \\
\pm 0.8\end{array}$ & $\begin{array}{c}0.7 \\
\pm 0.4\end{array}$ \\
\hline
\end{tabular}


Tables

Table 9. Gas concentrations measured in the HIT-4 experiment.

\begin{tabular}{|c|c|c|c|c|}
\hline \multicolumn{2}{|c|}{ Pretest } & \multicolumn{3}{|c|}{ Species (mole\%) } \\
\hline Label & Location & $\mathbf{N}_{2}$ & $\mathrm{O}_{2}$ & $\mathbf{H}_{2}$ \\
\hline 1 & $4.88 \mathrm{~m}$ & 69.6 & 18.2 & 13.2 \\
\hline 2 & $4.42 \mathrm{~m}$ & 67.6 & 17.7 & 12.6 \\
\hline 3 & $3.96 \mathrm{~m}$ & 69.0 & 18.0 & 13.1 \\
\hline 4 & $3.51 \mathrm{~m}$ & 68.1 & 17.7 & 12.8 \\
\hline 5 & $3.05 \mathrm{~m}$ & 69.0 & 17.9 & 12.8 \\
\hline 6 & $2.59 \mathrm{~m}$ & 67.2 & 17.0 & 12.7 \\
\hline 7 & $2.13 \mathrm{~m}$ & 69.1 & 18.0 & 13.0 \\
\hline 8 & $1.68 \mathrm{~m}$ & 65.6 & 17.1 & 12.4 \\
\hline 9 & $1.22 \mathrm{~m}$ & 69.4 & 18.1 & 13.1 \\
\hline \multicolumn{2}{|c|}{$\begin{array}{l}\text { Pretest Mean } \\
\text { Standard Deviation }\end{array}$} & $\begin{array}{r}68.3 \\
\pm 1.3\end{array}$ & $\begin{array}{l}17.7 \\
\pm 0.4\end{array}$ & $\begin{array}{l}12.9 \\
\pm 0.3\end{array}$ \\
\hline \multicolumn{2}{|c|}{ Posttest } & \multicolumn{3}{|c|}{ Species (mole\%) } \\
\hline Label & Location & $\mathrm{N}_{2}$ & $\mathrm{O}_{2}$ & $\mathrm{H}_{2}$ \\
\hline 10 & $4.88 \mathrm{~m}$ & 77.1 & 15.9 & 5.1 \\
\hline 11 & $4.42 \mathrm{~m}$ & 77.0 & 16.0 & 5.1 \\
\hline 12 & $3.96 \mathrm{~m}$ & 78.4 & 16.2 & 5.2 \\
\hline 13 & $3.51 \mathrm{~m}$ & 78.0 & 16.1 & 5.1 \\
\hline 14 & $3.05 \mathrm{~m}$ & 77.9 & 16.1 & 5.1 \\
\hline 15 & $2.59 \mathrm{~m}$ & 76.9 & 15.9 & 5.1 \\
\hline 16 & $2.13 \mathrm{~m}$ & 77.2 & 16.0 & 5.1 \\
\hline 17 & $1.68 \mathrm{~m}$ & 78.9 & 16.3 & 5.3 \\
\hline 18 & $1.22 \mathrm{~m}$ & 77.1 & 16.0 & 5.1 \\
\hline \multicolumn{2}{|c|}{$\begin{array}{l}\text { Posttest Mean } \\
\text { Standard Deviation }\end{array}$} & $\begin{array}{l}77.6 \\
\pm 0.7\end{array}$ & $\begin{array}{l}16.0 \\
\pm 0.1 \\
\end{array}$ & $\begin{array}{c}5.1 \\
\pm 0.1 \\
\end{array}$ \\
\hline
\end{tabular}


Tables

Table 10. Gas concentrations measured in the HIT-5 experiment.

\begin{tabular}{|c|c|c|c|c|}
\hline \multicolumn{2}{|c|}{ Pretest } & \multicolumn{3}{|c|}{ Species (mole\%) } \\
\hline Label & Location & $\mathrm{N}_{2}$ & $\mathrm{O}_{2}$ & $\mathrm{H}_{2}$ \\
\hline 1 & $4.88 \mathrm{~m}$ & 63.2 & 17.5 & 18.3 \\
\hline 2 & $4.42 \mathrm{~m}$ & 63.2 & 17.5 & 18.4 \\
\hline 3 & $3.96 \mathrm{~m}$ & 63.9 & 17.7 & 18.9 \\
\hline 4 & $3.51 \mathrm{~m}$ & 63.2 & 17.5 & 18.3 \\
\hline 5 & $3.05 \mathrm{~m}$ & 62.9 & 17.4 & 18.3 \\
\hline 6 & $2.59 \mathrm{~m}$ & 63.0 & 17.4 & 18.4 \\
\hline 7 & $2.13 \mathrm{~m}$ & 63.5 & 17.6 & 18.6 \\
\hline 8 & $1.68 \mathrm{~m}$ & 63.5 & 17.6 & 18.6 \\
\hline 9 & $1.22 \mathrm{~m}$ & 63.0 & 17.4 & 18.5 \\
\hline \multicolumn{2}{|c|}{$\begin{array}{l}\text { Pretest Mean } \\
\text { Standard Deviation }\end{array}$} & $\begin{array}{l}63.3 \\
\pm 0.3\end{array}$ & $\begin{array}{l}17.5 \\
\pm 0.1\end{array}$ & $\begin{array}{l}18.5 \\
\pm 0.2\end{array}$ \\
\hline \multicolumn{2}{|c|}{ Posttest } & \multicolumn{3}{|c|}{ Species (mole\%) } \\
\hline Label & Location & $\mathbf{N}_{2}$ & $\mathrm{O}_{2}$ & $\mathbf{H}_{2}$ \\
\hline 10 & $4.88 \mathrm{~m}$ & 77.1 & 13.1 & .5 .7 \\
\hline 11 & $4.42 \mathrm{~m}$ & 79.5 & 13.4 & 5.8 \\
\hline 12 & $3.96 \mathrm{~m}$ & 76.0 & 12.7 & 5.6 \\
\hline 13 & $3.51 \mathrm{~m}$ & 78.6 & 13.3 & 5.8 \\
\hline 14 & $3.05 \mathrm{~m}$ & 80.2 & 13.4 & 6.0 \\
\hline 15 & $2.59 \mathrm{~m}$ & 78.0 & 13.1 & 5.7 \\
\hline 16 & $2.13 \mathrm{~m}$ & 79.5 & 13.5 & 5.9 \\
\hline 17 & $1.68 \mathrm{~m}$ & 80.4 & 13.6 & 5.9 \\
\hline 18 & $1.22 \mathrm{~m}$ & 79.3 & 13.4 & 5.8 \\
\hline \multicolumn{2}{|c|}{$\begin{array}{l}\text { Posttest Mean } \\
\text { Standard Deviation }\end{array}$} & $\begin{array}{l}78.7 \\
\pm 1.5\end{array}$ & $\begin{array}{l}13.3 \\
\pm 0.3\end{array}$ & $\begin{array}{c}5.8 \\
\pm 0.1\end{array}$ \\
\hline
\end{tabular}


Tables

Table 11. Gas concentrations measured in the HIT-6 experiment.

\begin{tabular}{|c|c|c|c|c|}
\hline \multicolumn{2}{|c|}{ Pretest } & \multicolumn{3}{|c|}{ Species (mole\%) } \\
\hline Label & Location & $\mathrm{N}_{2}$ & $\mathrm{O}_{2}$ & $\mathrm{H}_{2}$ \\
\hline 1 & $4.88 \mathrm{~m}$ & 60.3 & 15.8 & 22.6 \\
\hline 2 & $4.42 \mathrm{~m}$ & 59.6 & 15.6 & 24.0 \\
\hline 3 & $3.96 \mathrm{~m}$ & 59.6 & 15.6 & 24.1 \\
\hline 4 & $3.51 \mathrm{~m}$ & 61.0 & 16.0 & 22.6 \\
\hline 5 & $3.05 \mathrm{~m}$ & 65.0 & 17.1 & 17.4 \\
\hline 6 & $2.59 \mathrm{~m}$ & 73.4 & 19.2 & 6.7 \\
\hline 7 & $2.13 \mathrm{~m}$ & 79.2 & 20.8 & 0.8 \\
\hline 8 & $1.68 \mathrm{~m}$ & 78.4 & 20.6 & 0.2 \\
\hline 9 & $1.22 \mathrm{~m}$ & 77.2 & 20.3 & 1.8 \\
\hline \multicolumn{2}{|c|}{$\begin{array}{l}\text { Pretest Mean } \\
\text { Standard Deviation }\end{array}$} & $\begin{array}{l}66.9 \\
\pm 8.4\end{array}$ & $\begin{array}{l}17.6 \\
\pm 2.2\end{array}$ & $\begin{array}{c}15.0 \\
\pm 10.2\end{array}$ \\
\hline \multicolumn{2}{|c|}{ Posttest } & \multicolumn{3}{|c|}{ Species (mole\%) } \\
\hline Label & Location & $\mathrm{N}_{2}$ & $\mathrm{O}_{2}$ & $\mathrm{H}_{2}$ \\
\hline 10 & $4.88 \mathrm{~m}$ & 78.8 & 16.0 & 5.5 \\
\hline 11 & $4.42 \mathrm{~m}$ & 77.9 & 15.9 & 4.9 \\
\hline 12 & $3.96 \mathrm{~m}$ & 77.8 & 15.8 & 5.0 \\
\hline 13 & $3.51 \mathrm{~m}$ & 78.4 & 15.9 & 5.0 \\
\hline 14 & $3.05 \mathrm{~m}$ & 78.5 & 16.0 & 4.7 \\
\hline 15 & $2.59 \mathrm{~m}$ & 78.0 & 15.7 & 5.0 \\
\hline 16 & $2.13 \mathrm{~m}$ & 77.2 & 15.7 & 5.0 \\
\hline 17 & $1.68 \mathrm{~m}$ & 78.4 & 15.9 & 4.9 \\
\hline 18 & $1.22 \mathrm{~m}$ & 77.4 & 15.7 & 4.9 \\
\hline \multicolumn{2}{|c|}{$\begin{array}{l}\text { Posttest Mean } \\
\text { Standard Deviation }\end{array}$} & $\begin{array}{l}78.0 \\
\pm 0.5\end{array}$ & $\begin{array}{l}15.8 \\
\pm 0.1\end{array}$ & $\begin{array}{c}5.0 \\
\pm 0.2\end{array}$ \\
\hline
\end{tabular}


Tables

Table 12. Gas concentrations measured in the HIT-7 experiment.

\begin{tabular}{|c|c|c|c|c|}
\hline \multicolumn{2}{|c|}{ Pretest } & \multicolumn{3}{|c|}{ Species (mole\%) } \\
\hline Label & Location & $\mathbf{N}_{2}$ & $\mathrm{O}_{2}$ & $\mathbf{H}_{2}$ \\
\hline 1 & $4.88 \mathrm{~m}$ & 57.1 & 16.8 & 25.5 \\
\hline 2 & $4.42 \mathrm{~m}$ & 64.7 & 17.2 & 25.5 \\
\hline 3 & $3.96 \mathrm{~m}$ & 58.1 & 17.2 & 25.6 \\
\hline 4 & $3.51 \mathrm{~m}$ & 59.2 & 17.5 & 24.3 \\
\hline 5 & $3.05 \mathrm{~m}$ & 60.9 & 18.1 & 20.8 \\
\hline 6 & $2.59 \mathrm{~m}$ & 68.0 & 20.2 & 13.2 \\
\hline 7 & $2.13 \mathrm{~m}$ & 75.9 & 22.5 & 1.8 \\
\hline 8 & $1.68 \mathrm{~m}$ & 78.4 & 23.3 & 0.2 \\
\hline 9 & $1.22 \mathrm{~m}$ & 76.4 & 22.7 & 1.6 \\
\hline \multicolumn{2}{|c|}{$\begin{array}{l}\text { Pretest Mean } \\
\text { Standard Deviation }\end{array}$} & $\begin{array}{l}66.5 \\
\pm 8.5\end{array}$ & $\begin{array}{l}19.5 \\
\pm 2.7\end{array}$ & $\begin{array}{c}15.4 \\
\pm 11.3\end{array}$ \\
\hline \multicolumn{2}{|c|}{ Posttest $(t=19$ hrs $)$} & \multicolumn{3}{|c|}{ Species (mole\%) } \\
\hline Label & Location & $\mathbf{N}_{2}$ & $\mathrm{O}_{2}$ & $\mathbf{H}_{2}$ \\
\hline 10 & $4.88 \mathrm{~m}$ & 75.8 & 15.5 & 8.9 \\
\hline 11 & $4.42 \mathrm{~m}$ & 74.8 & 15.7 & 8.7 \\
\hline 12 & $3.96 \mathrm{~m}$ & 74.3 & 17.1 & 9.3 \\
\hline 13 & $3.51 \mathrm{~m}$ & 71.2 & 19.2 & 9.8 \\
\hline 14 & $3.05 \mathrm{~m}$ & 70.5 & 19.2 & 9.9 \\
\hline 15 & $2.59 \mathrm{~m}$ & 71.0 & 19.5 & 10.0 \\
\hline 16 & $2.13 \mathrm{~m}$ & 70.1 & 19.5 & 10.3 \\
\hline 17 & $1.68 \mathrm{~m}$ & - & - & - \\
\hline 18 & $1.22 \mathrm{~m}$ & 70.4 & 19.9 & 10.5 \\
\hline \multicolumn{2}{|c|}{$\begin{array}{l}\text { Posttest Mean } \\
\text { Standard Deviation }\end{array}$} & $\begin{array}{r}68.9 \\
\pm 9.0 \\
\end{array}$ & $\begin{array}{r}18.2 \\
\pm 1.8 \\
\end{array}$ & $\begin{array}{c}9.7 \\
\pm 0.6\end{array}$ \\
\hline \multicolumn{2}{|c|}{ Posttest (t $=22 \mathrm{hrs}$, well-mixed) } & \multicolumn{3}{|c|}{ Species (mole\%) } \\
\hline 19 & $4.42 \mathrm{~m}$ & 70.7 & 18.0 & 9.4 \\
\hline 20 & $1.68 \mathrm{~m}$ & 70.9 & 18.1 & 9.5 \\
\hline \multicolumn{2}{|c|}{$\begin{array}{l}\text { Posttest Mean } \\
\text { Standard Deviation }\end{array}$} & $\begin{array}{l}70.8 \\
\pm 0.1\end{array}$ & $\begin{array}{l}18.0 \\
\pm 0.1\end{array}$ & $\begin{array}{l}9.5 \\
\pm 0.1\end{array}$ \\
\hline
\end{tabular}


Tables

Table 13. Gas concentrations measured in the HIT-8 experiment.

\begin{tabular}{|c|c|c|c|c|}
\hline \multicolumn{2}{|c|}{ Pretest } & \multicolumn{3}{|c|}{ Species (mole\%) } \\
\hline Label & Location & $\mathrm{N}_{2}$ & $\mathrm{O}_{2}$ & $\mathrm{H}_{2}$ \\
\hline 1 & $4.88 \mathrm{~m}$ & 60.0 & 16.4 & 22.7 \\
\hline 2 & $4.42 \mathrm{~m}$ & 60.0 & 16.3 & 22.6 \\
\hline 3 & $3.96 \mathrm{~m}$ & 59.1 & 16.3 & 22.6 \\
\hline 4 & $3.51 \mathrm{~m}$ & 60.9 & 16.4 & 22.4 \\
\hline 5 & $3.05 \mathrm{~m}$ & 59.9 & 16.5 & 22.6 \\
\hline 6 & $2.59 \mathrm{~m}$ & 60.3 & 16.2 & 22.2 \\
\hline 7 & $2.13 \mathrm{~m}$ & 61.2 & 16.4 & 22.7 \\
\hline 8 & $1.68 \mathrm{~m}$ & 61.3 & 16.5 & 22.3 \\
\hline 9 & $1.22 \mathrm{~m}$ & 61.3 & 16.2 & 23.1 \\
\hline \multicolumn{2}{|c|}{$\begin{array}{l}\text { Pretest Mean } \\
\text { Standard Deviation }\end{array}$} & $\begin{array}{l}60.4 \\
\pm 0.8\end{array}$ & $\begin{array}{l}16.4 \\
\pm 0.1\end{array}$ & $\begin{array}{l}22.6 \\
\pm 0.3\end{array}$ \\
\hline 13 & & 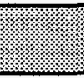 & 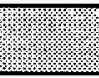 & (3) \\
\hline \multicolumn{2}{|c|}{ Posttest } & \multicolumn{3}{|c|}{ Species (mole\%) } \\
\hline Label & Location & $\mathrm{N}_{2}$ & $\mathrm{O}_{2}$ & $\mathrm{H}_{2}$ \\
\hline 10 & $4.88 \mathrm{~m}$ & 91.8 & 7.3 & 0.3 \\
\hline 11 & $4.42 \mathrm{~m}$ & 91.6 & 7.5 & 0.3 \\
\hline 12 & $3.96 \mathrm{~m}$ & 92.0 & 7.4 & 0.3 \\
\hline 13 & $3.51 \mathrm{~m}$ & 92.2 & 7.4 & 0.3 \\
\hline 14 & $3.05 \mathrm{~m}$ & 92.0 & 7.4 & 0.3 \\
\hline 15 & $2.59 \mathrm{~m}$ & 91.6 & 7.4 & 0.3 \\
\hline 16 & $2.13 \mathrm{~m}$ & 91.5 & 7.4 & 0.3 \\
\hline 17 & $1.68 \mathrm{~m}$ & 92.0 & 7.4 & 0.3 \\
\hline 18 & $1.22 \mathrm{~m}$ & 91.8 & 7.3 & 0.3 \\
\hline \multicolumn{2}{|c|}{$\begin{array}{l}\text { Posttest Mean } \\
\text { Standard Deviation }\end{array}$} & $\begin{array}{l}91.8 \\
\pm 0.2\end{array}$ & $\begin{array}{c}7.4 \\
\pm 0.1\end{array}$ & $\begin{array}{c}0.3 \\
\pm 0.0\end{array}$ \\
\hline
\end{tabular}


Tables

Table 14. Gas concentrations measured in the HIT-9 experiment.

\begin{tabular}{|c|c|c|c|c|}
\hline \multicolumn{2}{|c|}{ Pretest } & \multicolumn{3}{|c|}{ Species (mole\%) } \\
\hline Label & Location & $\mathrm{N}_{2}$ & $\mathrm{O}_{2}$ & $\mathbf{H}_{2}$ \\
\hline 1 & $4.88 \mathrm{~m}$ & 64.3 & 16.3 & 18.5 \\
\hline 2 & $4.42 \mathrm{~m}$ & 64.5 & 16.3 & 18.5 \\
\hline 3 & $3.96 \mathrm{~m}$ & 64.5 & 16.3 & 18.8 \\
\hline 4 & $3.51 \mathrm{~m}$ & 64.5 & 16.4 & 18.6 \\
\hline 5 & $3.05 \mathrm{~m}$ & 64.6 & 16.4 & 18.7 \\
\hline 6 & $2.59 \mathrm{~m}$ & 64.5 & 16.4 & 18.5 \\
\hline 7 & $2.13 \mathrm{~m}$ & 64.7 & 16.4 & 18.6 \\
\hline 8 & $1.68 \mathrm{~m}$ & 64.7 & 16.4 & 18.6 \\
\hline 9 & $1.22 \mathrm{~m}$ & 64.7 & 16.5 & 18.7 \\
\hline \multicolumn{2}{|c|}{$\begin{array}{l}\text { Pretest Mean } \\
\text { Standard Deviation }\end{array}$} & $\begin{array}{l}64.6 \\
\pm 0.1\end{array}$ & $\begin{array}{l}16.4 \\
\pm 0.1\end{array}$ & $\begin{array}{l}18.6 \\
\pm 0.1\end{array}$ \\
\hline \multicolumn{2}{|c|}{ Posttest } & \multicolumn{3}{|c|}{ Species (mole\%) } \\
\hline Label & Location & $\mathbf{N}_{2}$ & $\mathrm{O}_{2}$ & $\mathrm{H}_{2}$ \\
\hline 10 & $4.88 \mathrm{~m}$ & 83.5 & 11.9 & 4.3 \\
\hline 11 & $4.42 \mathrm{~m}$ & 83.5 & 12.0 & 4.3 \\
\hline 12 & $3.96 \mathrm{~m}$ & 84.7 & 12.0 & 4.5 \\
\hline 13 & $3.51 \mathrm{~m}$ & 83.8 & 12.0 & 4.4 \\
\hline 14 & $3.05 \mathrm{~m}$ & 83.9 & 11.9 & 4.4 \\
\hline 15 & $2.59 \mathrm{~m}$ & 83.7 & 12.0 & 4.4 \\
\hline 16 & $2.13 \mathrm{~m}$ & 83.7 & 12.0 & 4.3 \\
\hline 17 & $1.68 \mathrm{~m}$ & 83.7 & 11.9 & 4.3 \\
\hline 18 & $1.22 \mathrm{~m}$ & 83.7 & 12.0 & 4.4 \\
\hline \multicolumn{2}{|c|}{$\begin{array}{l}\text { Posttest Mean } \\
\text { Standard Deviation }\end{array}$} & $\begin{array}{l}83.8 \\
\pm 0.3\end{array}$ & $\begin{array}{l}12.0 \\
\pm 0.1\end{array}$ & $\begin{array}{c}4.4 \\
\pm 0.1\end{array}$ \\
\hline
\end{tabular}


Tables

Table 15. Gas concentrations measured in the HIT-10 experiment.

\begin{tabular}{|c|c|c|c|c|}
\hline \multicolumn{2}{|c|}{ Pretest } & \multicolumn{3}{|c|}{ Species (mole\%) } \\
\hline Label & Location & $\mathbf{N}_{2}$ & $\mathrm{O}_{2}$ & $\mathrm{H}_{2}$ \\
\hline 1 & $4.88 \mathrm{~m}$ & 68.0 & 18.1 & 13.3 \\
\hline 2 & $4.42 \mathrm{~m}$ & 68.1 & 18.3 & 13.4 \\
\hline 3 & $3.96 \mathrm{~m}$ & 68.3 & 18.4 & 13.3 \\
\hline 4 & $3.51 \mathrm{~m}$ & 68.0 & 18.2 & 13.3 \\
\hline 5 & $3.05 \mathrm{~m}$ & 68.0 & 18.3 & 13.2 \\
\hline 6 & $2.59 \mathrm{~m}$ & 67.4 & 18.2 & 13.3 \\
\hline 7 & $2.13 \mathrm{~m}$ & 68.2 & 18.4 & 13.5 \\
\hline 8 & $1.68 \mathrm{~m}$ & 68.2 & 18.5 & 13.5 \\
\hline 9 & $1.22 \mathrm{~m}$ & 68.0 & 18.3 & 13.2 \\
\hline \multicolumn{2}{|c|}{$\begin{array}{l}\text { Pretest Mean } \\
\text { Standard Deviation }\end{array}$} & $\begin{array}{l}68.0 \\
\pm 0.3\end{array}$ & $\begin{array}{l}18.3 \\
\pm 0.1\end{array}$ & $\begin{array}{l}13.3 \\
\pm 0.1\end{array}$ \\
\hline \multicolumn{2}{|c|}{ Posttest } & \multicolumn{3}{|c|}{ Species (mole\%) } \\
\hline Label & Location & $\mathrm{N}_{2}$ & $\mathrm{O}_{2}$ & $\mathrm{H}_{2}$ \\
\hline 10 & $4.88 \mathrm{~m}$ & 77.6 & 16.2 & 4.7 \\
\hline 11 & $4.42 \mathrm{~m}$ & 77.8 & 16.3 & 4.7 \\
\hline 12 & $3.96 \mathrm{~m}$ & 78.0 & 16.3 & 4.7 \\
\hline 13 & $3.51 \mathrm{~m}$ & 77.3 & 16.2 & 4.7 \\
\hline 14 & $3.05 \mathrm{~m}$ & 77.9 & 16.3 & 4.8 \\
\hline 15 & $2.59 \mathrm{~m}$ & 78.4 & 16.4 & 4.7 \\
\hline 16 & $2.13 \mathrm{~m}$ & 78.2 & 16.3 & 4.7 \\
\hline 17 & $1.68 \mathrm{~m}$ & 78.2 & 16.3 & 4.8 \\
\hline 18 & $1.22 \mathrm{~m}$ & 77.9 & 16.3 & 4.8 \\
\hline \multicolumn{2}{|c|}{$\begin{array}{l}\text { Posttest Mean } \\
\text { Standard Deviation }\end{array}$} & $\begin{array}{l}77.9 \\
\pm 0.3\end{array}$ & $\begin{array}{l}16.3 \\
\pm 0.1\end{array}$ & $\begin{array}{r}4.7 \\
\pm 0.1\end{array}$ \\
\hline
\end{tabular}


Tables

Table 16. Gas concentrations measured in the HIT-11 experiment.

\begin{tabular}{|c|c|c|c|c|}
\hline \multicolumn{2}{|c|}{ Pretest } & \multicolumn{3}{|c|}{ Species (mole\%) } \\
\hline Label & Location & $\mathrm{N}_{2}$ & $\mathrm{O}_{2}$ & $\mathrm{H}_{2}$ \\
\hline 1 & $4.88 \mathrm{~m}$ & 58.5 & 15.5 & 26.8 \\
\hline 2 & $4.42 \mathrm{~m}$ & 58.6 & 15.7 & 26.3 \\
\hline 3 & $3.96 \mathrm{~m}$ & 58.2 & 15.5 & 26.4 \\
\hline 4 & $3.51 \mathrm{~m}$ & 59.3 & 15.8 & 25.1 \\
\hline 5 & $3.05 \mathrm{~m}$ & 63.9 & 17.0 & 19.8 \\
\hline 6 & $2.59 \mathrm{~m}$ & 66.1 & 18.7 & 10.5 \\
\hline 7 & $2.13 \mathrm{~m}$ & 67.7 & 20.8 & 0.7 \\
\hline 8 & $1.68 \mathrm{~m}$ & 66.6 & 20.8 & 0.3 \\
\hline 9 & $1.22 \mathrm{~m}$ & 67.2 & 20.6 & 1.7 \\
\hline \multicolumn{2}{|c|}{$\begin{array}{l}\text { Pretest Mean } \\
\text { Standard Deviation }\end{array}$} & $\begin{array}{l}62.9 \\
\pm 4.2\end{array}$ & $\begin{array}{l}17.8 \\
\pm 2.4\end{array}$ & $\begin{array}{c}15.3 \\
\pm 11.9\end{array}$ \\
\hline \multicolumn{2}{|c|}{ Posttest } & \multicolumn{3}{|c|}{ Species (mole\%) } \\
\hline Label & Location & $\mathrm{N}_{2}$ & $\mathrm{O}_{2}$ & $\mathrm{H}_{2}$ \\
\hline 10 & $4.88 \mathrm{~m}$ & 78.3 & 15.7 & 4.7 \\
\hline 11 & $4.42 \mathrm{~m}$ & 78.2 & 15.7 & 4.7 \\
\hline 12 & $3.96 \mathrm{~m}$ & 78.2 & 15.7 & 4.7 \\
\hline 13 & $3.51 \mathrm{~m}$ & 78.3 & 15.8 & 4.7 \\
\hline 14 & $3.05 \mathrm{~m}$ & 78.7 & 15.8 & 4.8 \\
\hline 15 & $2.59 \mathrm{~m}$ & 78.3 & 15.8 & 4.7 \\
\hline 16 & $2.13 \mathrm{~m}$ & 78.6 & 15.8 & 4.7 \\
\hline 17 & $1.68 \mathrm{~m}$ & 78.1 & 15.7 & 4.7 \\
\hline 18 & $1.22 \mathrm{~m}$ & 77.9 & 15.7 & 4.7 \\
\hline \multicolumn{2}{|c|}{$\begin{array}{l}\text { Posttest Mean } \\
\text { Standard Deviation }\end{array}$} & $\begin{array}{l}78.3 \\
\pm 0.2\end{array}$ & $\begin{array}{r}15.7 \\
\pm 0.01\end{array}$ & $\begin{array}{c}4.7 \\
\pm 0.0\end{array}$ \\
\hline
\end{tabular}


Figures

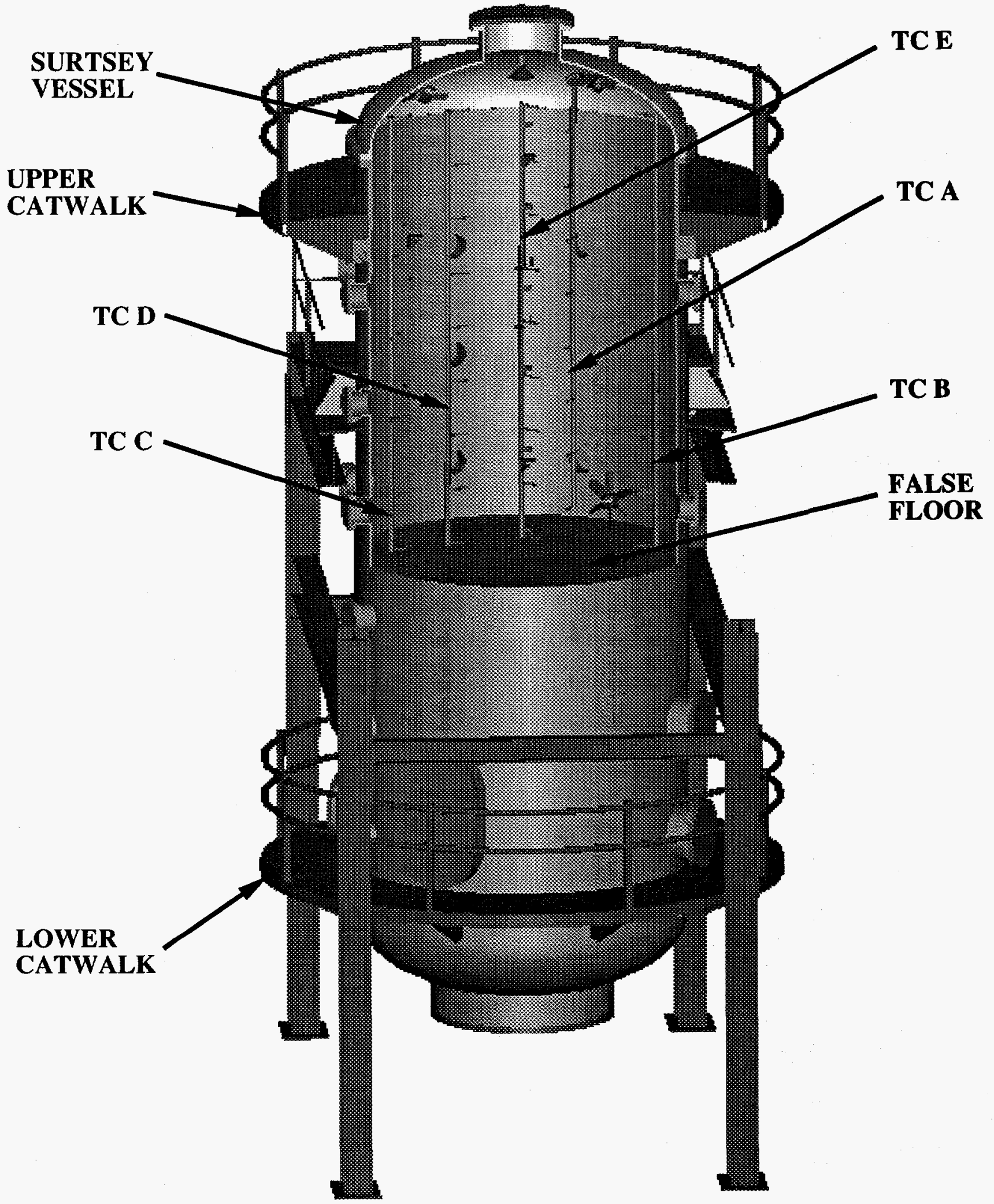

Figure 1. Location of the HIT experiments in the Surtsey vessel. 
Figures

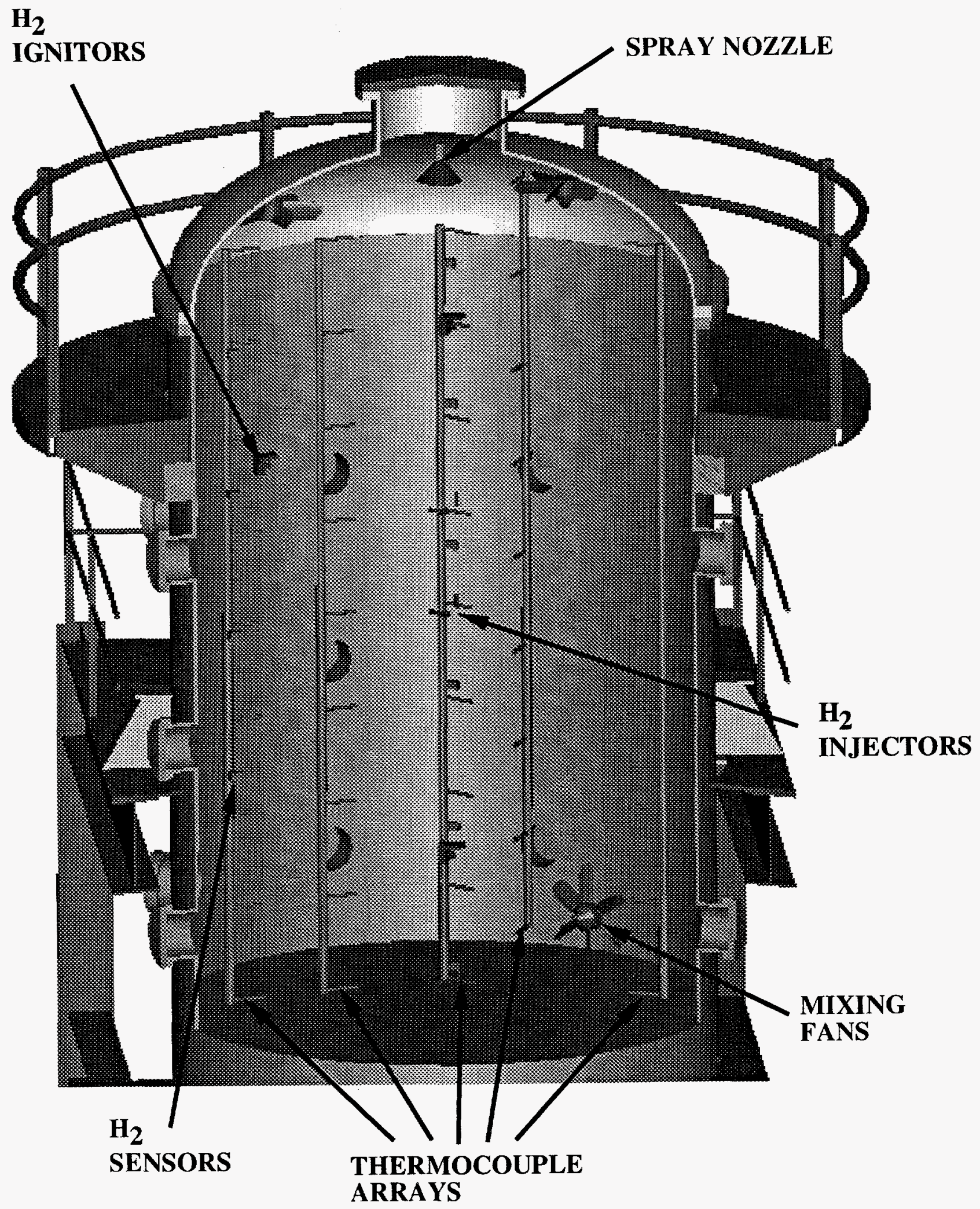

Figure 2. HIT instrumentation, mixing fans, hydrogen injectors, and spray nozzle. 


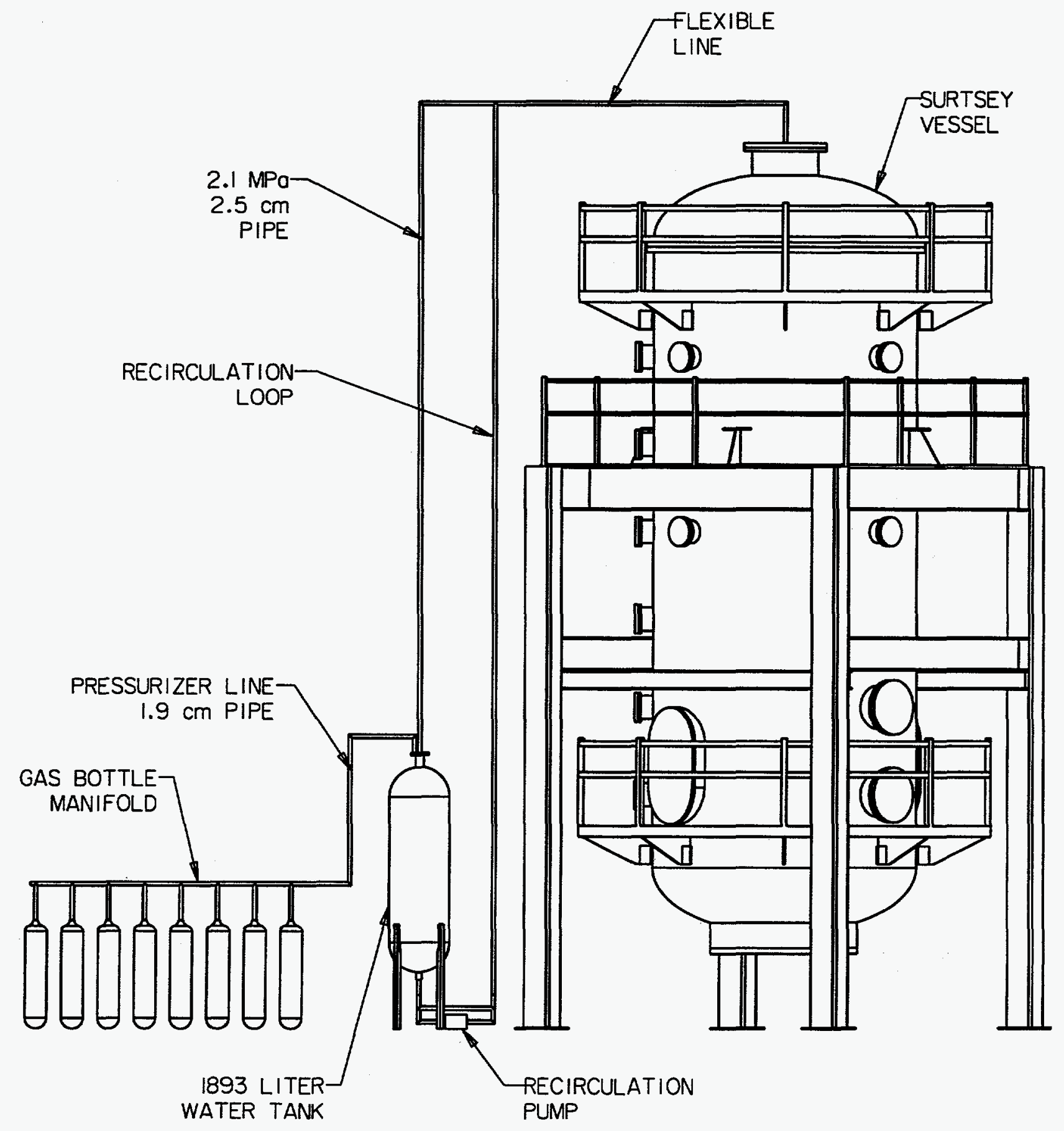

Figure 3. HIT engineered water spray delivery system. 
Figures
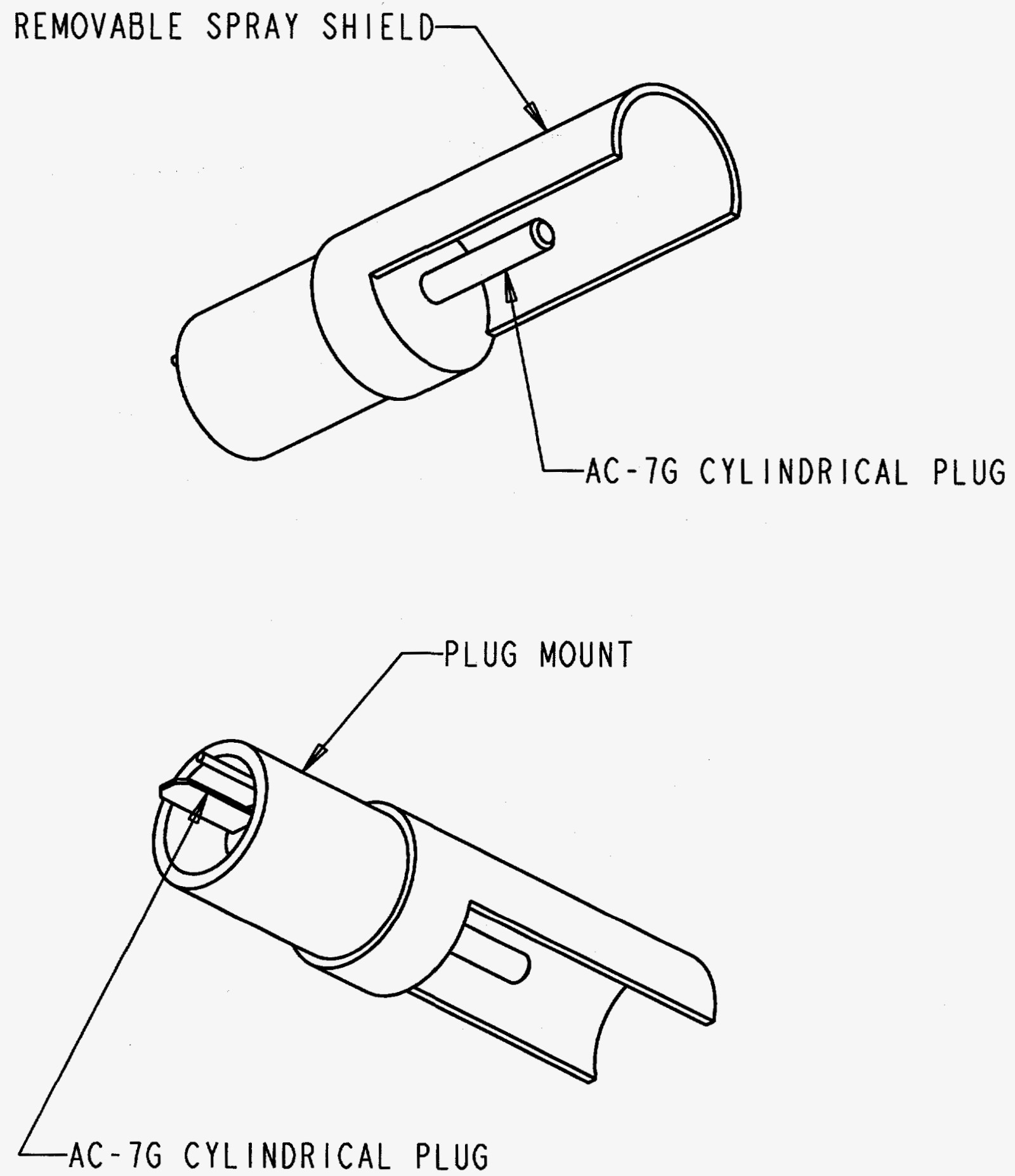

Figure 4. Thermal glow plug, glow plug mount, and spray shield. 


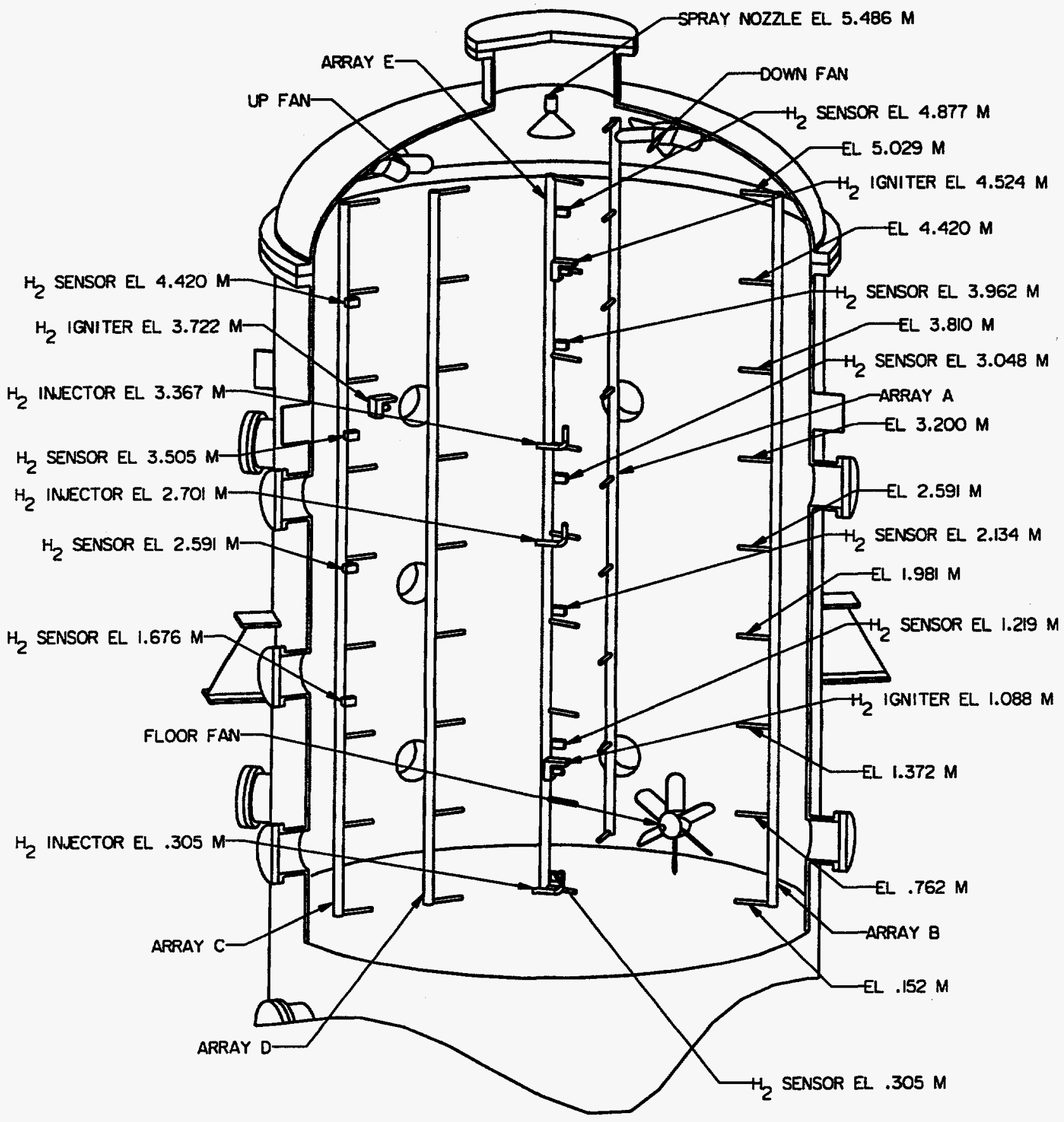

Figure 5. Location of the HIT instrumentation and systems in the Surtsey vessel. 
Figures

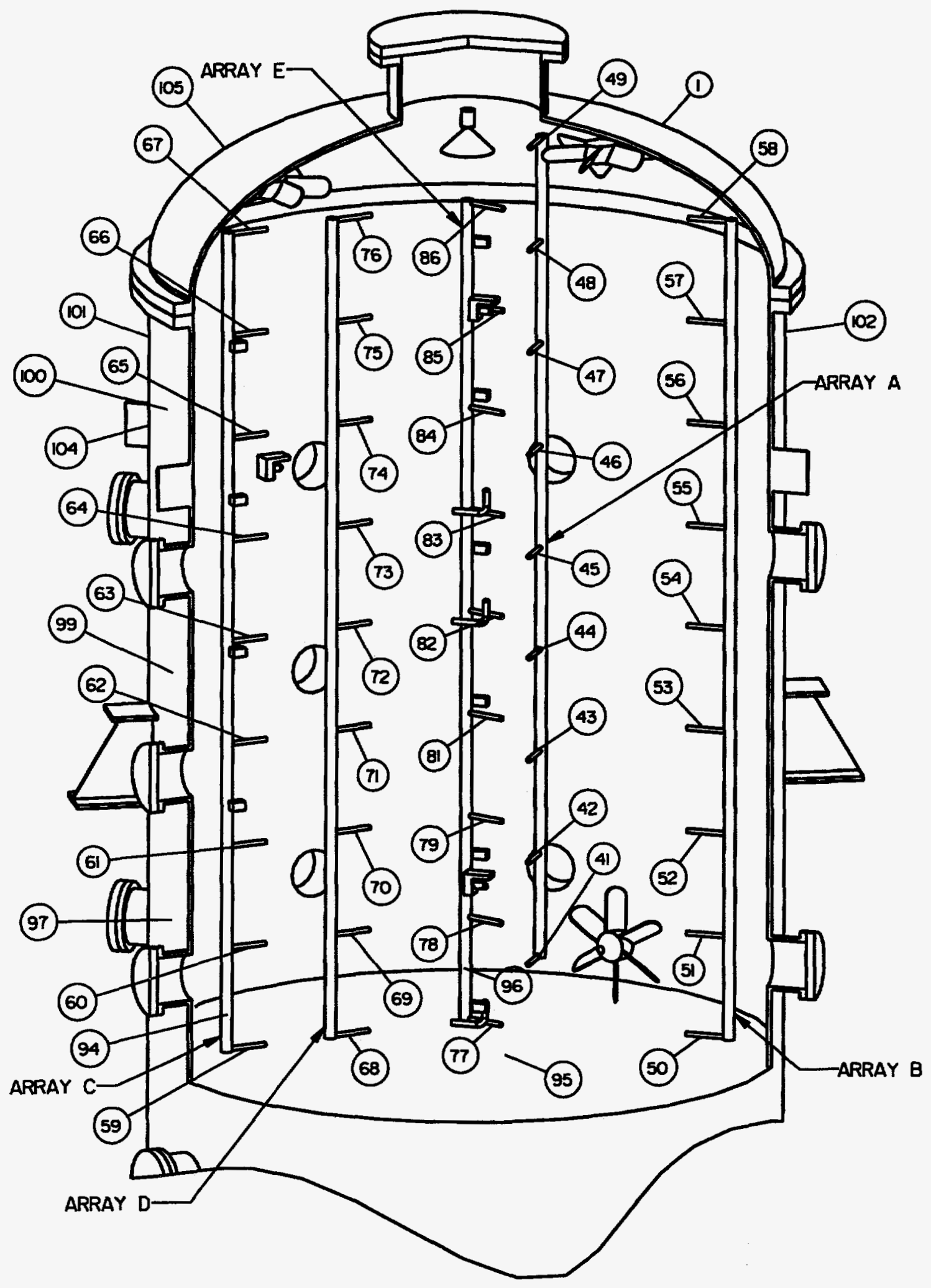

Figure 6. Identification of the Surtsey vessel wall and array thermocouples. 


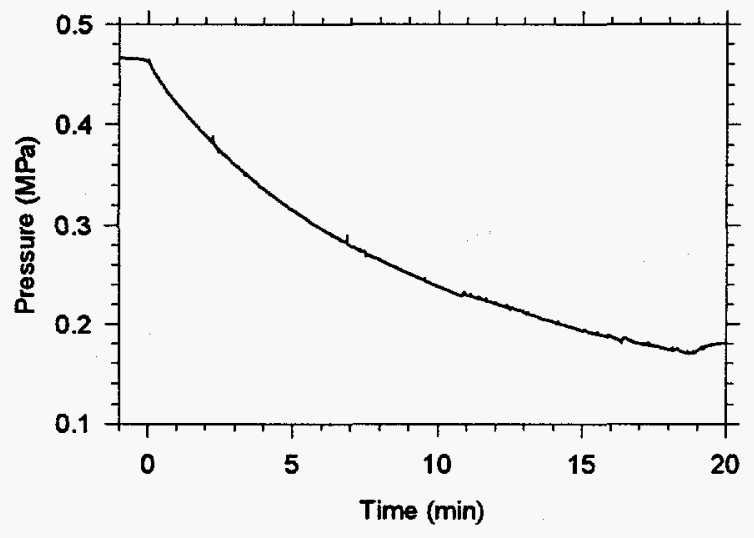

Figure 7. Surtsey vessel pressure in HIT-1.

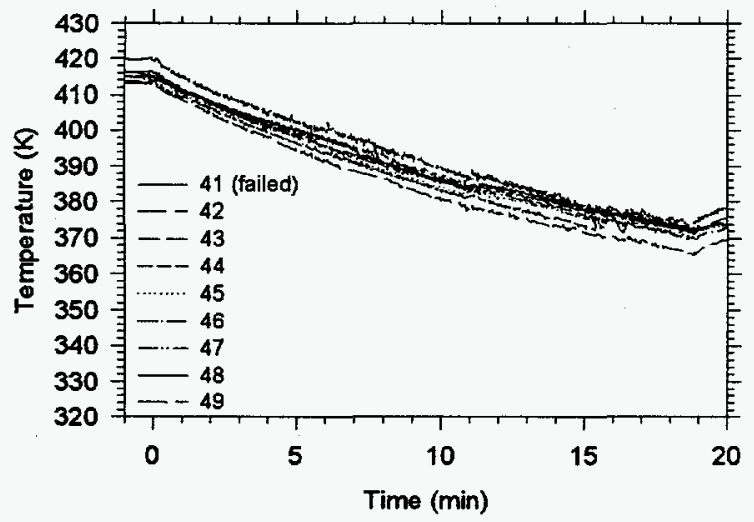

Figure 8. Surtsey vessel gas temperature from thermocouple array A in HIT-1.

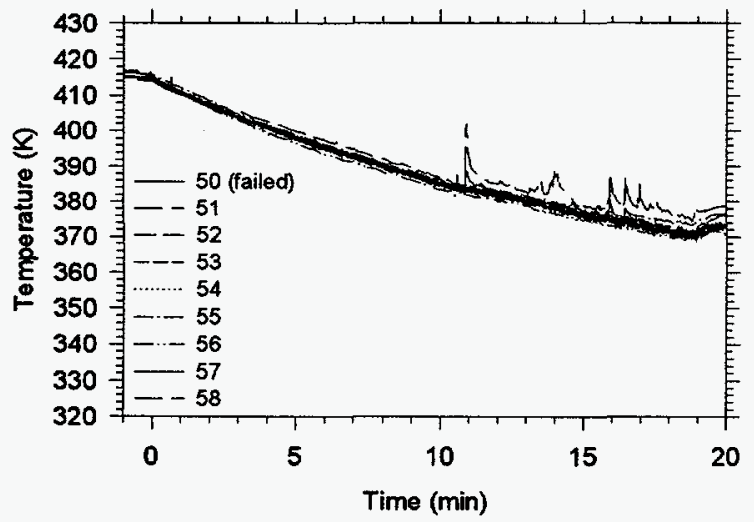

Figure 9. Surtsey vessel gas temperature from thermocouple array B in HIT -1 .

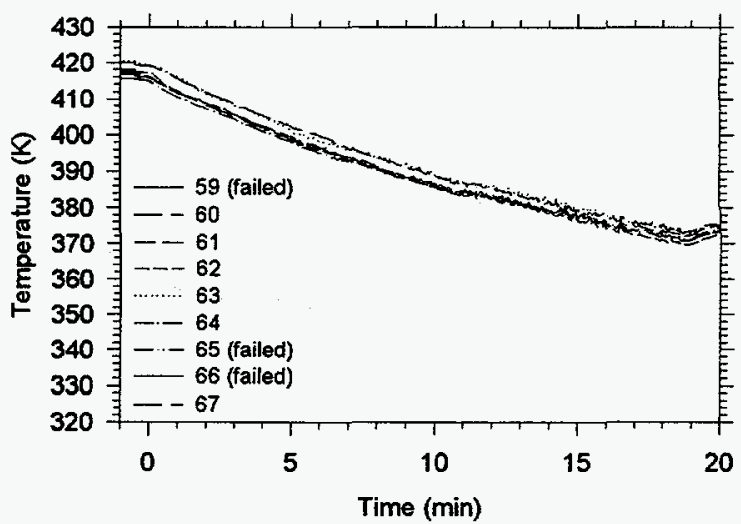

Figure 10. Surtsey vessel gas temperature from thermocouple array C in HIT-1.

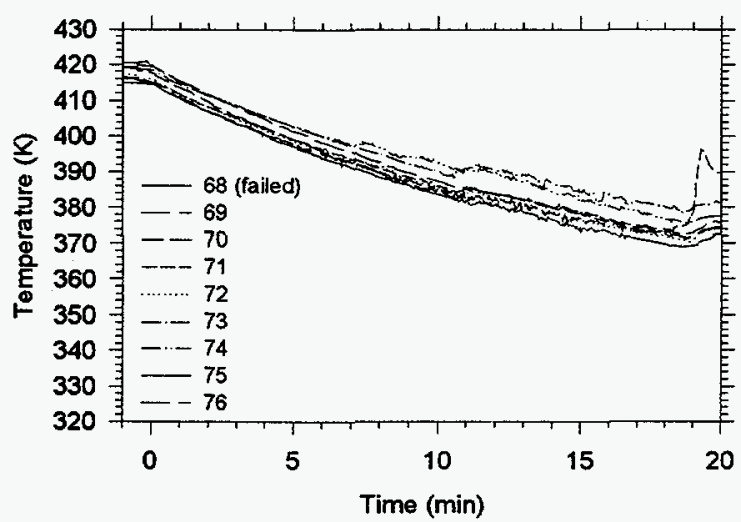

Figure 11. Surtsey vessel gas temperature from thermocouple array D in HIT-1.

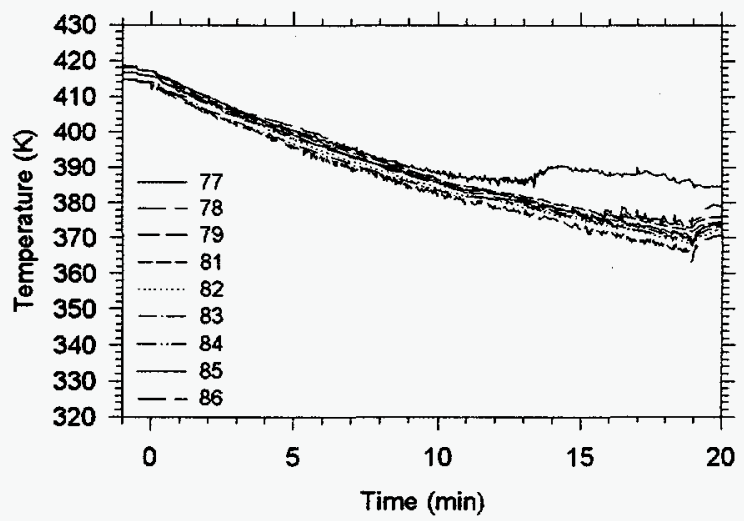

Figure 12. Surtsey vessel gas temperature from thermocouple array $E$ in HIT-1. 
Figures

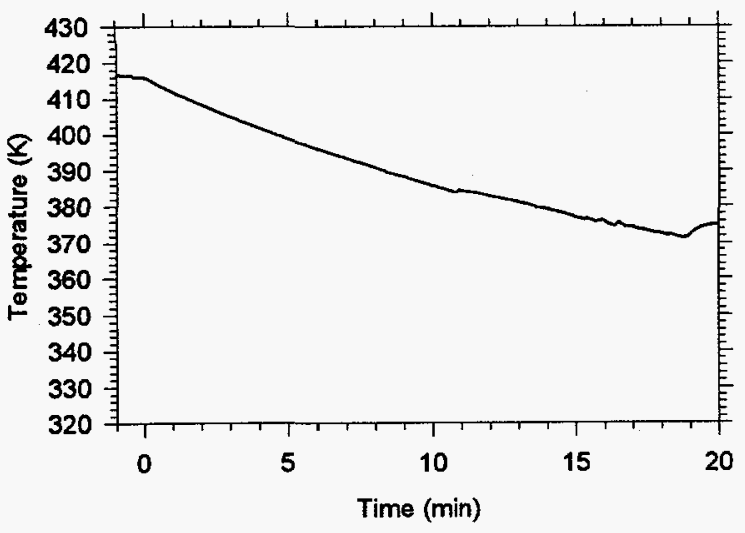

Figure 13. Surtsey vessel average gas temperature in HIT-1.

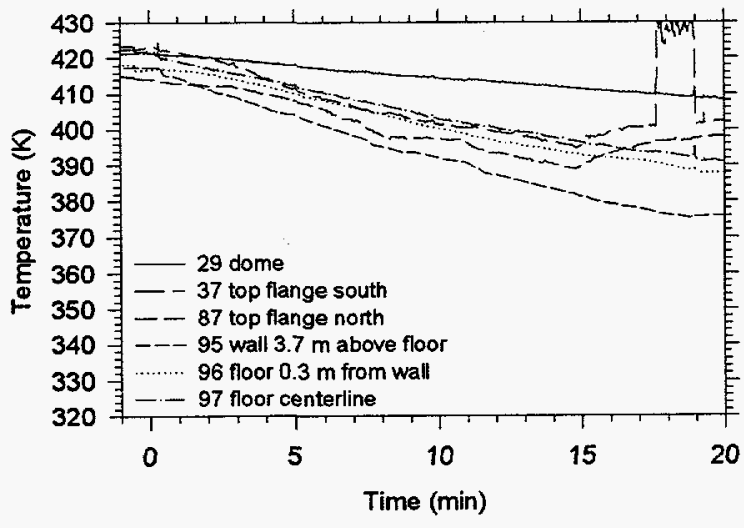

Figure 14. Surtsey vessel dome, wall, and floor temperatures in HIT-1.

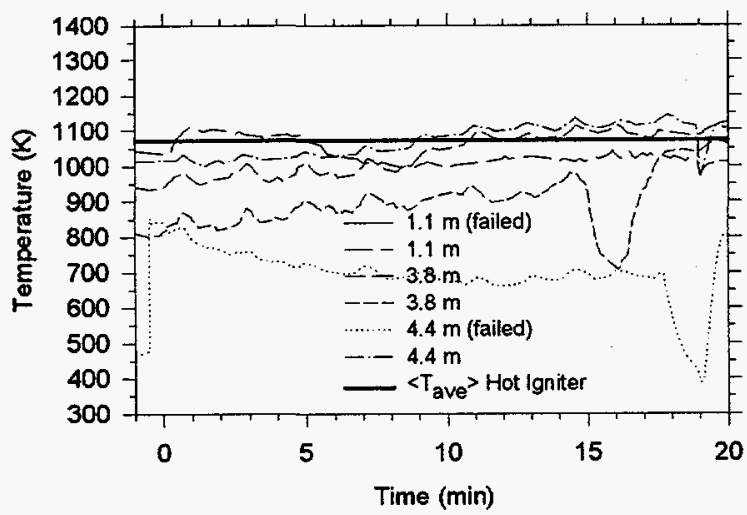

Figure 15. Igniter temperatures in HIT-1.

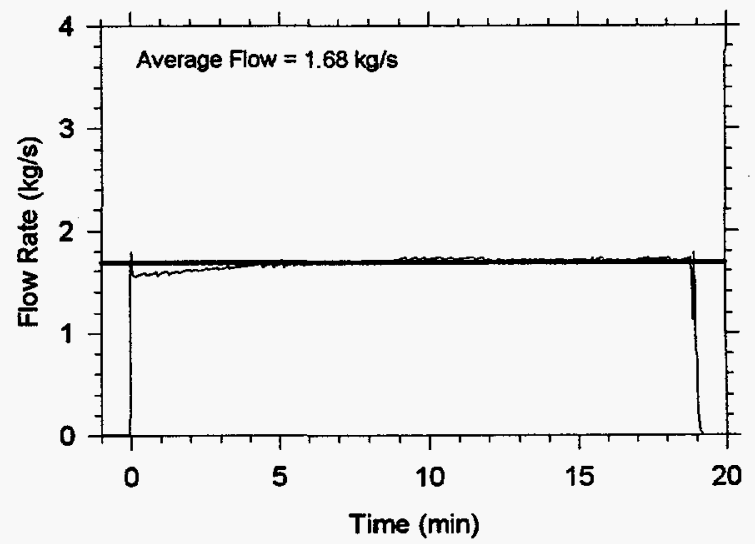

Figure 16. Spray flow rate in HIT-1.

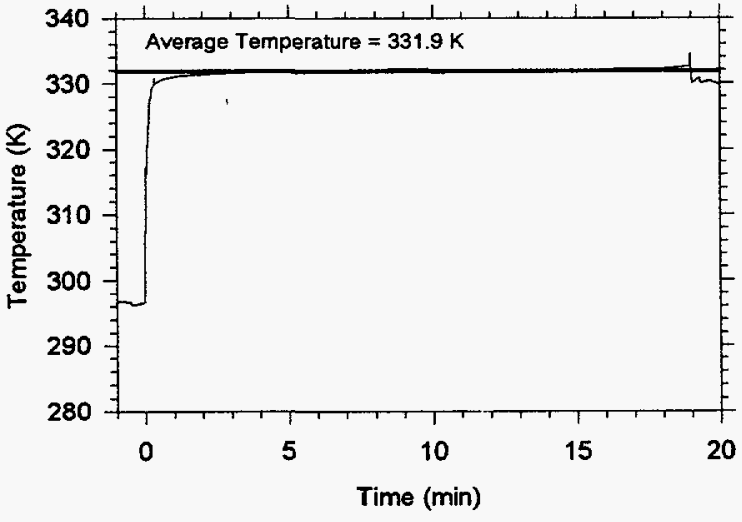

Figure 17. Spray temperature in HIT-1. 


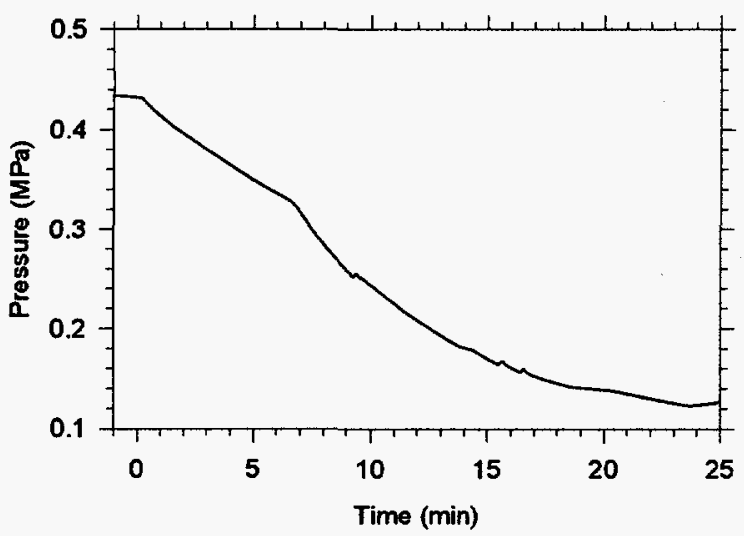

Figure 18. Surtsey vessel pressure in HIT-2.

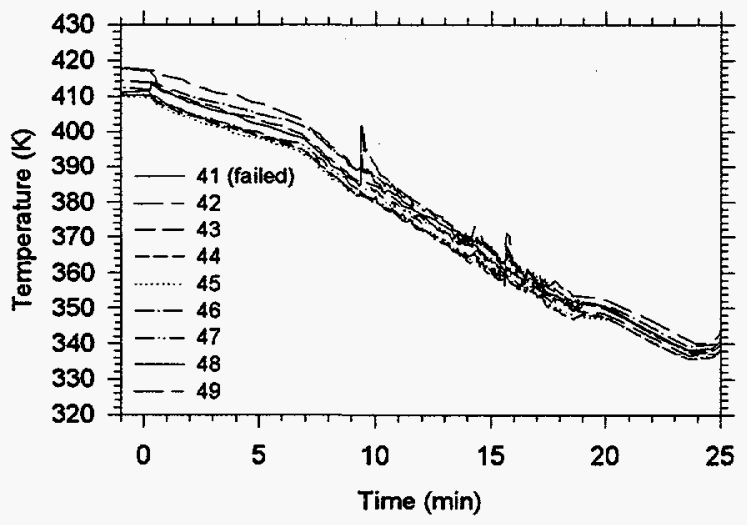

Figure 19. Surtsey vessel gas temperature from thermocouple array A in HIT-2.

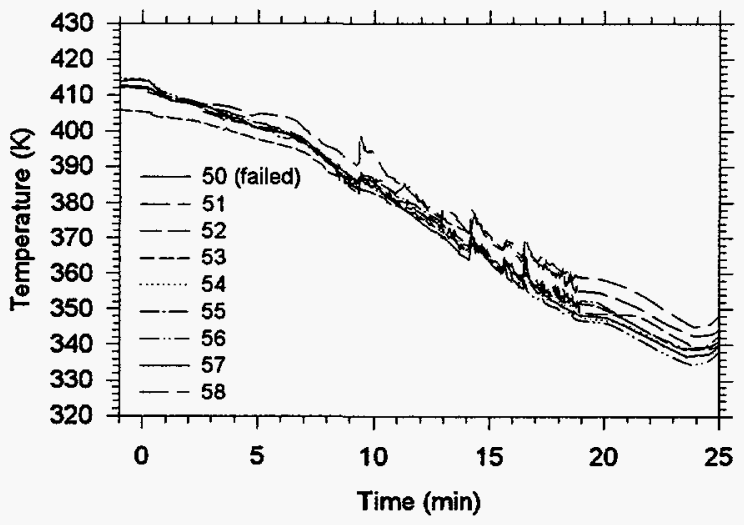

Figure 20. Surtsey vessel gas temperature from thermocouple array B in HIT-2.

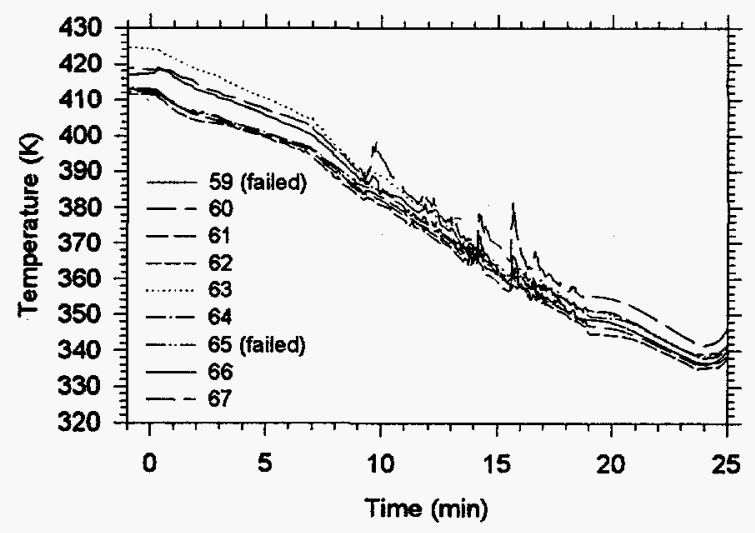

Figure 21. Surtsey vessel gas temperature from thermocouple array C in HIT-2.

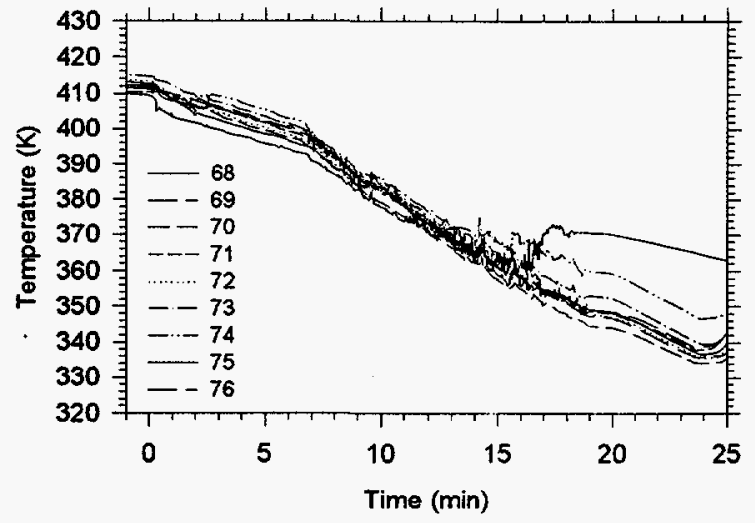

Figure 22. Surtsey vessel gas temperature from thermocouple array D in HIT-2.

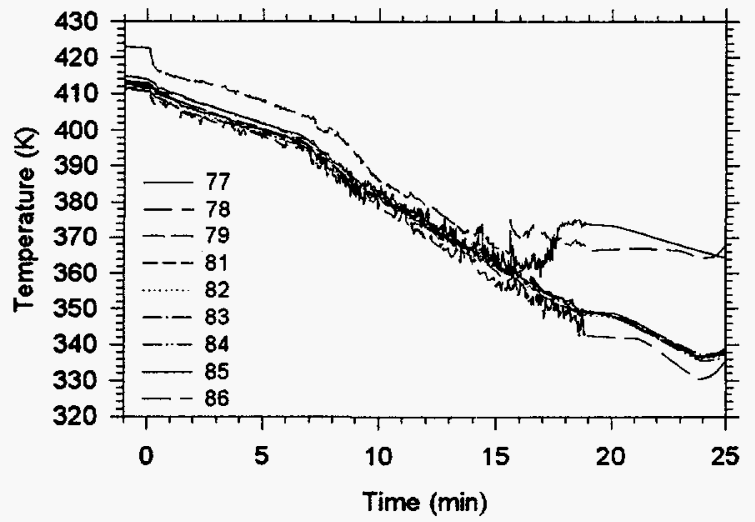

Figure 23. Surtsey vessel gas temperature from thermocouple array $E$ in HIT-2. 
Figures

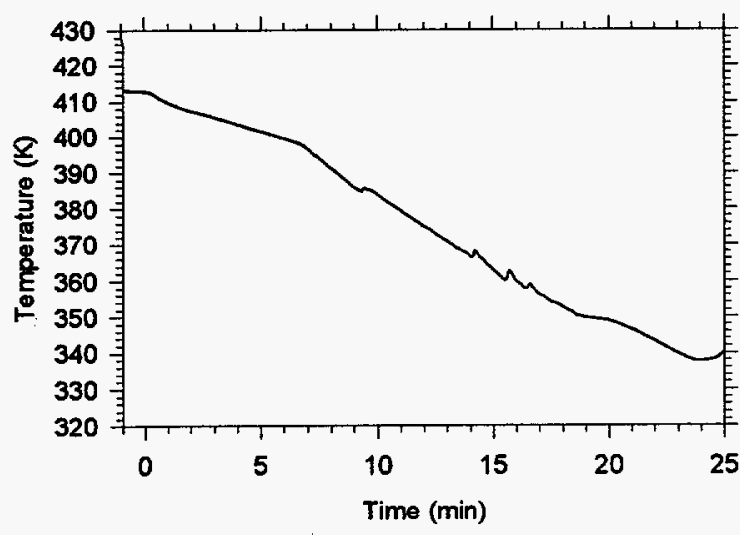

Figure 24. Surtsey vessel average gas temperature in HIT-2.

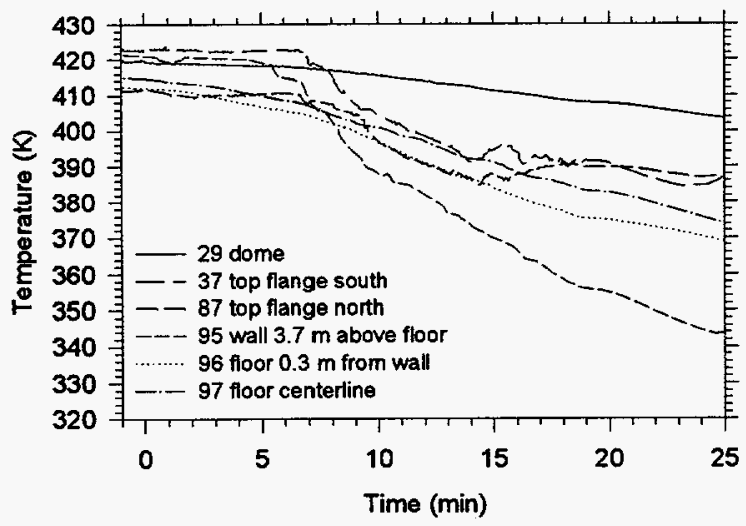

Figure 25. Surtsey vessel dome, wall, and floor temperatures in HIT-2.

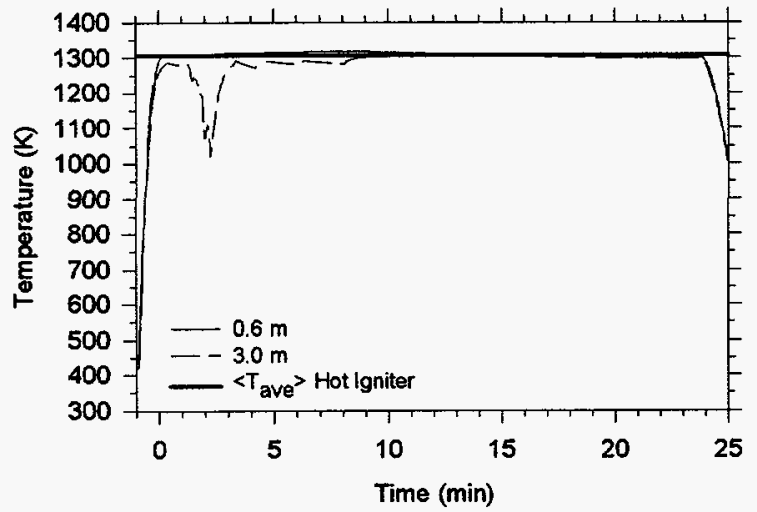

Figure 26. Igniter temperatures in HIT-2.

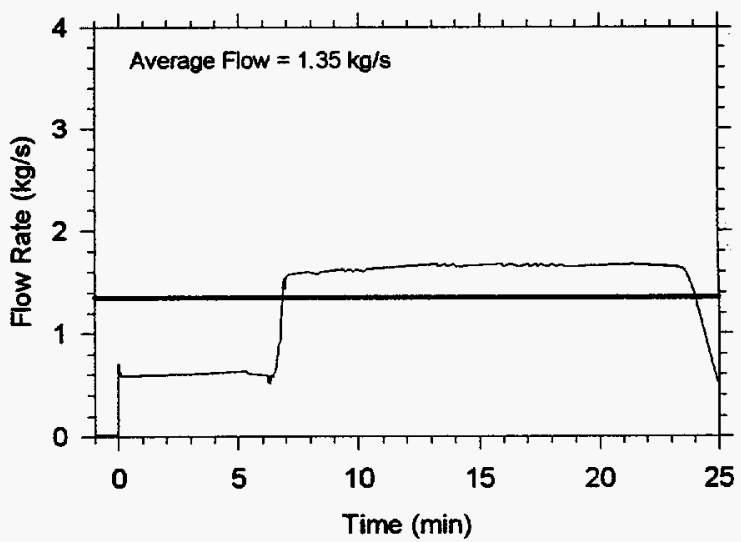

Figure 27. Spray flow rate in HIT-2.

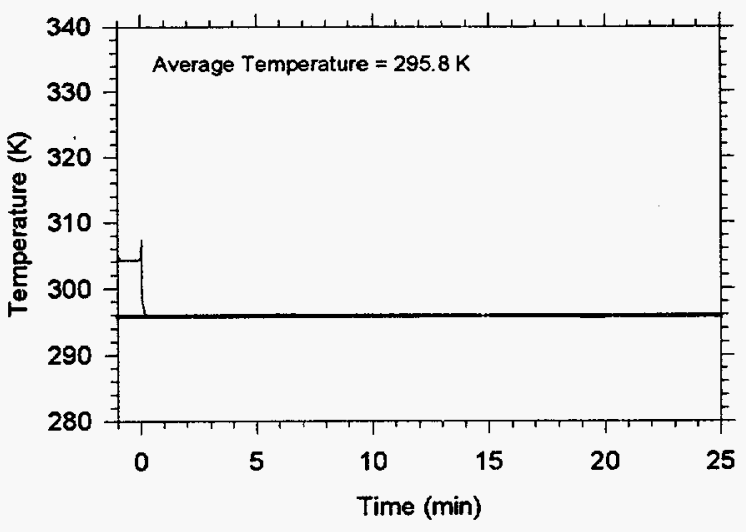

Figure 28. Spray temperature in HIT-2. 


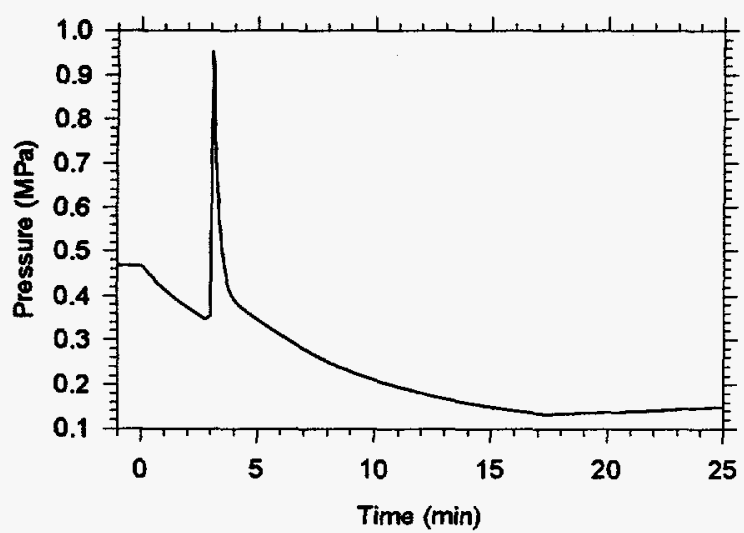

Figure 29. Surtsey vessel pressure in HIT-3.

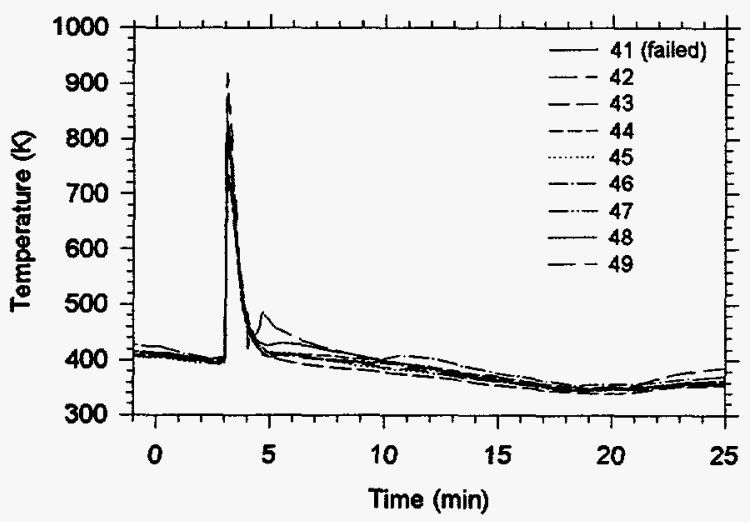

Figure 30. Surtsey vessel gas temperature from thermocouple array A in HIT-3.

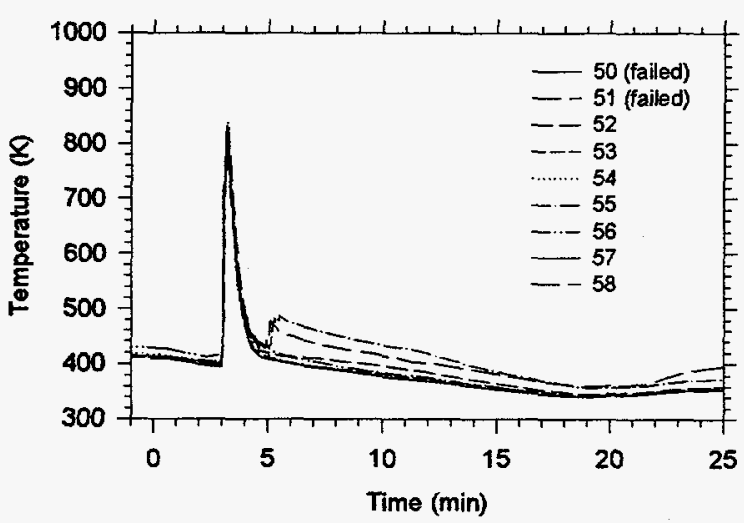

Figure 31. Surtsey vessel gas temperature from thermocouple array B in HIT-3.

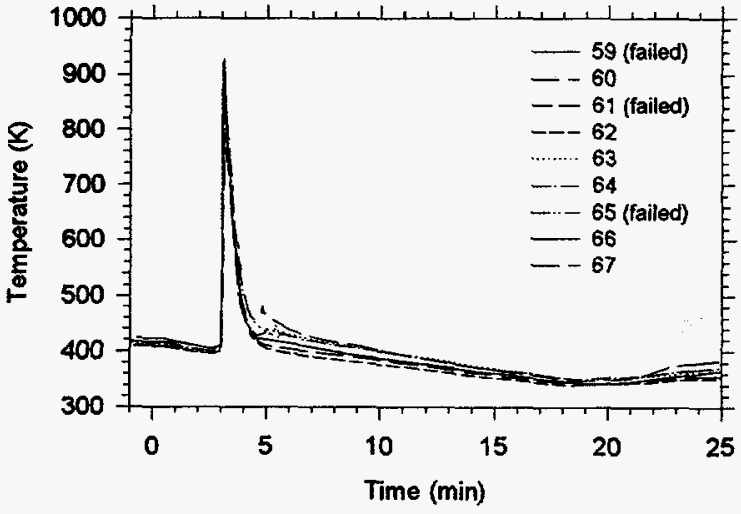

Figure 32. Surtsey vessel gas temperature from thermocouple array $C$ in HIT-3.

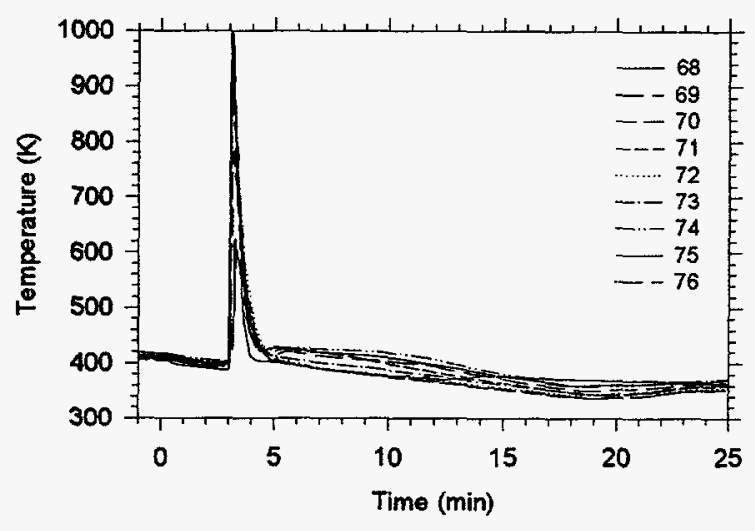

Figure 33. Surtsey vessel gas temperature from thermocouple array D in HIT-3.

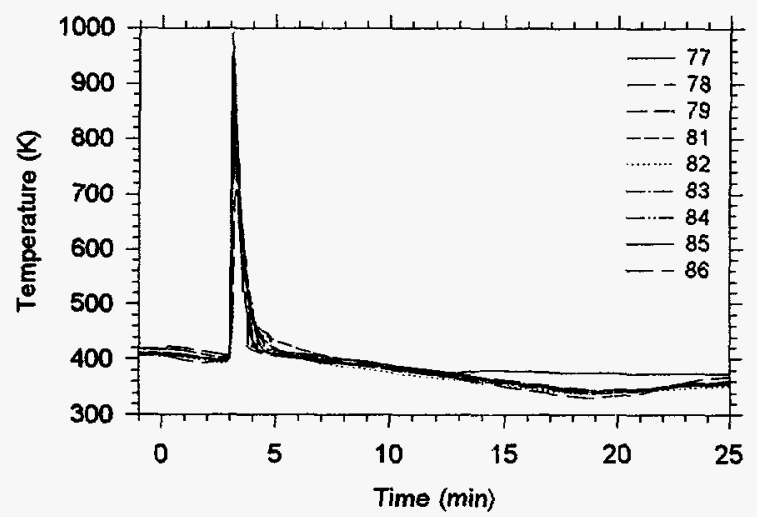

Figure 34. Surtsey vessel gas temperature from thermocouple array E in HIT-3. 
Figures

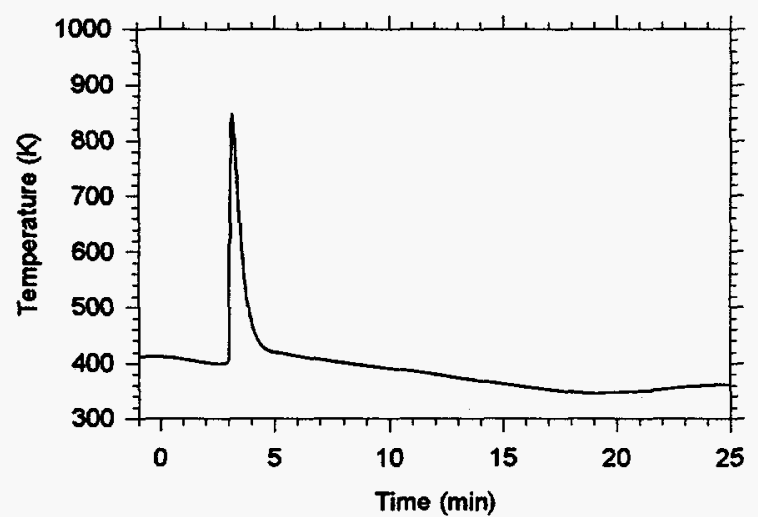

Figure 35. Surtsey vessel average gas temperature in HIT-3.

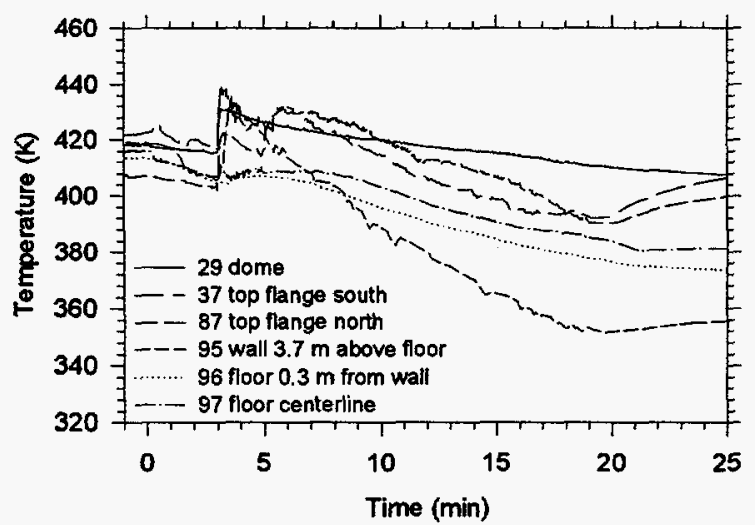

Figure 36. Surtsey vessel dome, wall, and floor temperatures in HIT-3.

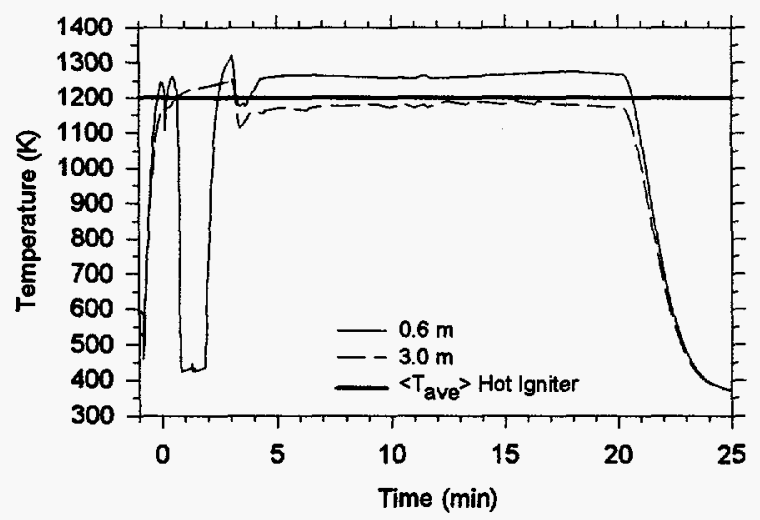

Figure 37. Igniter temperatures in HIT-3.

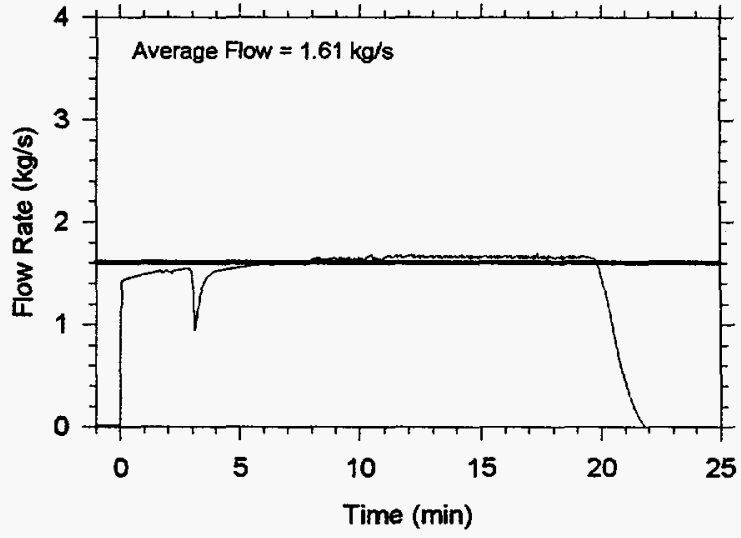

Figure 38. Spray flow rate in HIT-3.

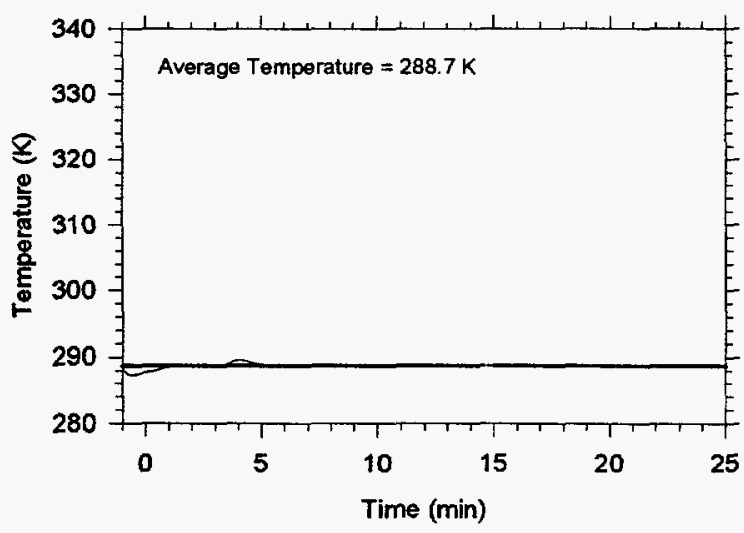

Figure 39. Spray temperature in HIT-3. 


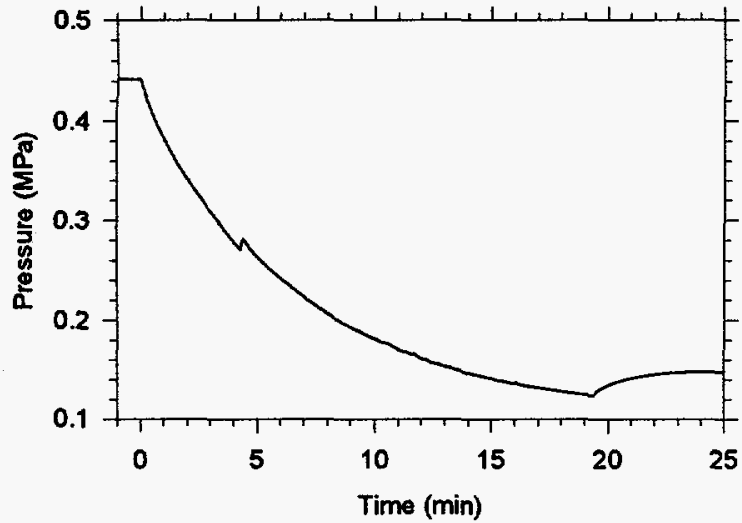

Figure 40. Surtsey vessel pressure in HIT-4.

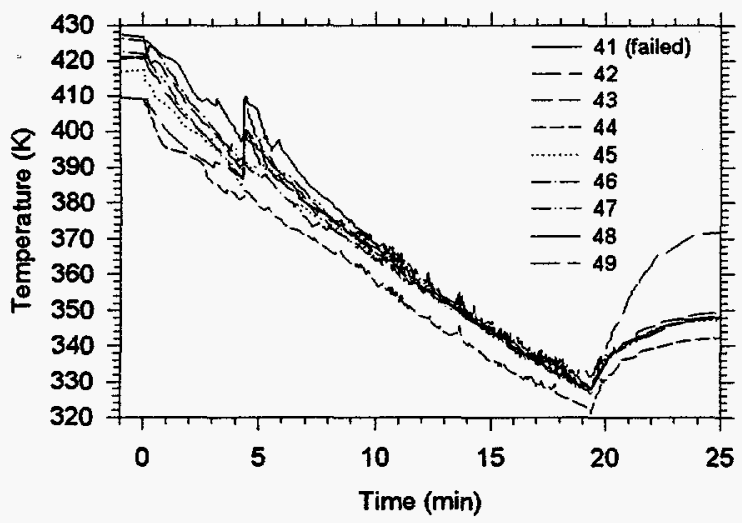

Figure 41. Surtsey vessel gas temperature from thermocouple array A in HIT-4.

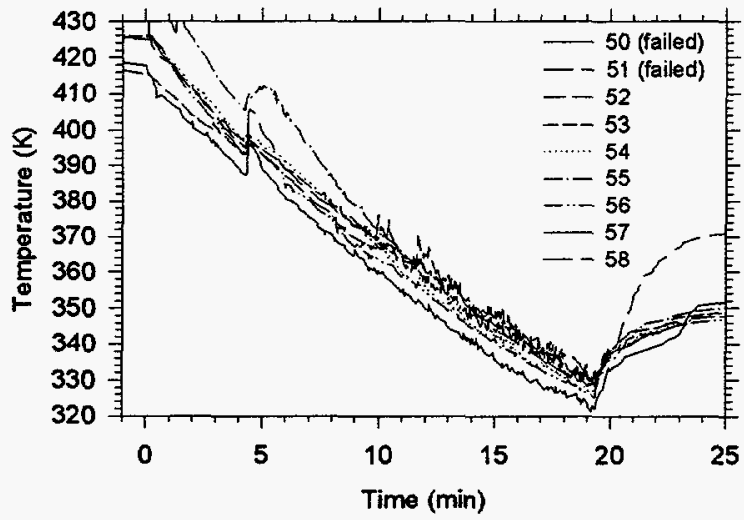

Figure 42. Surtsey vessel gas temperature from thermocouple array B in HIT-4.

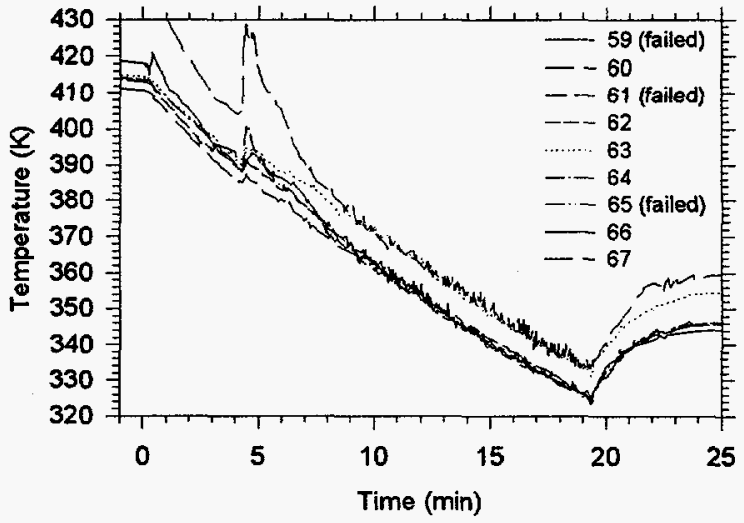

Figure 43. Surtsey vessel gas temperature from thermocouple array $C$ in HIT-4.

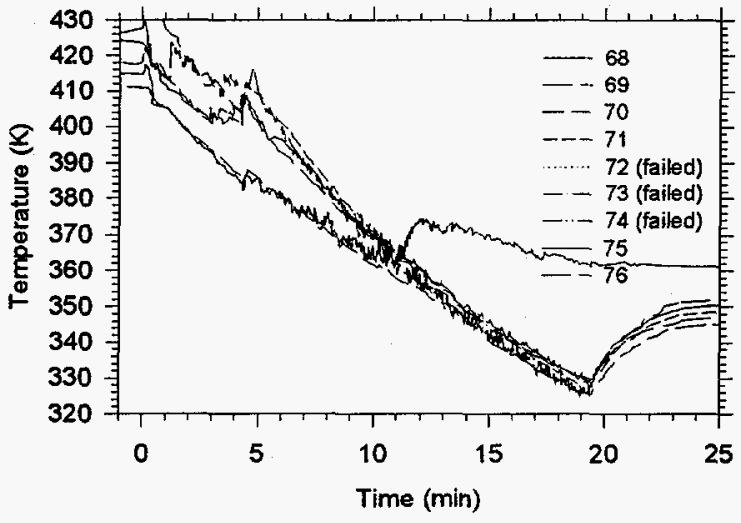

Figure 44. Surtsey vessel gas temperature from thermocouple array D in HIT-4.

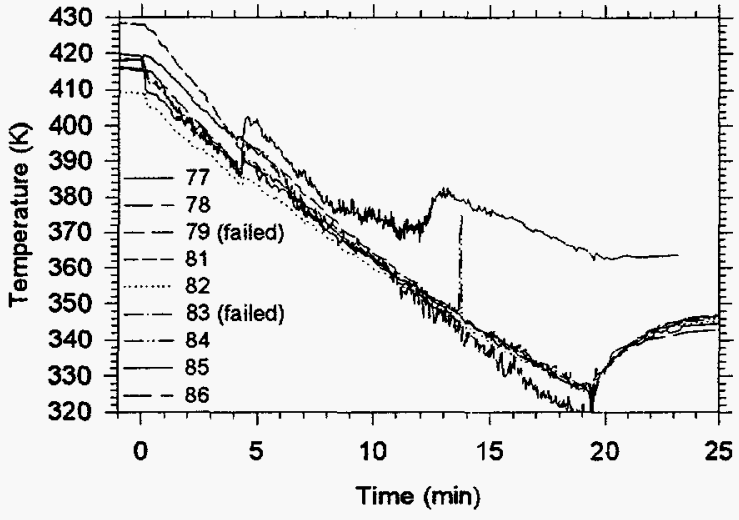

Figure 45. Surtsey vessel gas temperature from thermocouple array E in HIT-4. 
Figures

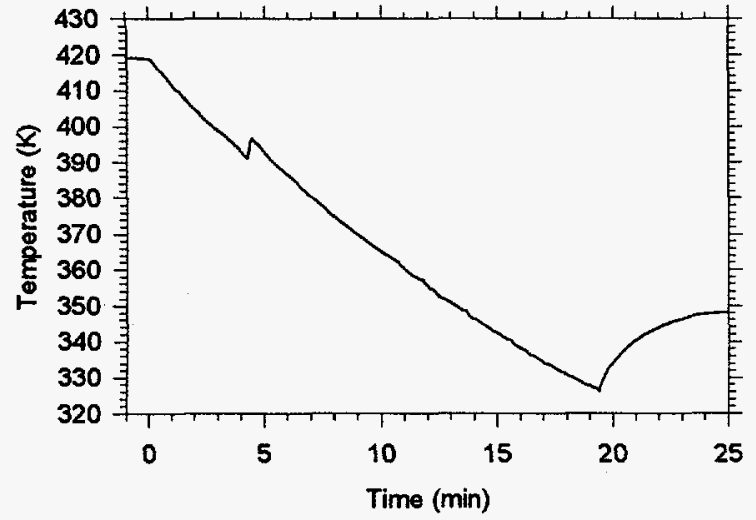

Figure 46. Surtsey vessel average gas temperature in HIT-4.

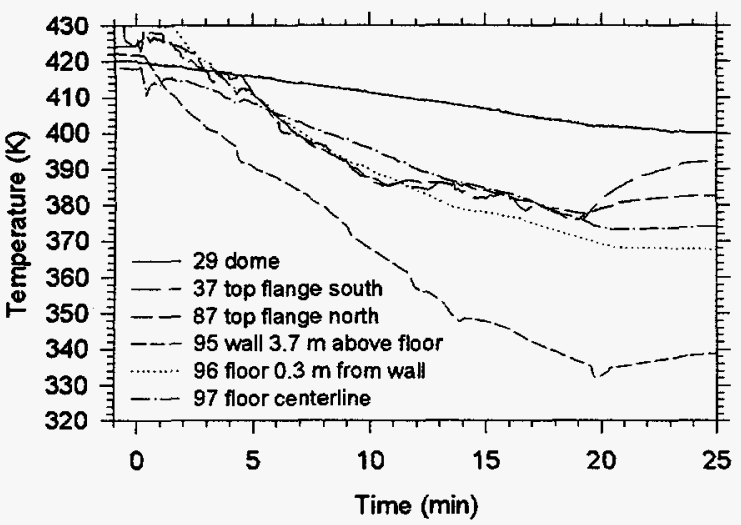

Figure 47. Surtsey vessel dome, wall, and floor temperatures in HIT-4.

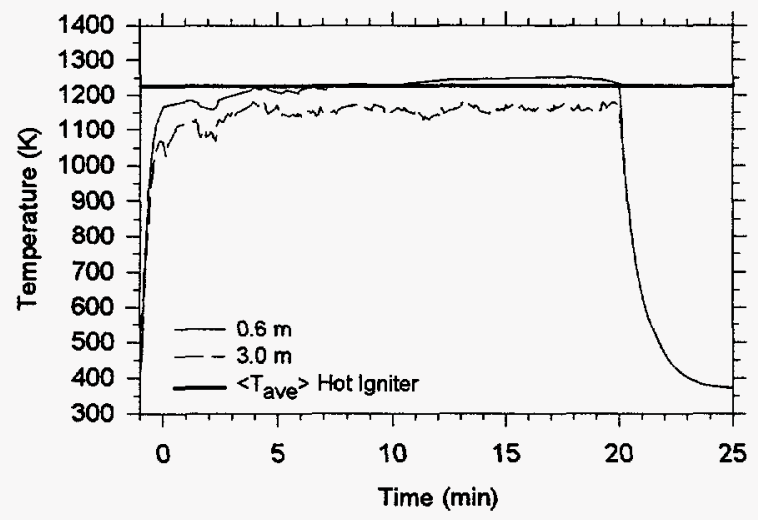

Figure 48. Igniter temperatures in HIT 4 .

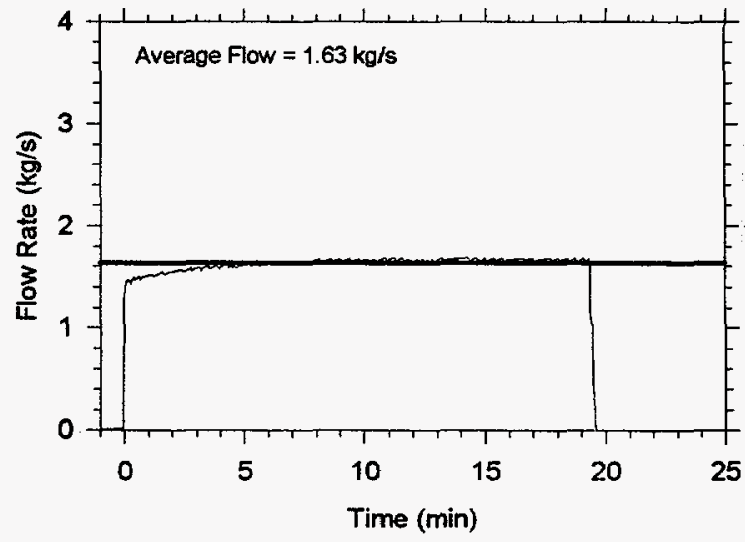

Figure 49. Spray flow rate in HIT-4.

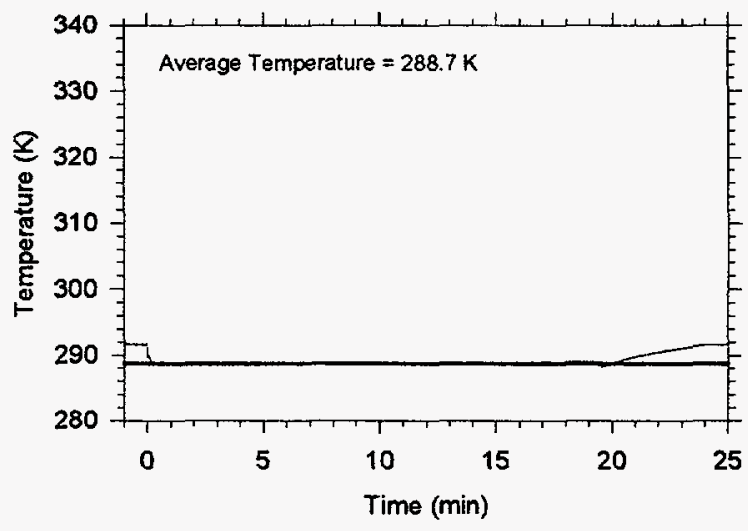

Figure 50. Spray temperature in HIT-4. 


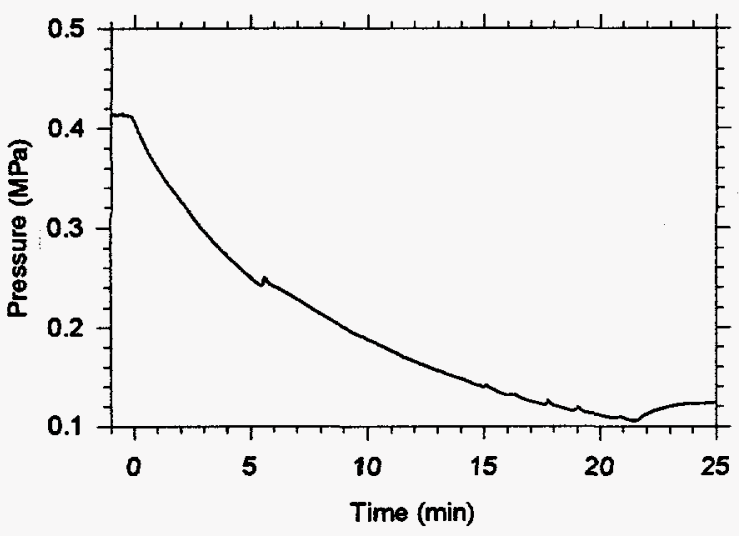

Figure 51. Surtsey vessel pressure in HIT-5.

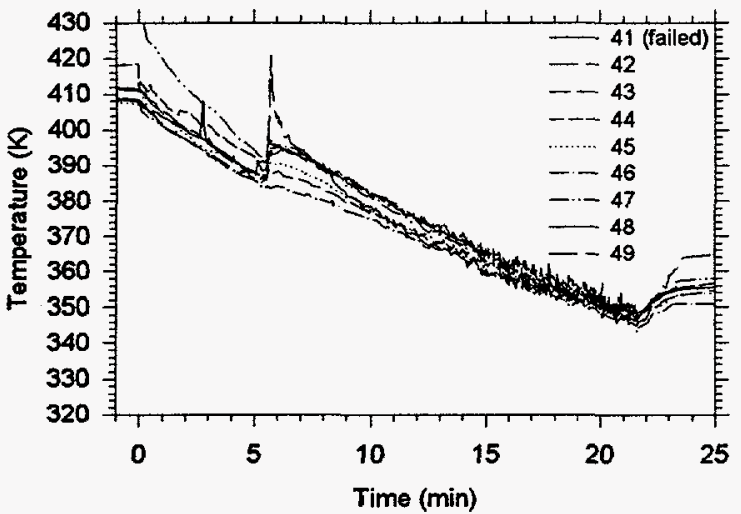

Figure 52. Surtsey vessel gas temperature from thermocouple array A in HIT-5.

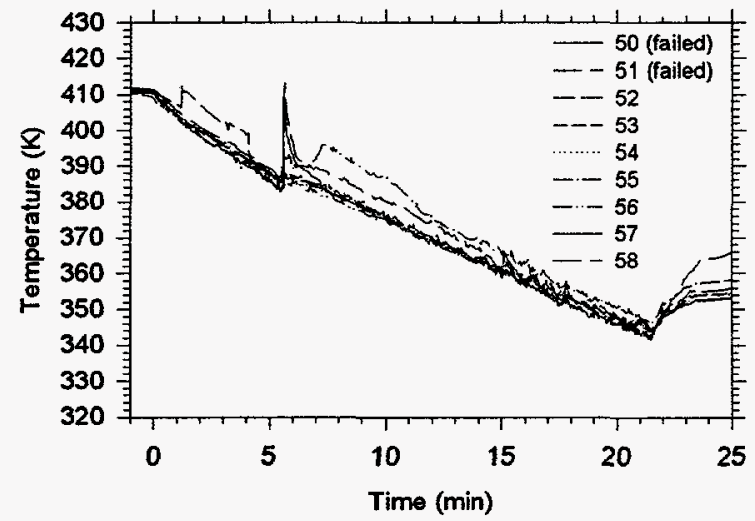

Figure 53. Surtsey vessel gas temperature from thermocouple array B in HIT-5.

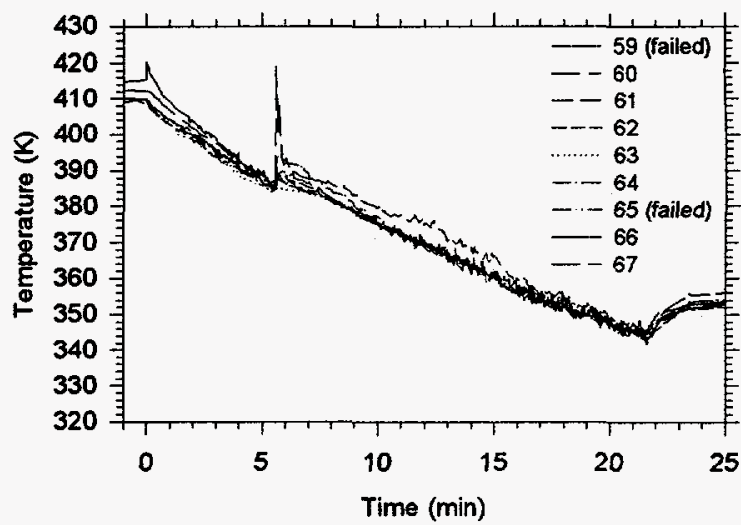

Figure 54. Surtsey vessel gas temperature from thermocouple array C in HIT-5.

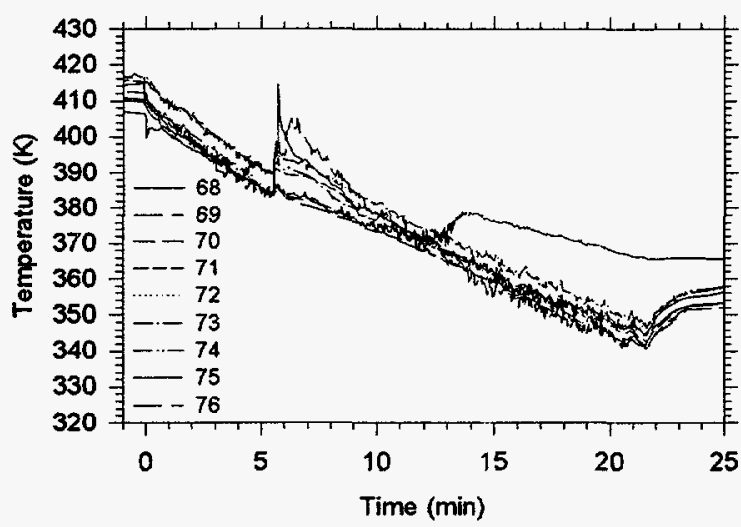

Figure 55. Surtsey vessel gas temperature from thermocouple array D in HIT-5.

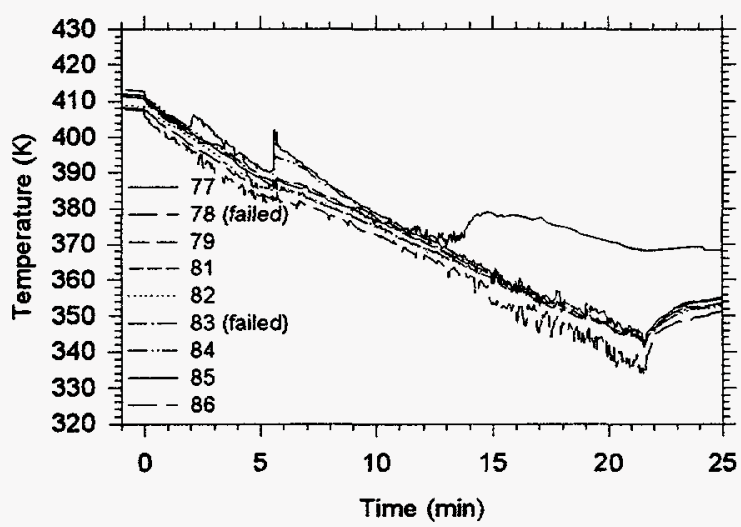

Figure 56. Surtsey vessel gas temperature from thermocouple array $E$ in HIT-5. 
Figures

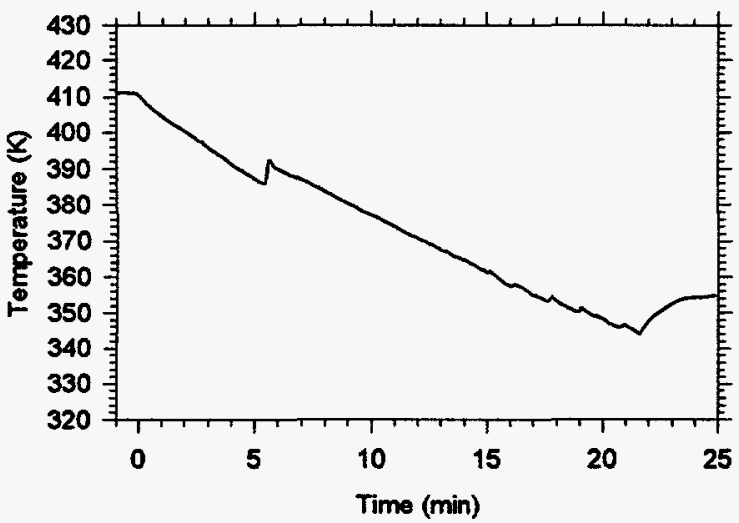

Figure 57. Surtsey vessel average gas temperature in HIT-5.

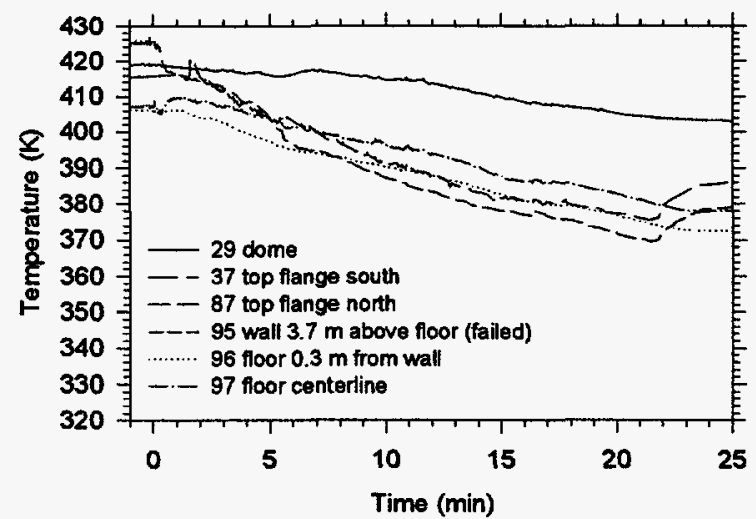

Figure 58. Surtsey vessel dome, wall, and floor temperatures in HIT-5.

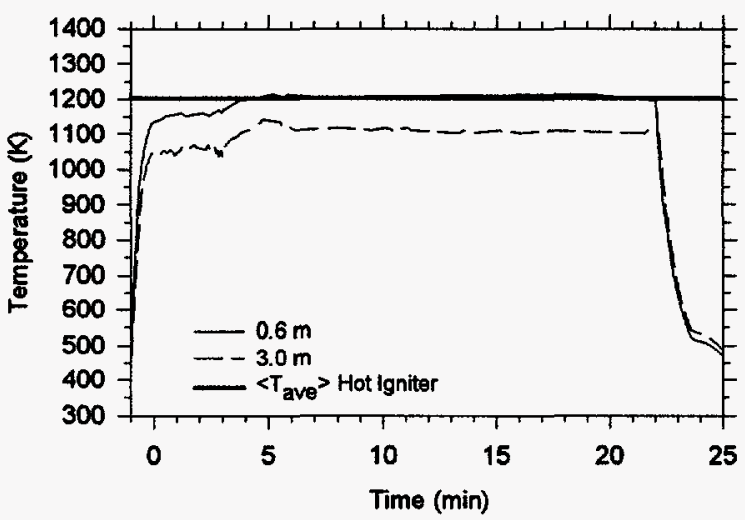

Figure 59. Igniter temperatures in HIT-5.

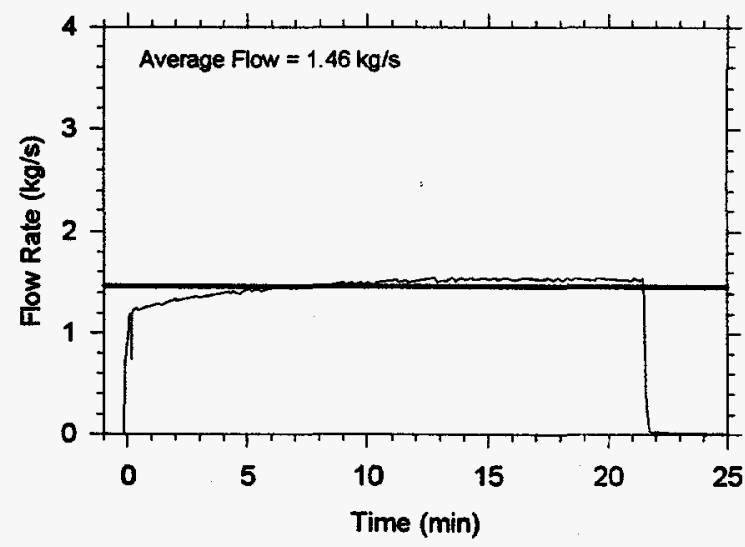

Figure 60. Spray flow rate in HIT-5.

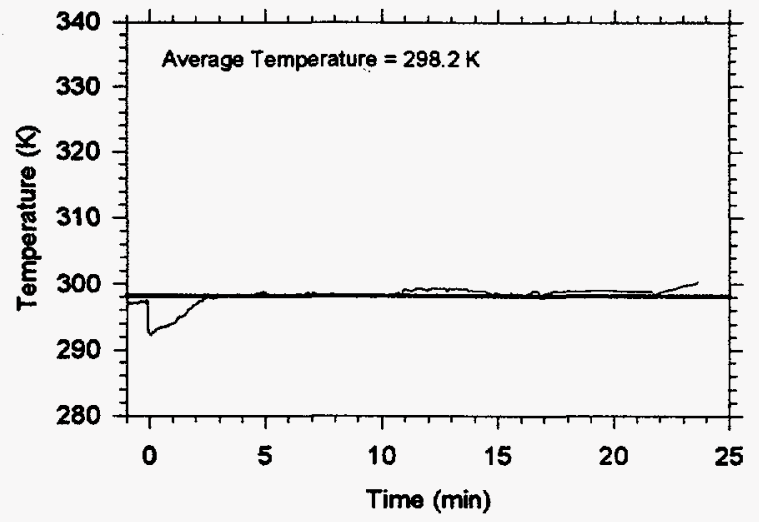

Figure 61. Spray temperature in HIT-5. 


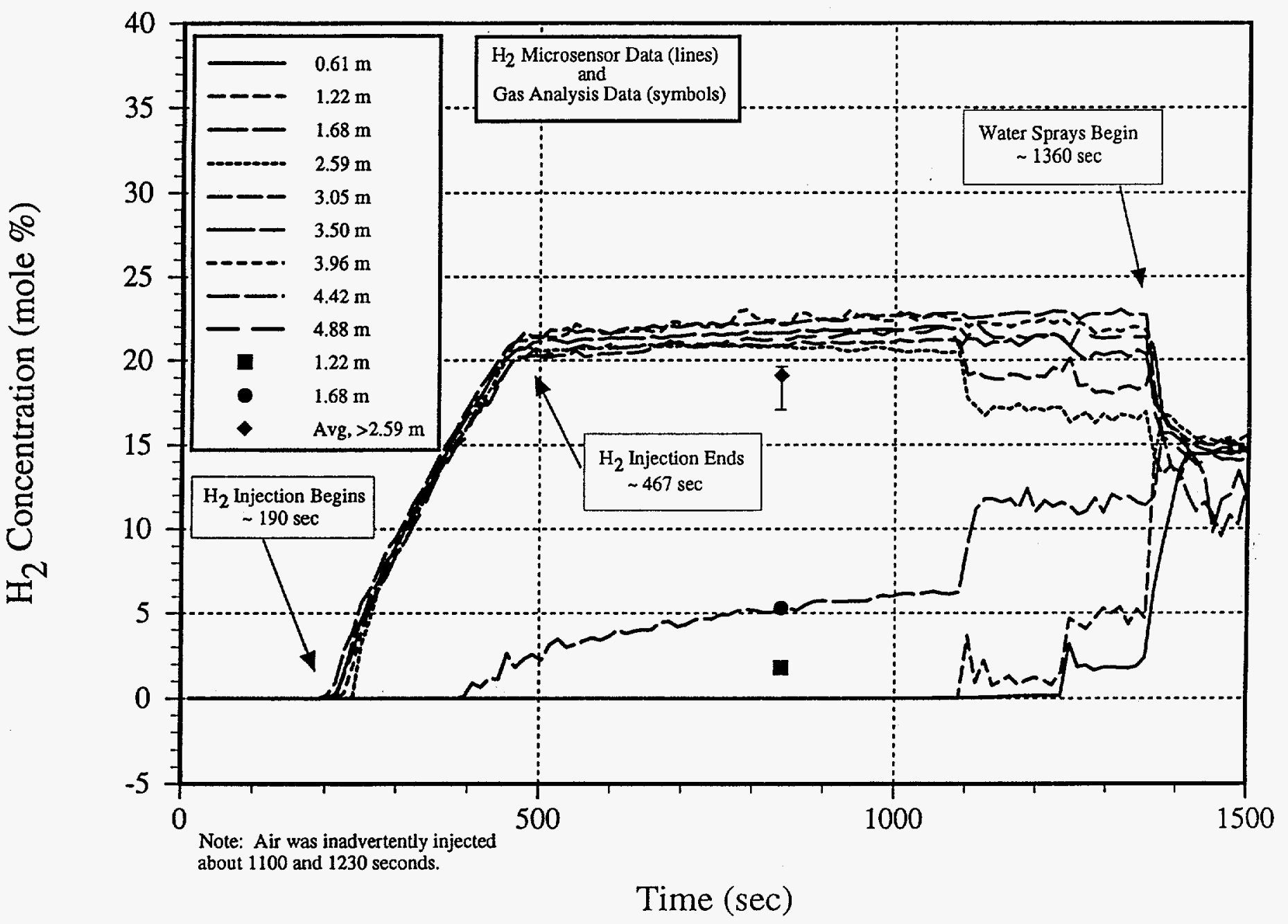

Figure 62. Hydrogen concentration measurements by microsensors and gas grab samples in a stratification test. 
Figures

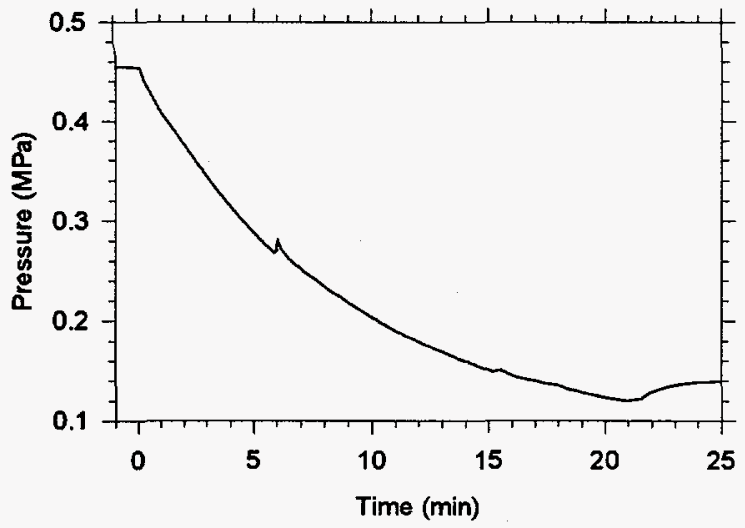

Figure 63. Surtsey vessel pressure in HIT-6.

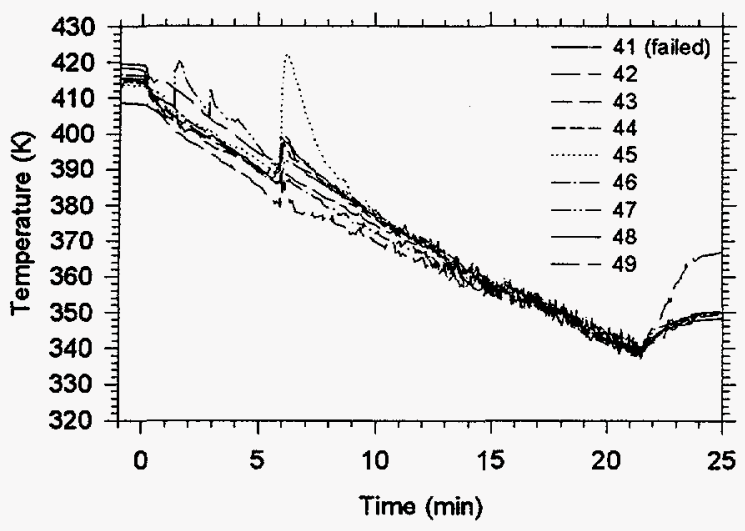

Figure 64. Surtsey vessel gas temperature from thermocouple array $A$ in HIT-6.

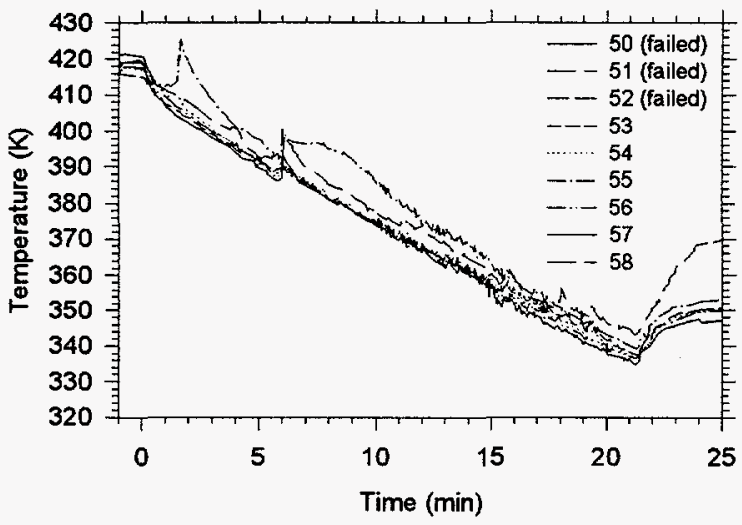

Figure 65. Surtsey vessel gas temperature from thermocouple array B in HIT-6.

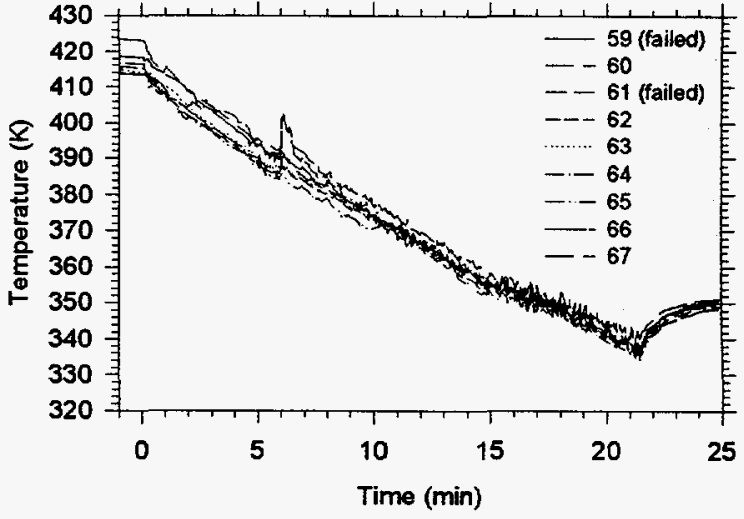

Figure 66. Surtsey vessel gas temperature from thermocouple array $C$ in HIT-6.

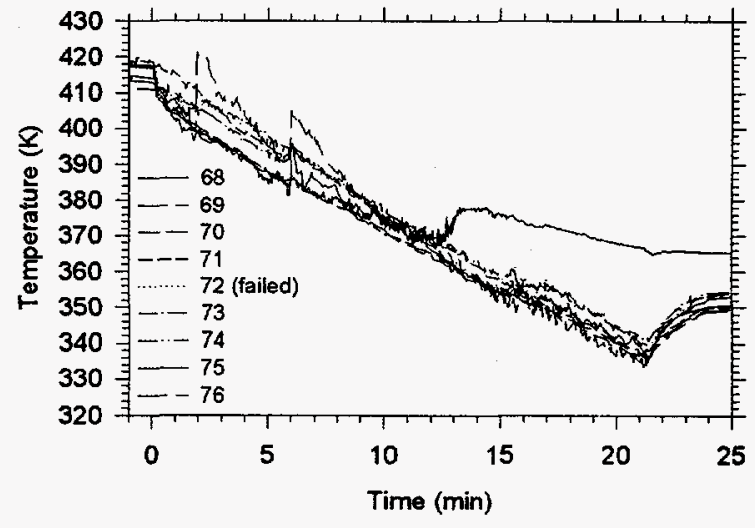

Figure 67. Surtsey vessel gas temperature from thermocouple array $D$ in HIT-6.

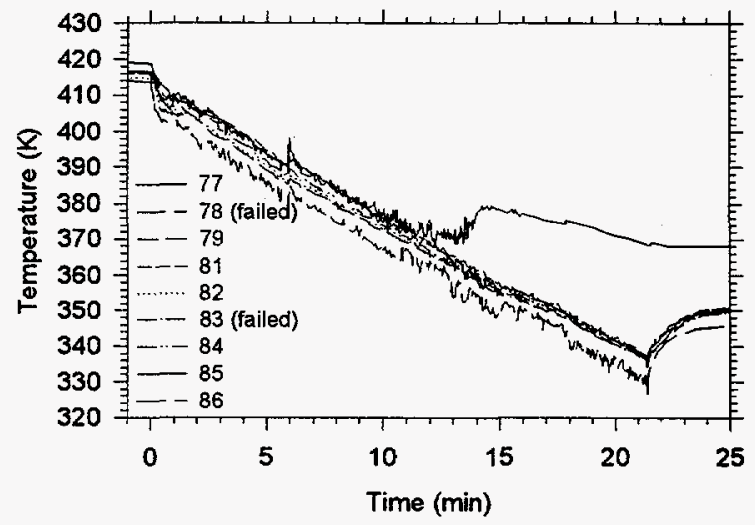

Figure 68. Surtsey vessel gas temperature from thermocouple array $E$ in HIT-6. 


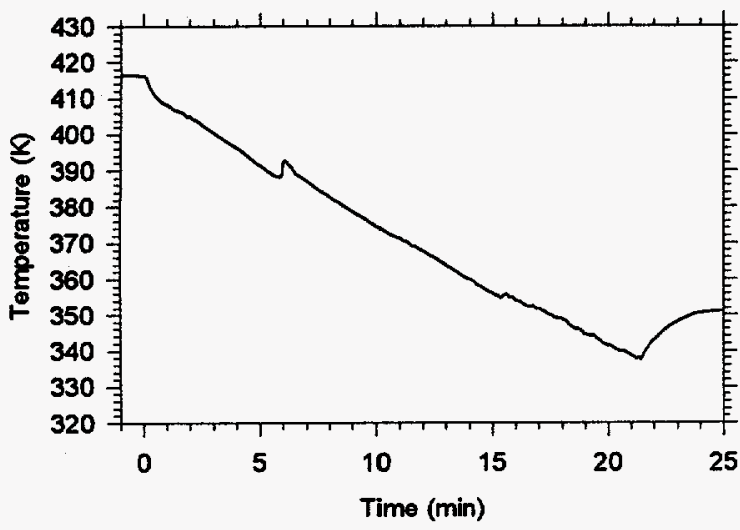

Figure 69. Surtsey vessel average gas temperature in HIT-6.

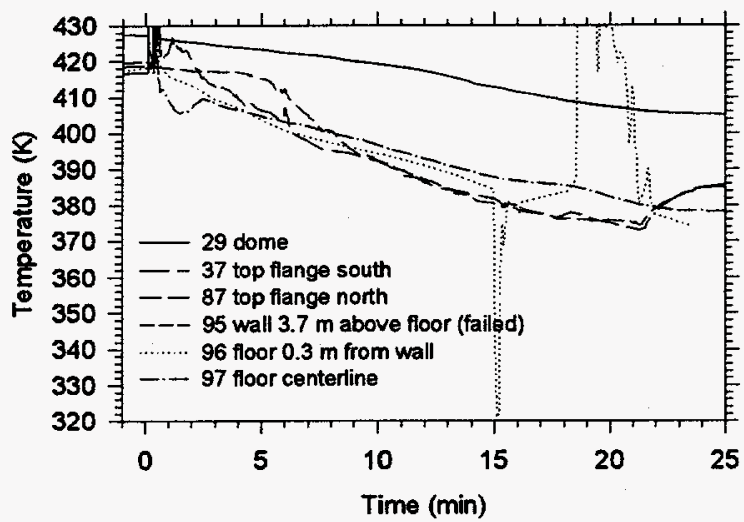

Figure 70. Surtsey vessel dome, wall, and floor temperatures in HIT-6.

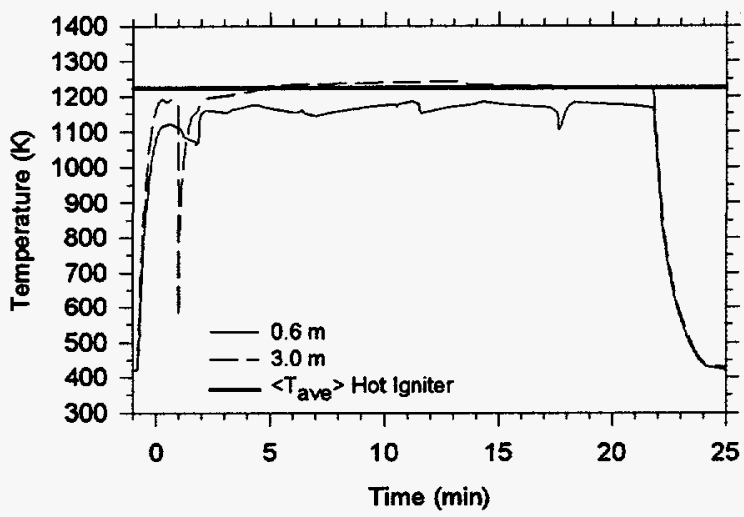

Figure 71. Igniter temperatures in HIT-6.

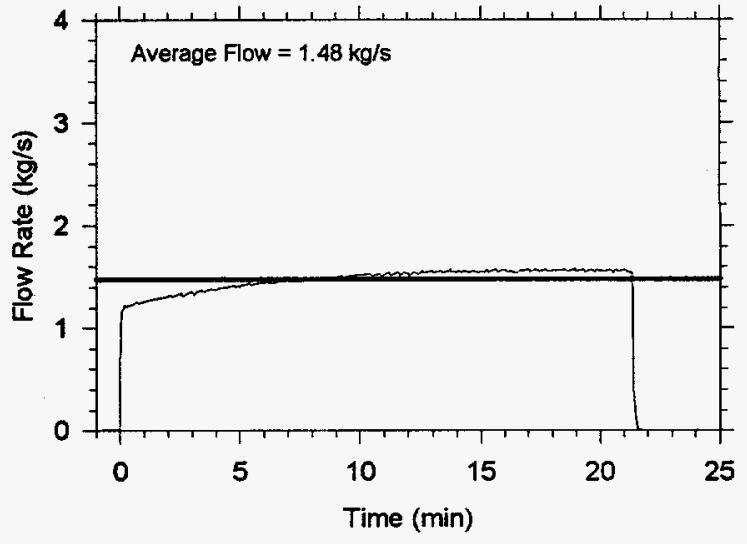

Figure 72. Spray flow rate in HIT-6.

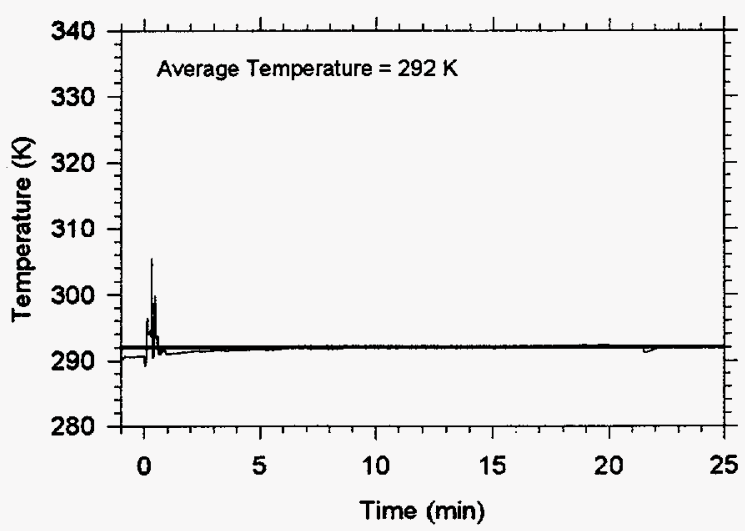

Figure 73. Spray temperature in HIT-6. 


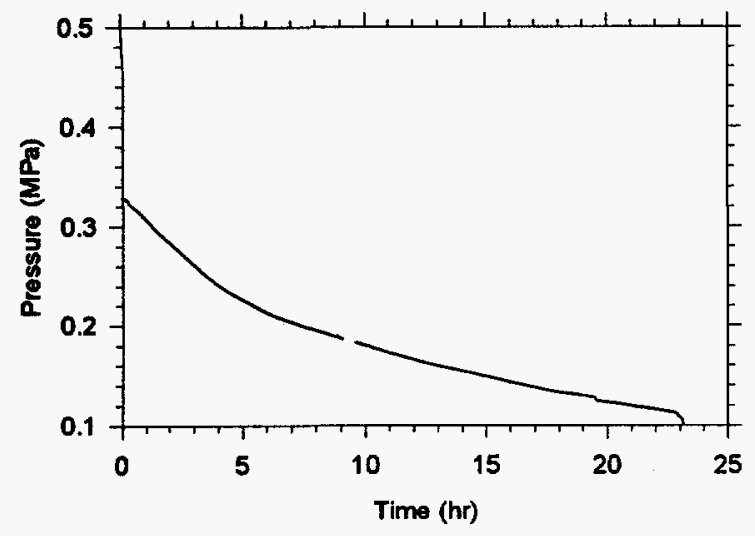

Figure 74. Surtsey vessel pressure in HIT-7.

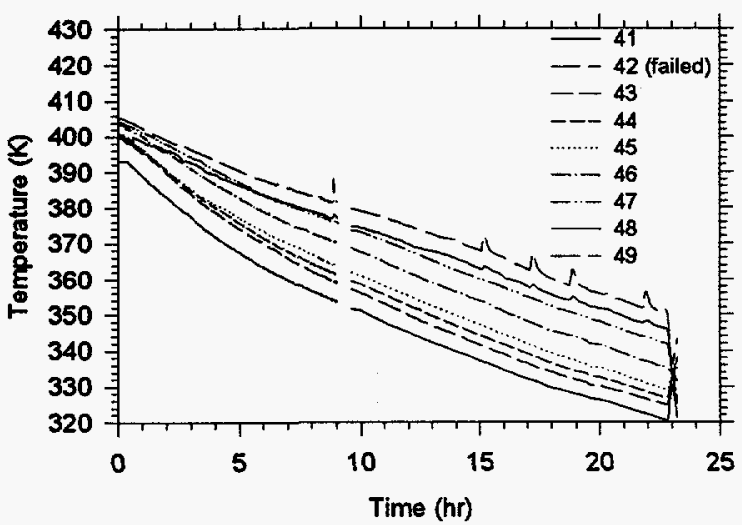

Figure 75. Surtsey vessel gas temperature from thermocouple array A in HIT-7.

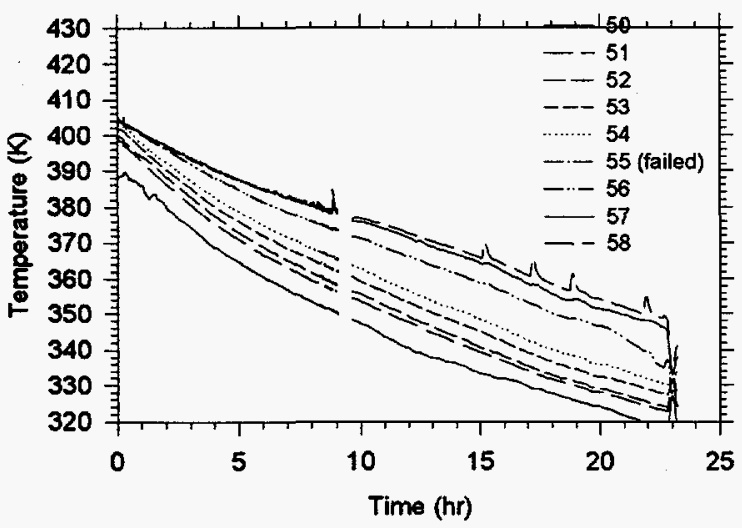

Figure 76. Surtsey vessel gas temperature from thermocouple array B in HIT-7.

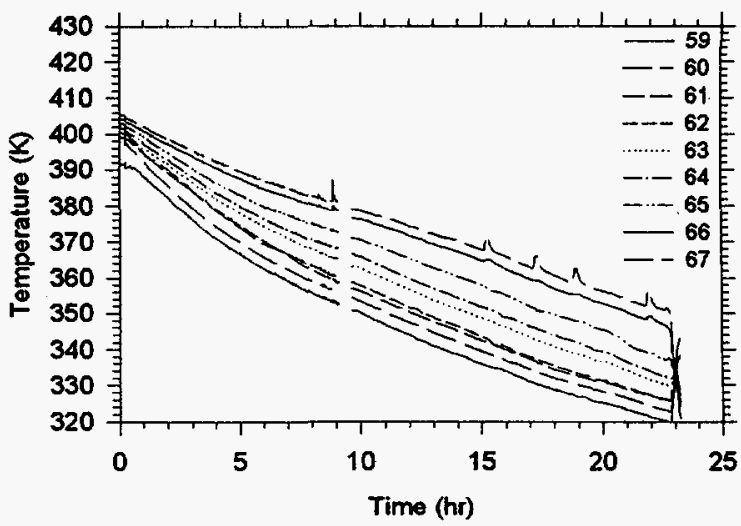

Figure 77. Surtsey vessel gas temperature from thermocouple array C in HIT-7.

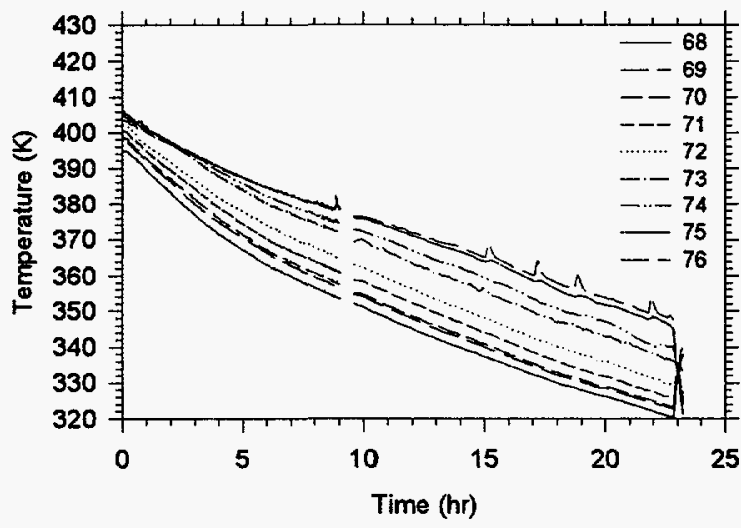

Figure 78. Surtsey vessel gas temperature from thermocouple array D in HIT-7.

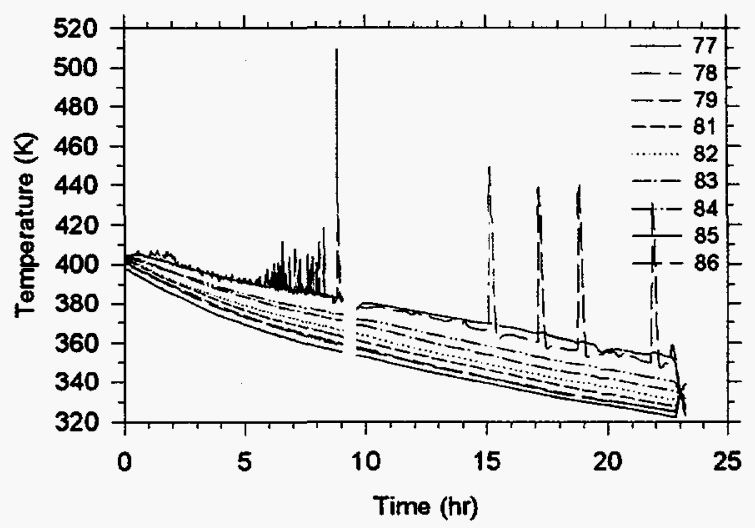

Figure 79. Surtsey vessel gas temperature from themocouple array E in HIT-7. 


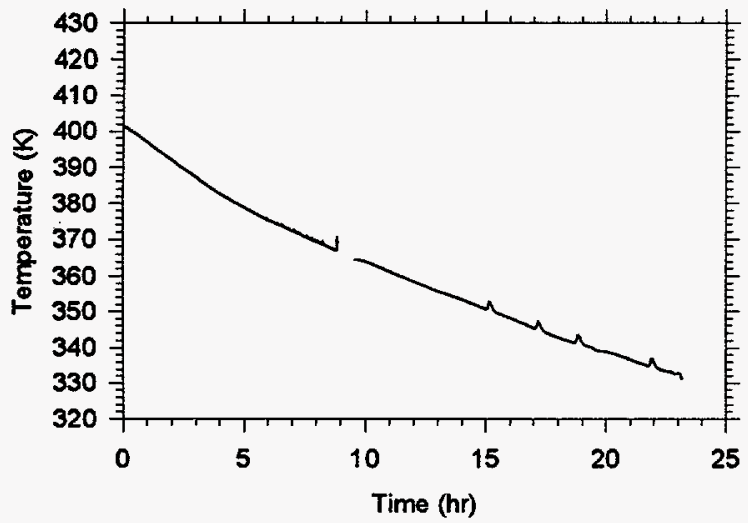

Figure 80. Surtsey vessel average gas temperature in HIT-7.

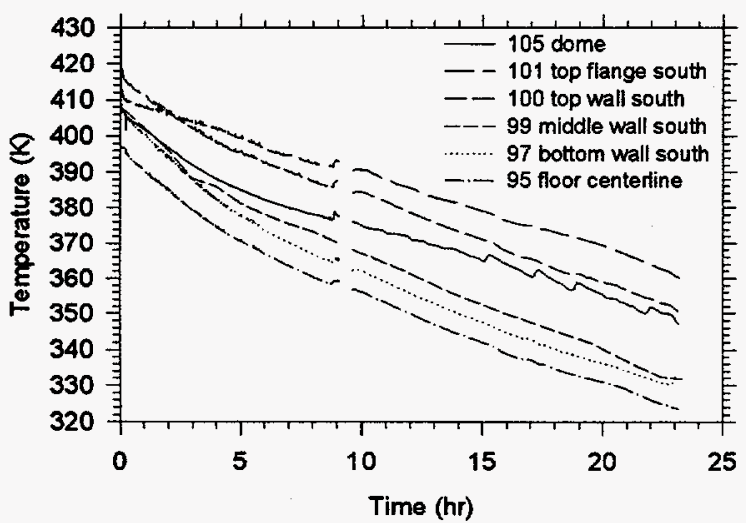

Figure 81. Surtsey vessel dome, wall, and floor temperatures in HIT-7.

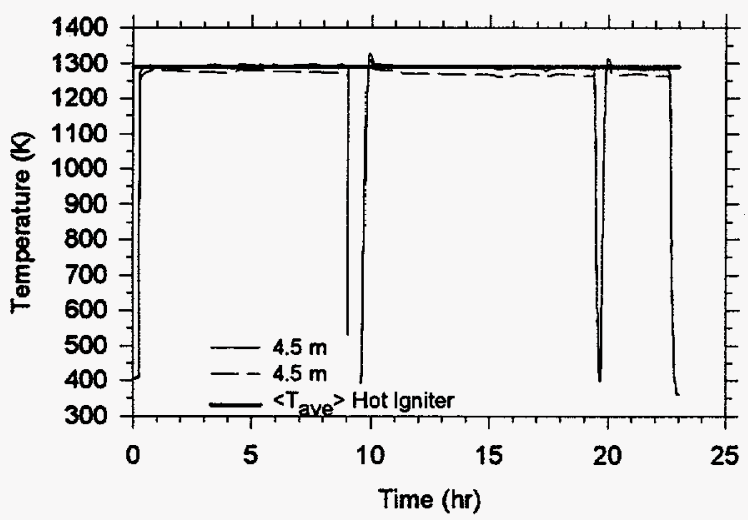

Figure 82. Igniter temperatures in HIT-7. 
Figures

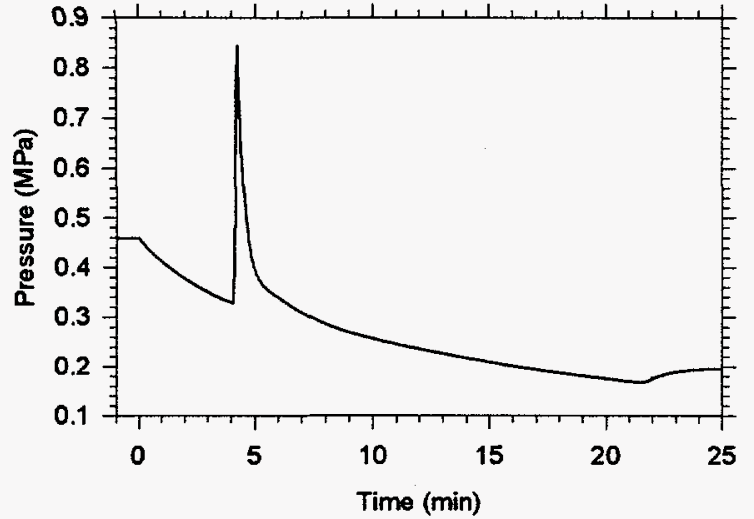

Figure 83. Surtsey vessel pressure in HIT-8.

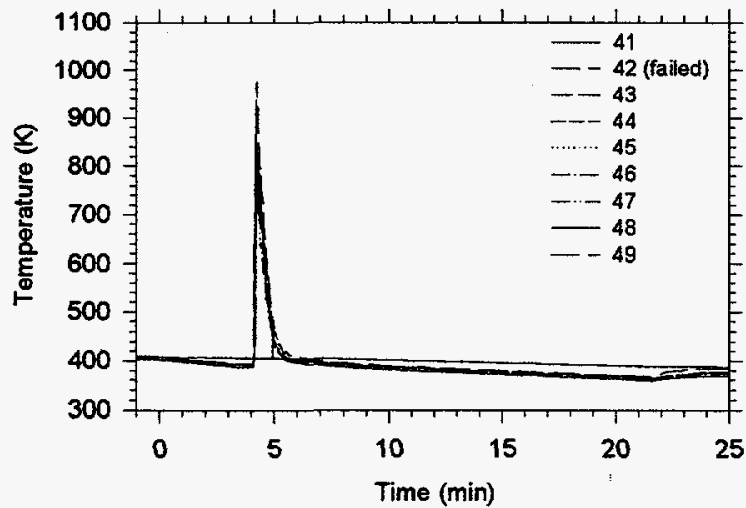

Figure 84. Surtsey vessel gas temperature from thermocouple array A in HIT-8.

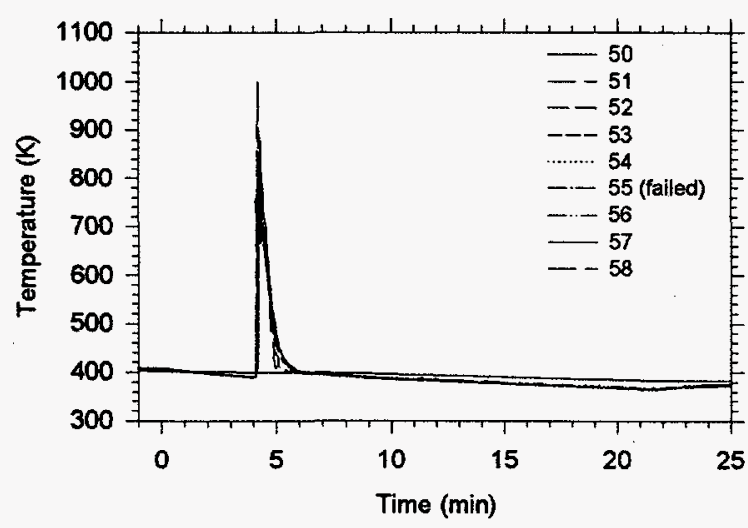

Figure 85. Surtsey vessel gas temperature from thermocouple array B in HIT-B.

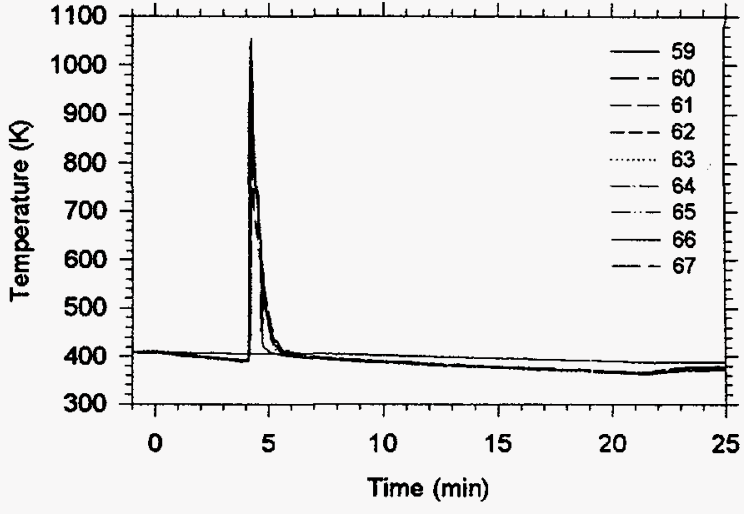

Figure 86 . Surtsey vessel gas temperature from thermocouple array C in HIT-8.

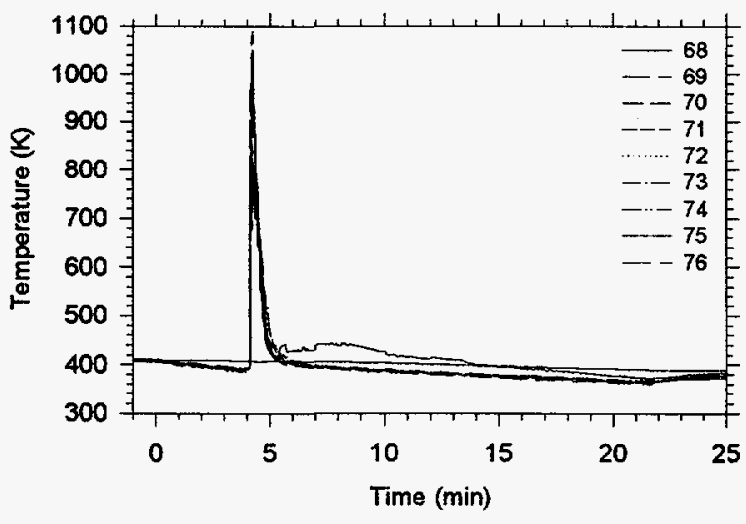

Figure 87. Surtsey vessel gas temperature from thermocouple array D in HIT-8.

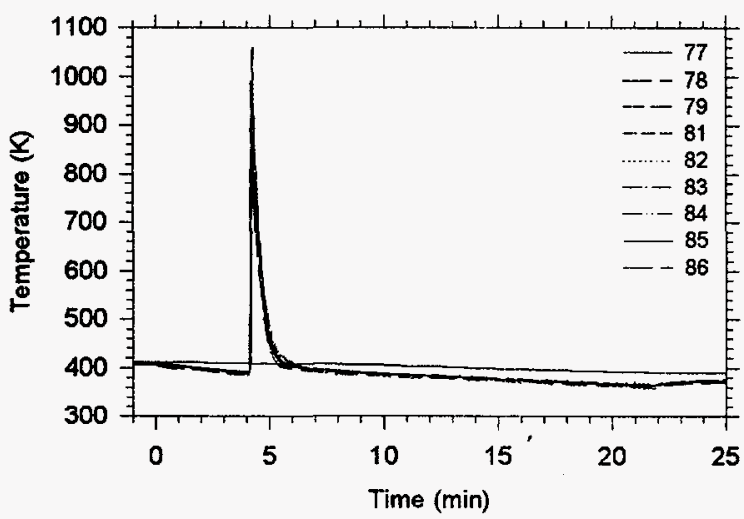

Figure 88. Surtsey vessel gas temperature from thermocouple array E in HIT-8. 


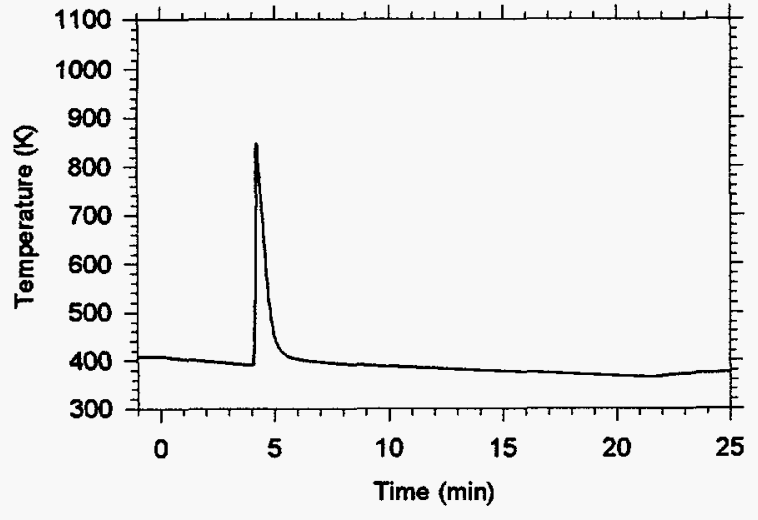

Figure 89. Surtsey vessel average gas temperature in HIT 8 .

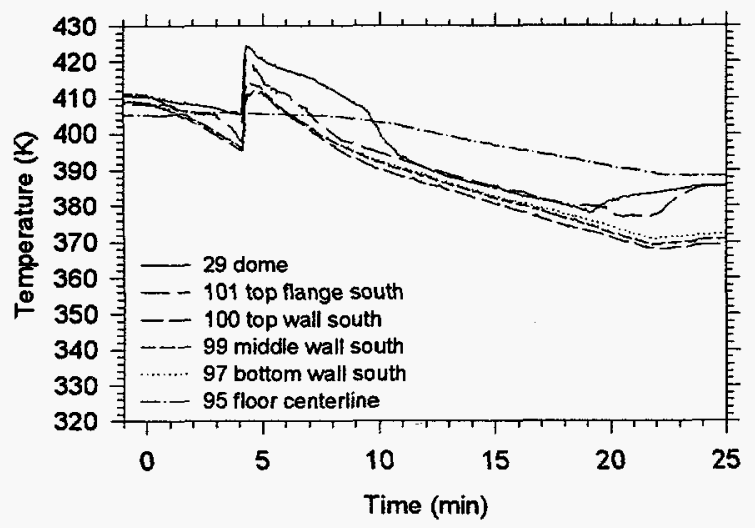

Figure 90. Surtsey vessel dome, wall, and floor temperatures in HIT-8.

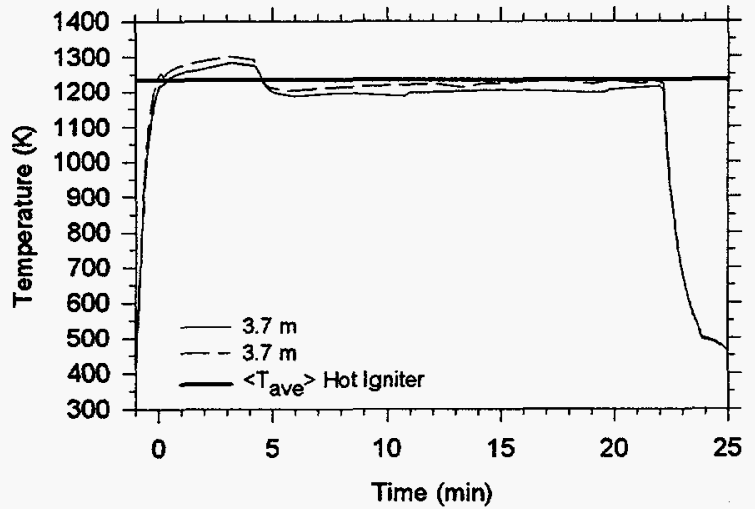

Figure 91. Igniter temperatures in HIT-8.

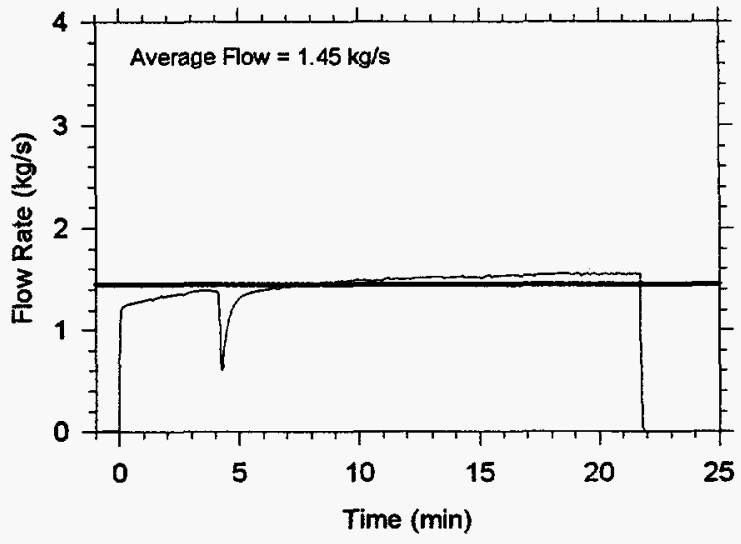

Figure 92. Spray flow rate in HIT-8.

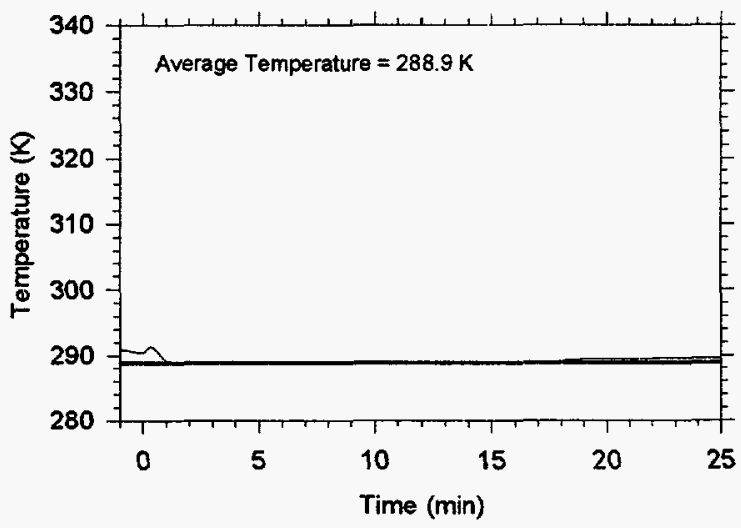

Figure 93. Spray temperature in HIT-8. 
Figures

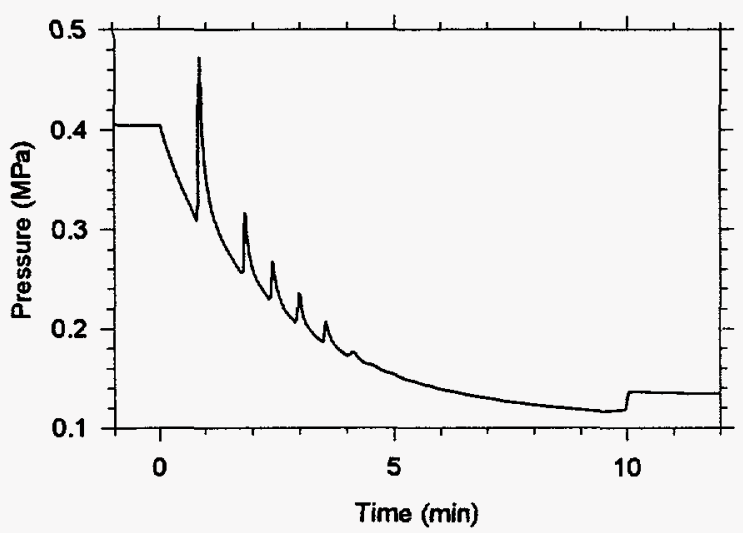

Figure 94. Surtsey vessel pressure in HIT-9.

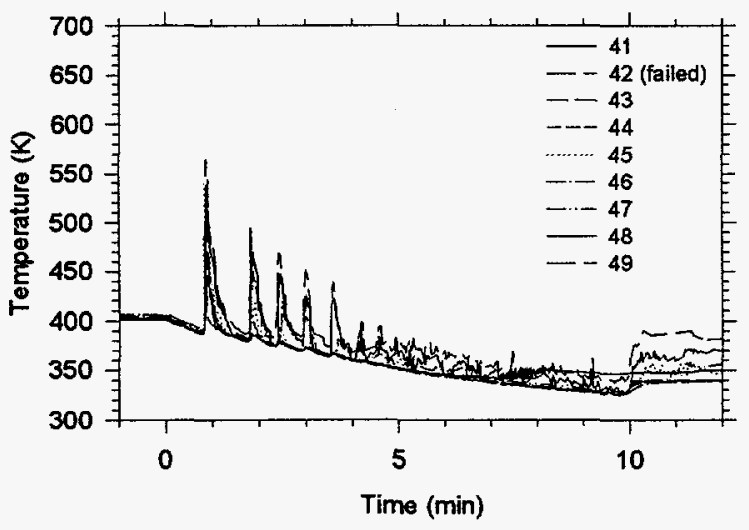

Figure 95. Surtsey vessel gas temperature from thermocouple array A in HIT-9.

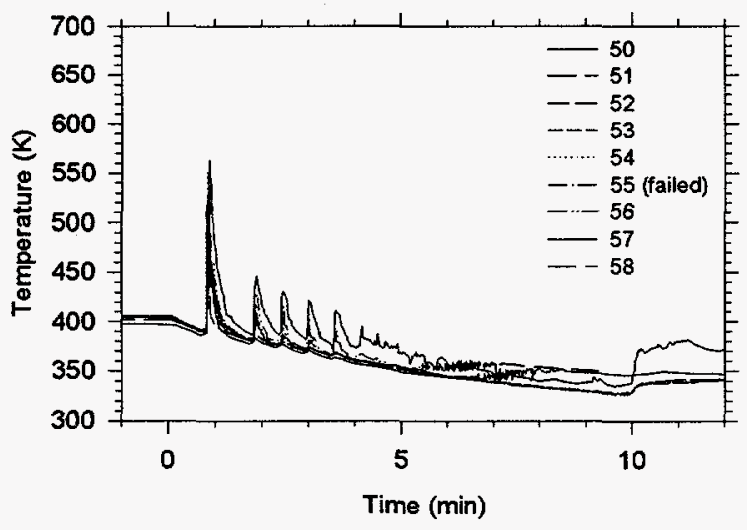

Figure 96. Surtsey vessel gas temperature from thermocouple array B in HIT-9.

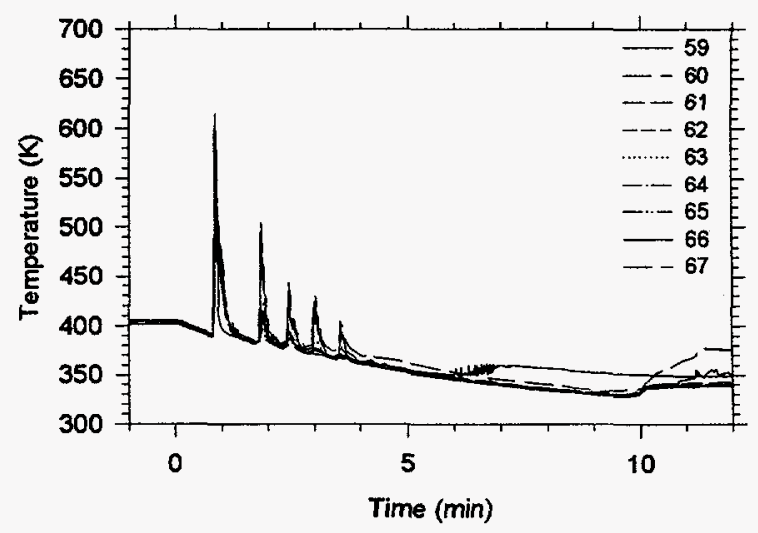

Figure 97. Surtsey vessel gas temperature from thermocouple array C in HIT-9.

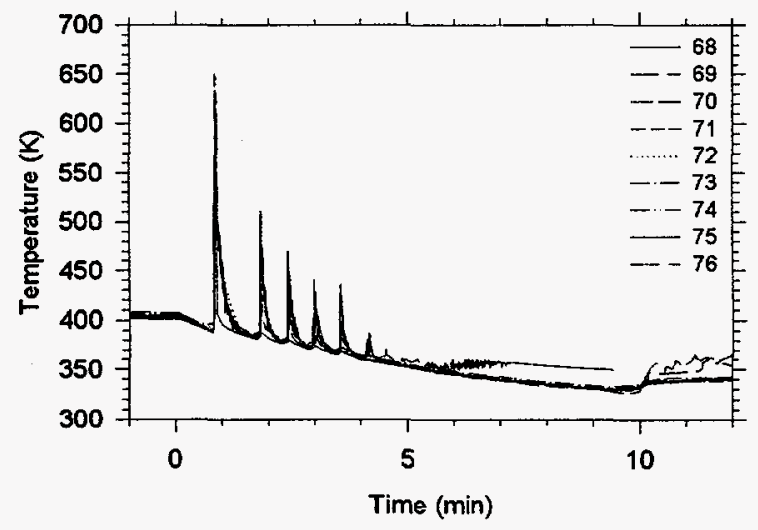

Figure 98. Surtsey vessel gas temperature from thermocouple array $D$ in HIT-9.

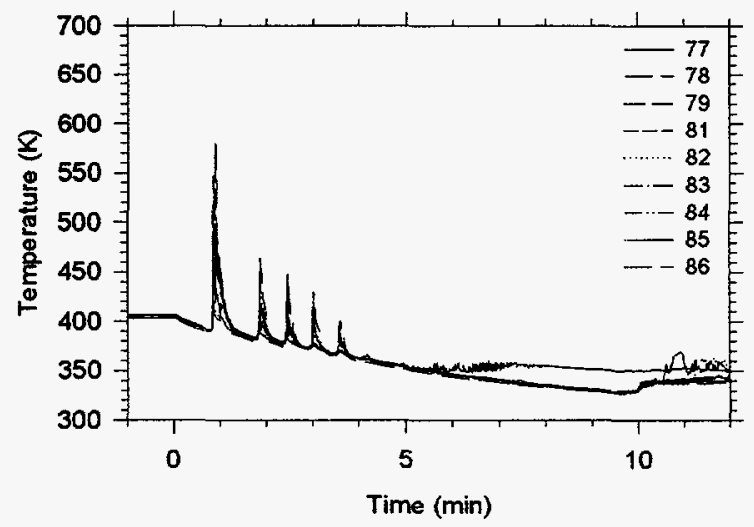

Figure 99. Surtsey vessel gas temperature from thermocouple array E in HIT-9. 


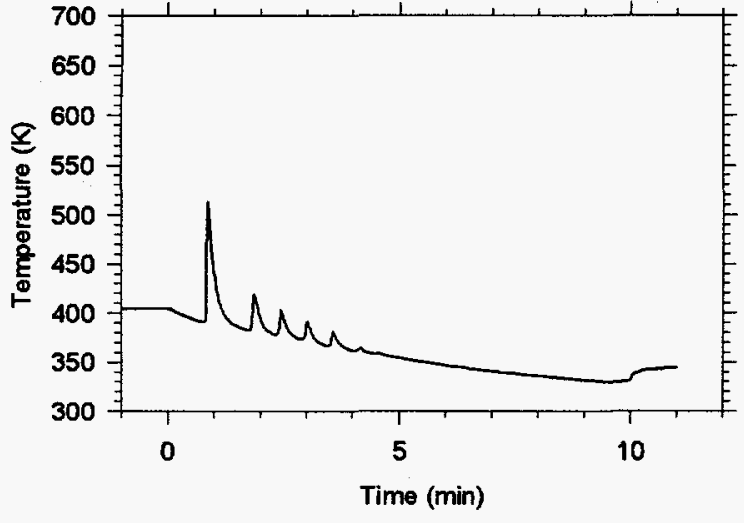

Figure 100. Surtsey vessel average gas temperature in HIT-9.

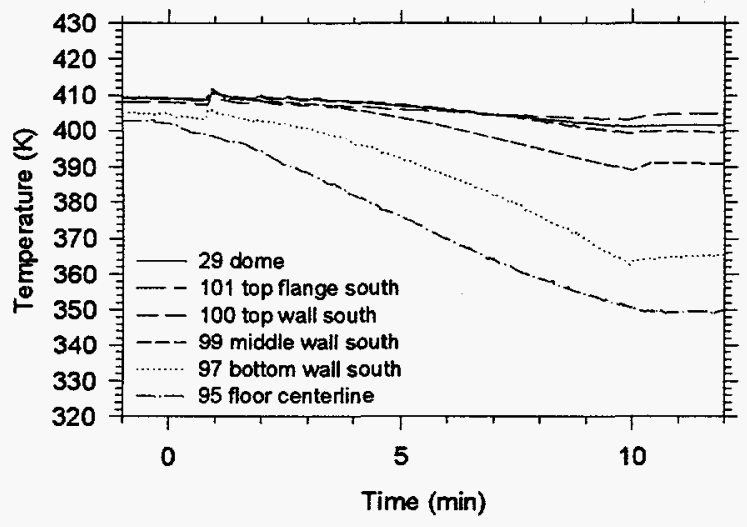

Figure 101. Surtsey vessel dome, wall, and floor temperatures in HIT-9.

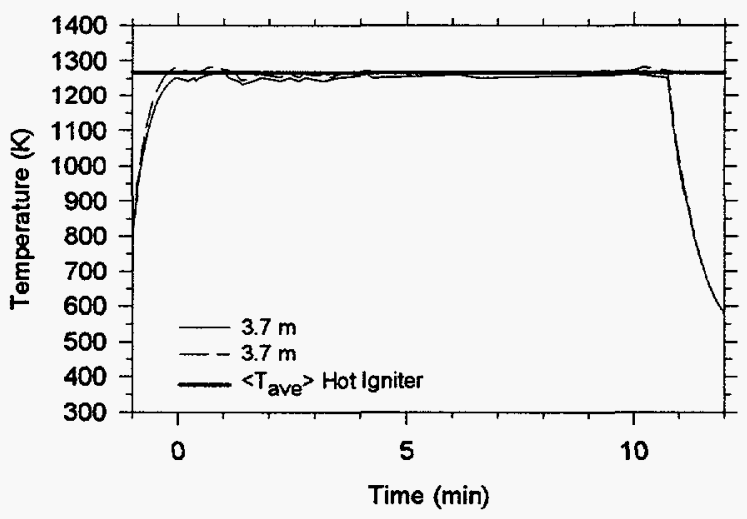

Figure 102. Igniter temperatures in HIT-9.

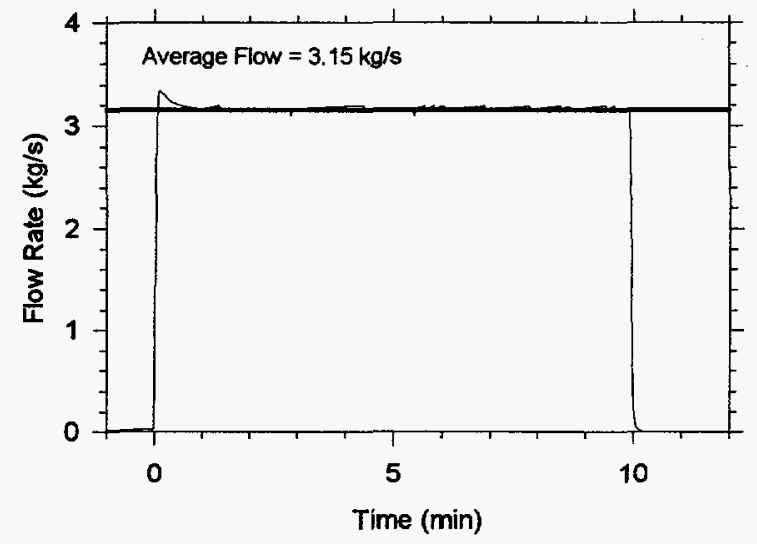

Figure 103. Spray flow rate in HIT-9.

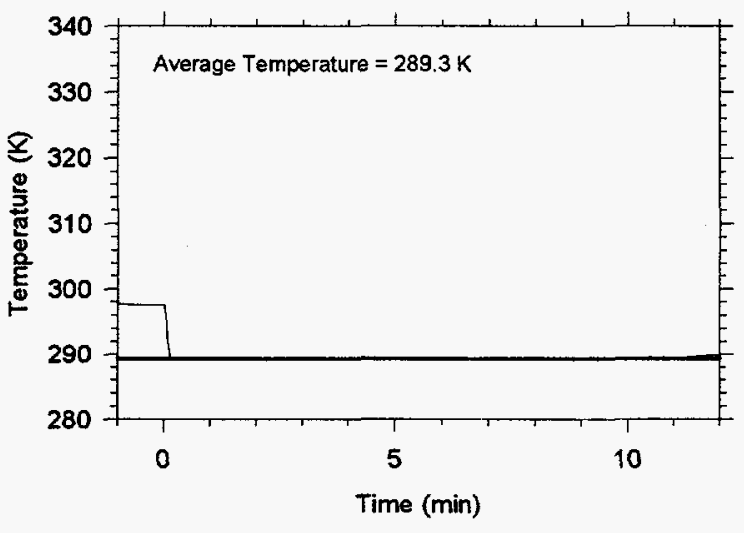

Figure 104. Spray temperature in HIT-9. 
Figures

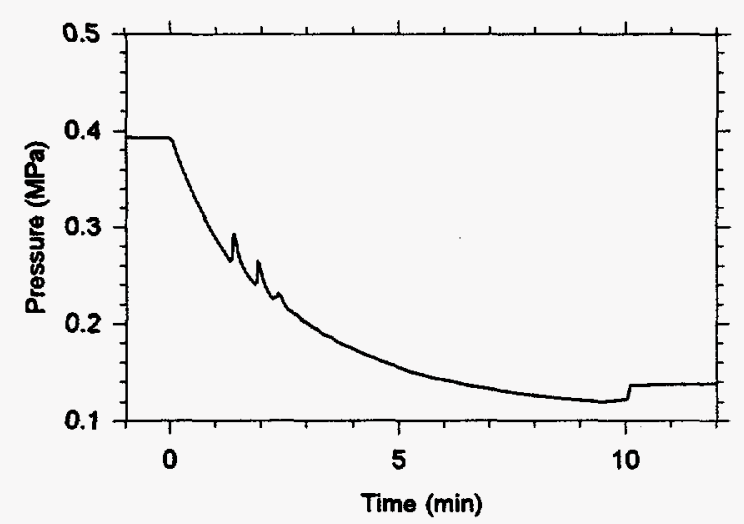

Figure 105. Surtsey vessel pressure in HIT-10.

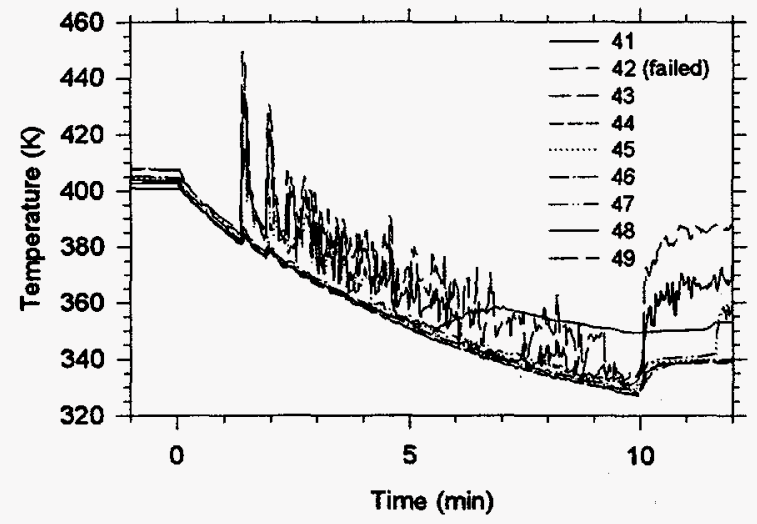

Figure 106. Surtsey vessel gas temperature from thermocouple array A in HIT-10.

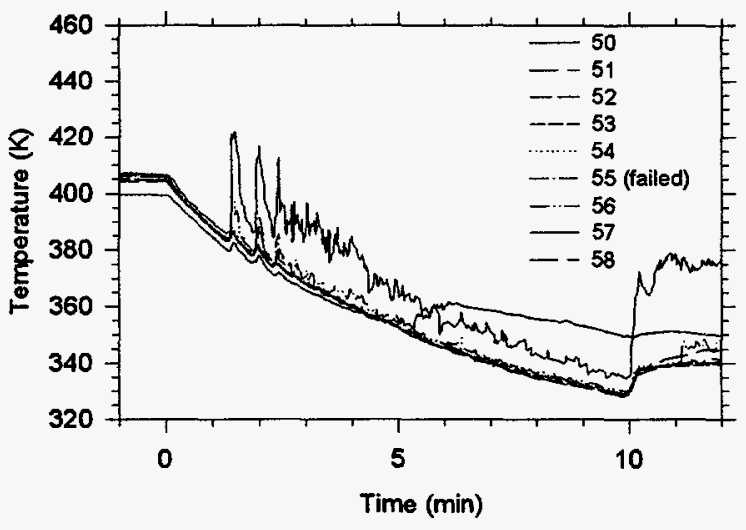

Figure 107. Surtsey vessel gas temperature from thermocouple array B in HIT-10.

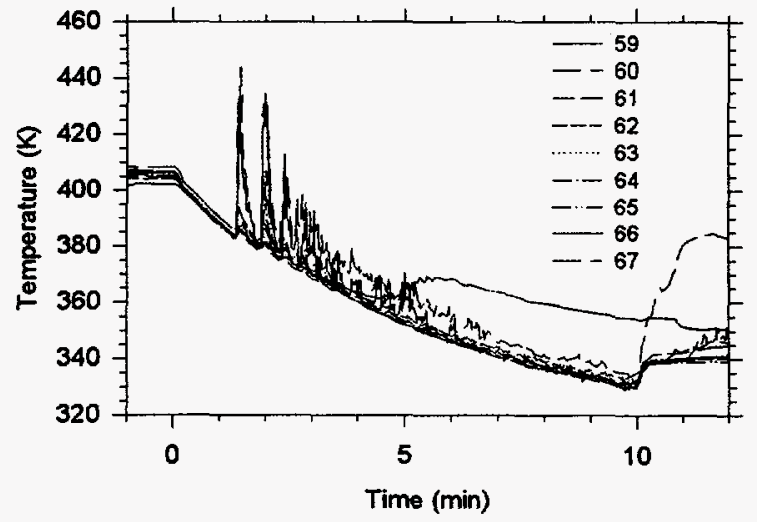

Figure 108. Surtsey vessel gas temperature from thermocouple array C in HIT-10.

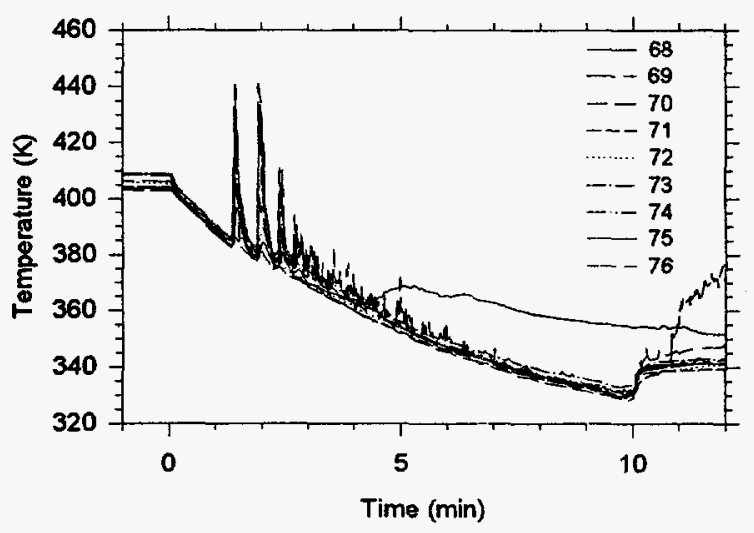

Figure 109. Surtsey vessel gas temperature from thermocouple array D in HIT-10.

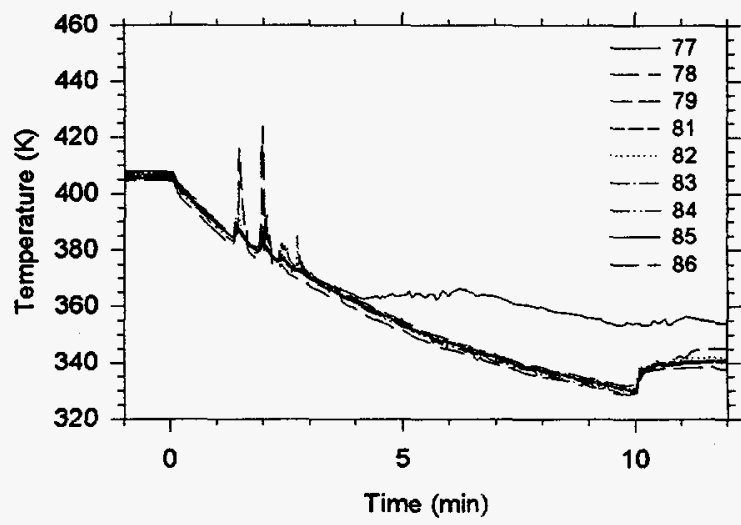

Figure 110. Surtsey vessel gas temperature from thermocouple array E in HIT-10. 


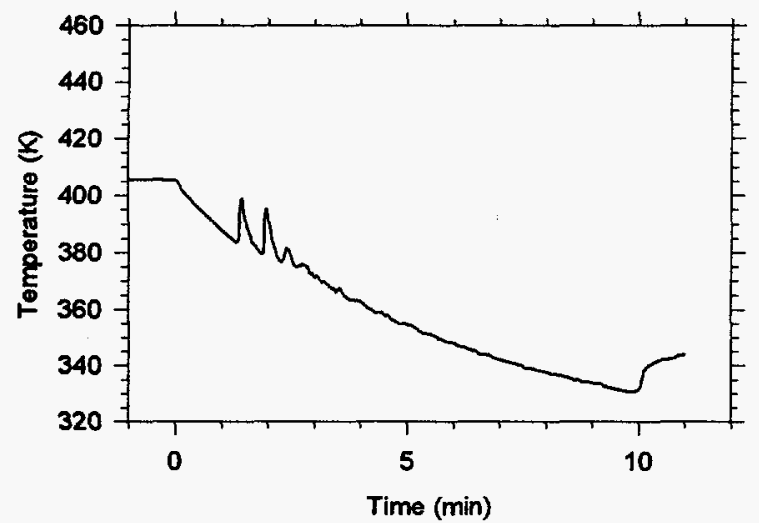

Figure 111. Surtsey vessel average gas temperature in HIT-10.

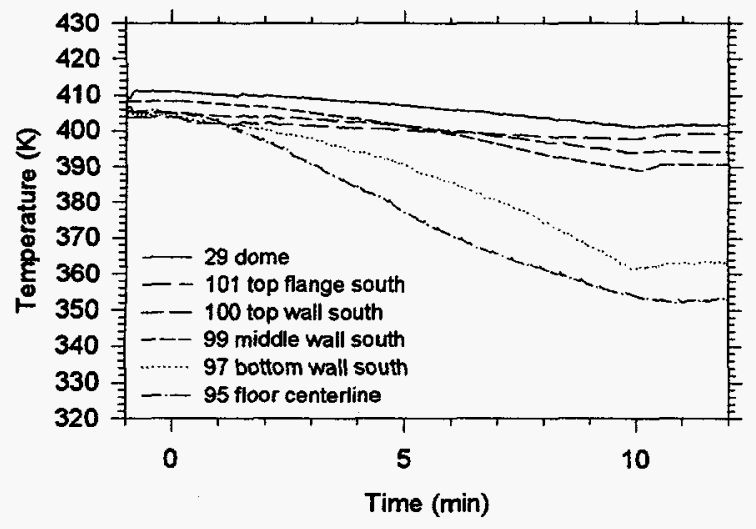

Figure 112. Surtsey vessel dome, wall, and floor temperatures in HIT-10.

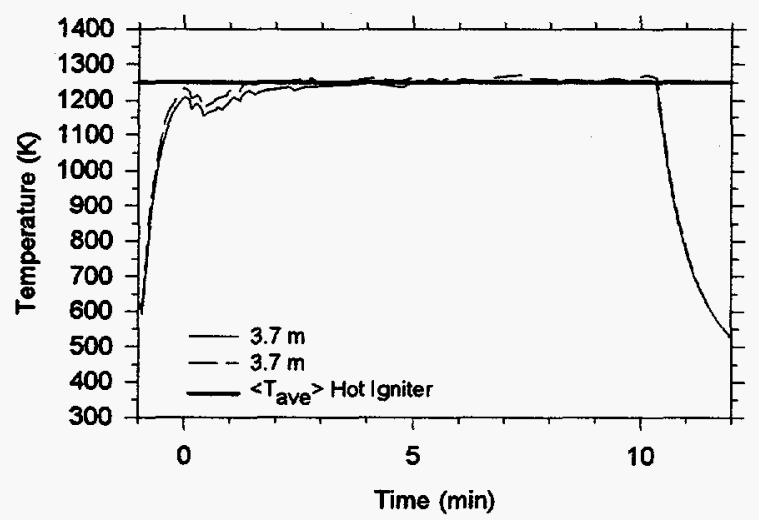

Figure 113. Igniter temperatures in HIT-10.

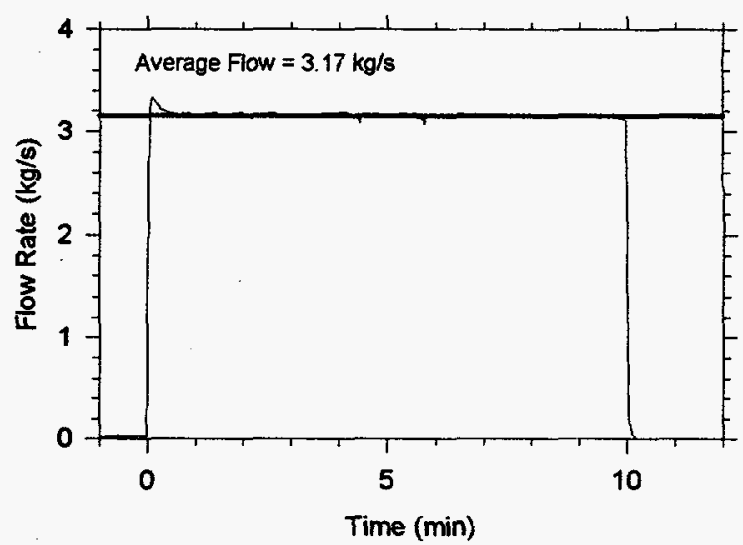

Figure 114. Spray flow rate in HIT-10.

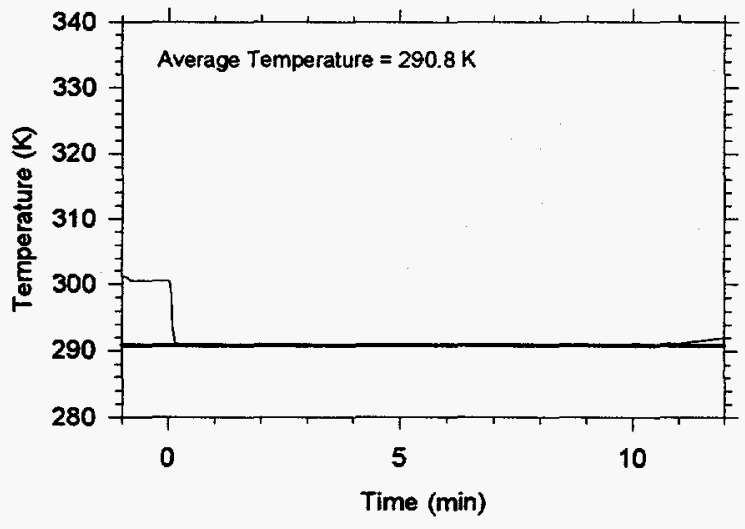

Figure 115. Spray temperature in HIT-10. 
Figures

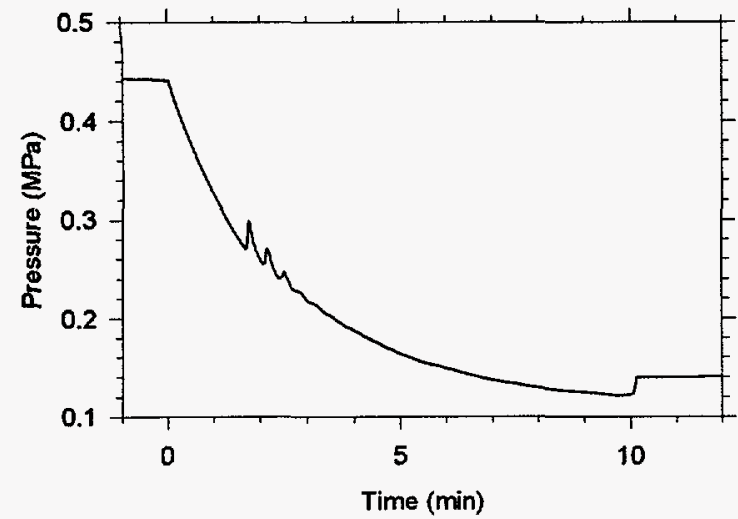

Figure 116. Surtsey vessel pressure in HIT-11.

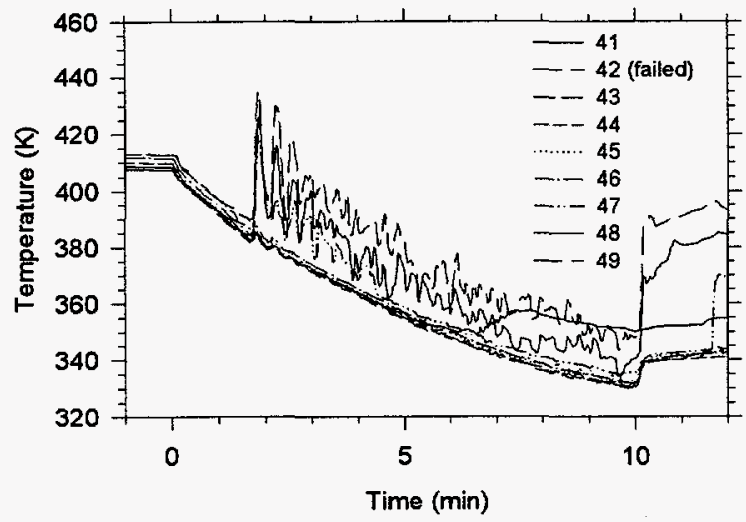

Figure 117. Surtsey vessel gas temperature from thermocouple array A in HIT-11.

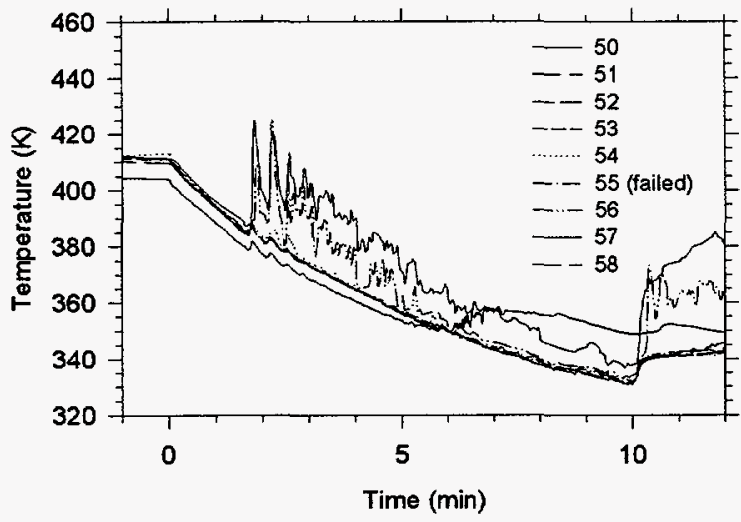

Figure 118. Surtsey vessel gas temperature from thermocouple array B in HIT-11.

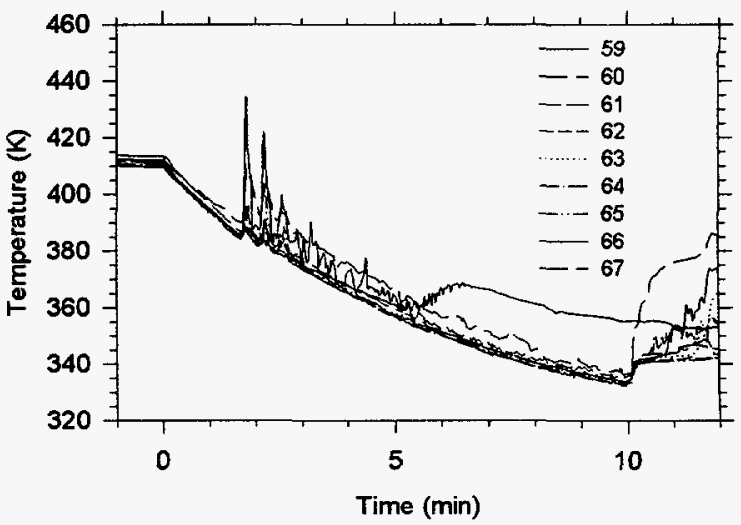

Figure 119. Surtsey vessel gas temperature from thermocouple array $\mathrm{C}$ in HIT-11.

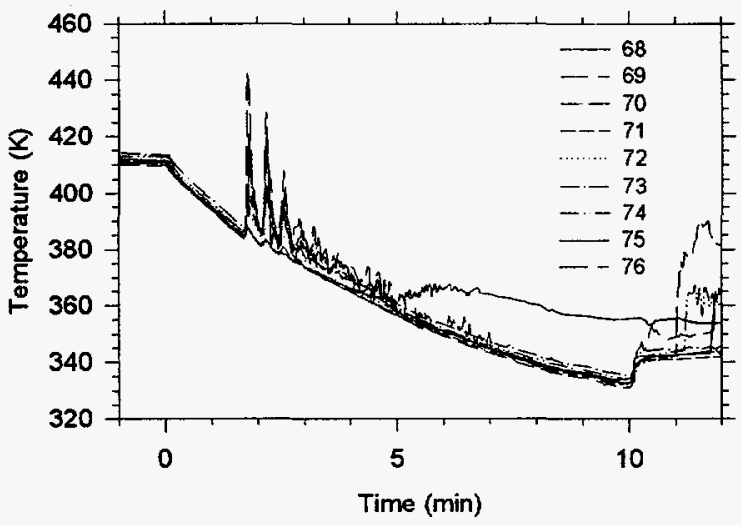

Figure 120. Surtsey vessel gas temperature from thermocouple array D in HIT-11.

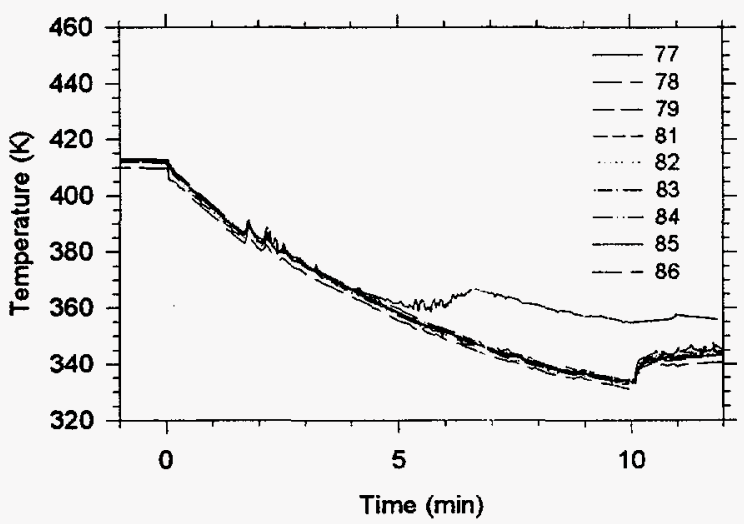

Figure 121. Surtsey vessel gas temperature from thermocouple array $E$ in HIT-11. 


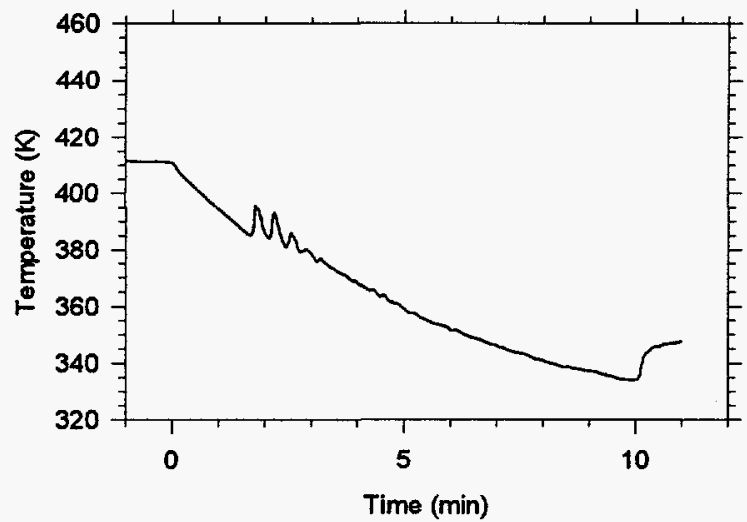

Figure 122. Surtsey vessel average gas temperature in HIT-11.

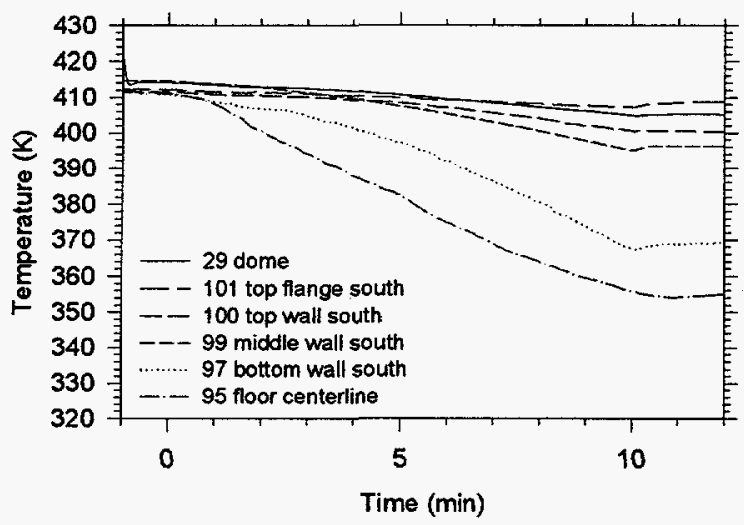

Figure 123. Surtsey vessel dome, wall, and floor temperatures in HIT-11.

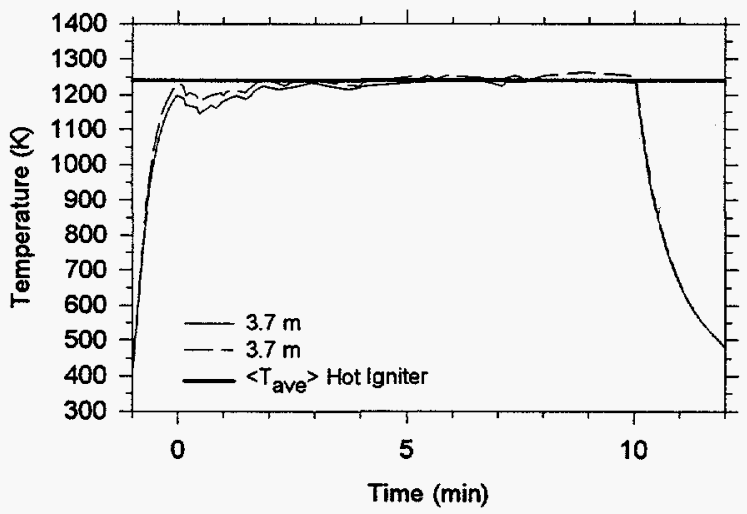

Figure 124. Igniter temperatures in HIT-11.

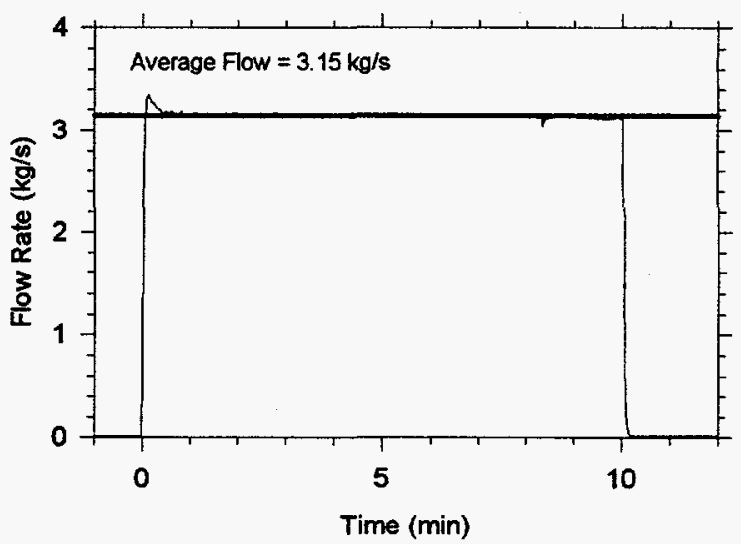

Figure 125. Spray flow rate in HIT-11.

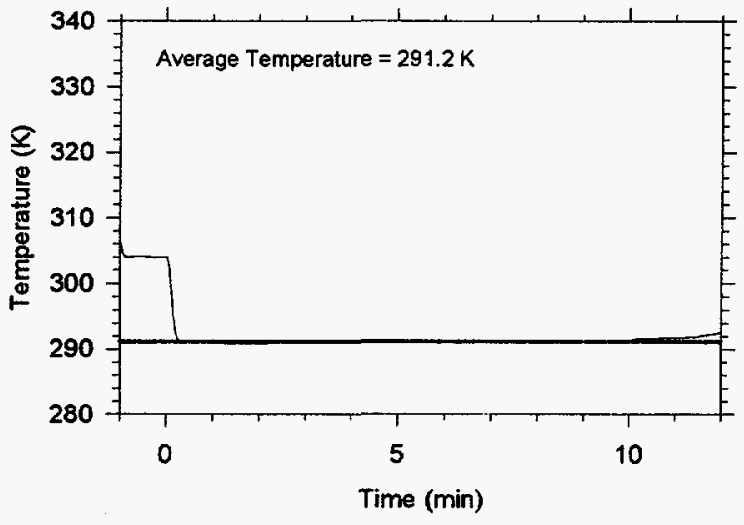

Figure 126. Spray temperature in HIT-11. 
Figures

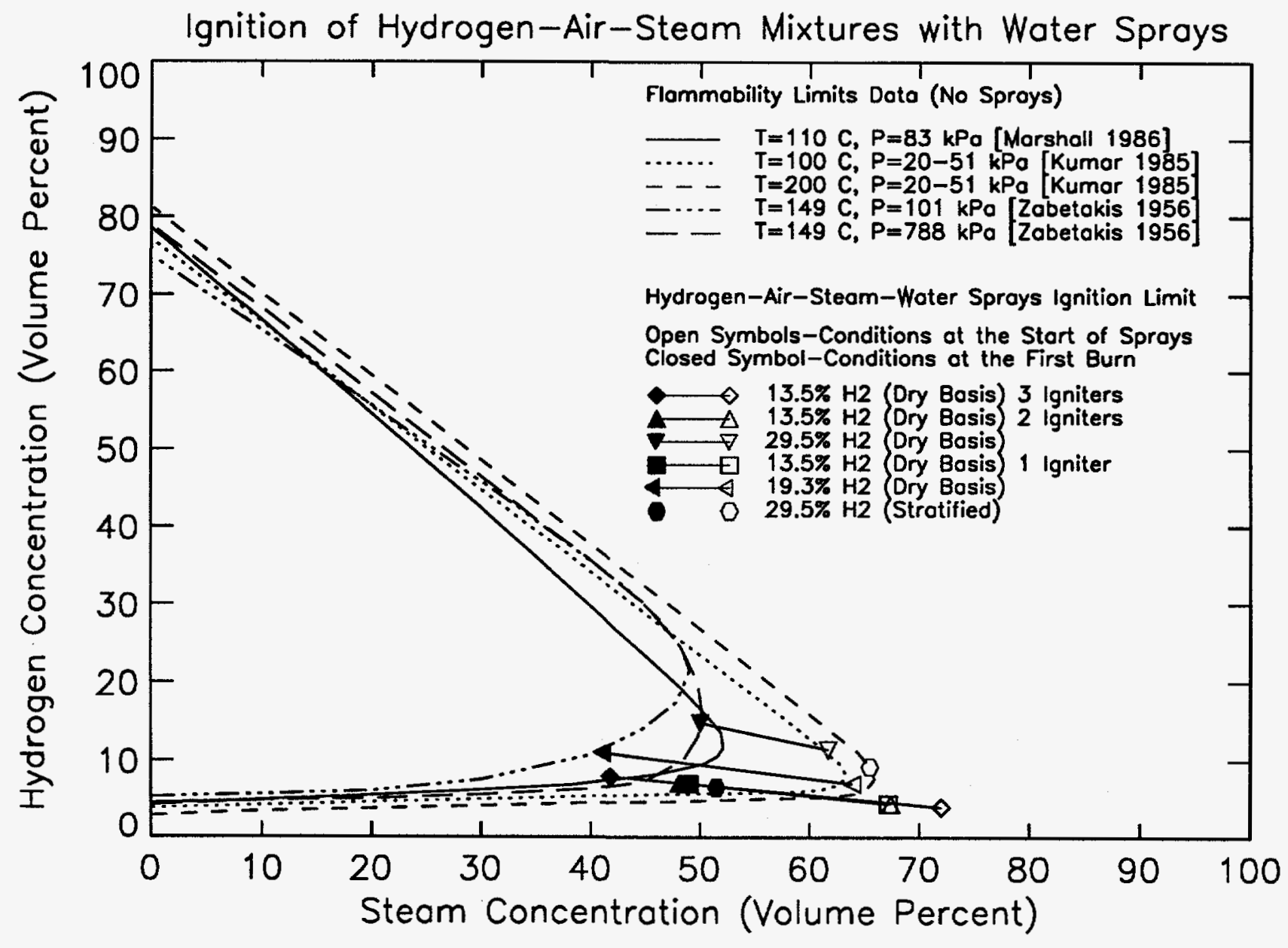

Figure 127. Comparison of experimental results with flammability limits data obtained for quiescent hydrogen-air-steam mixtures. 


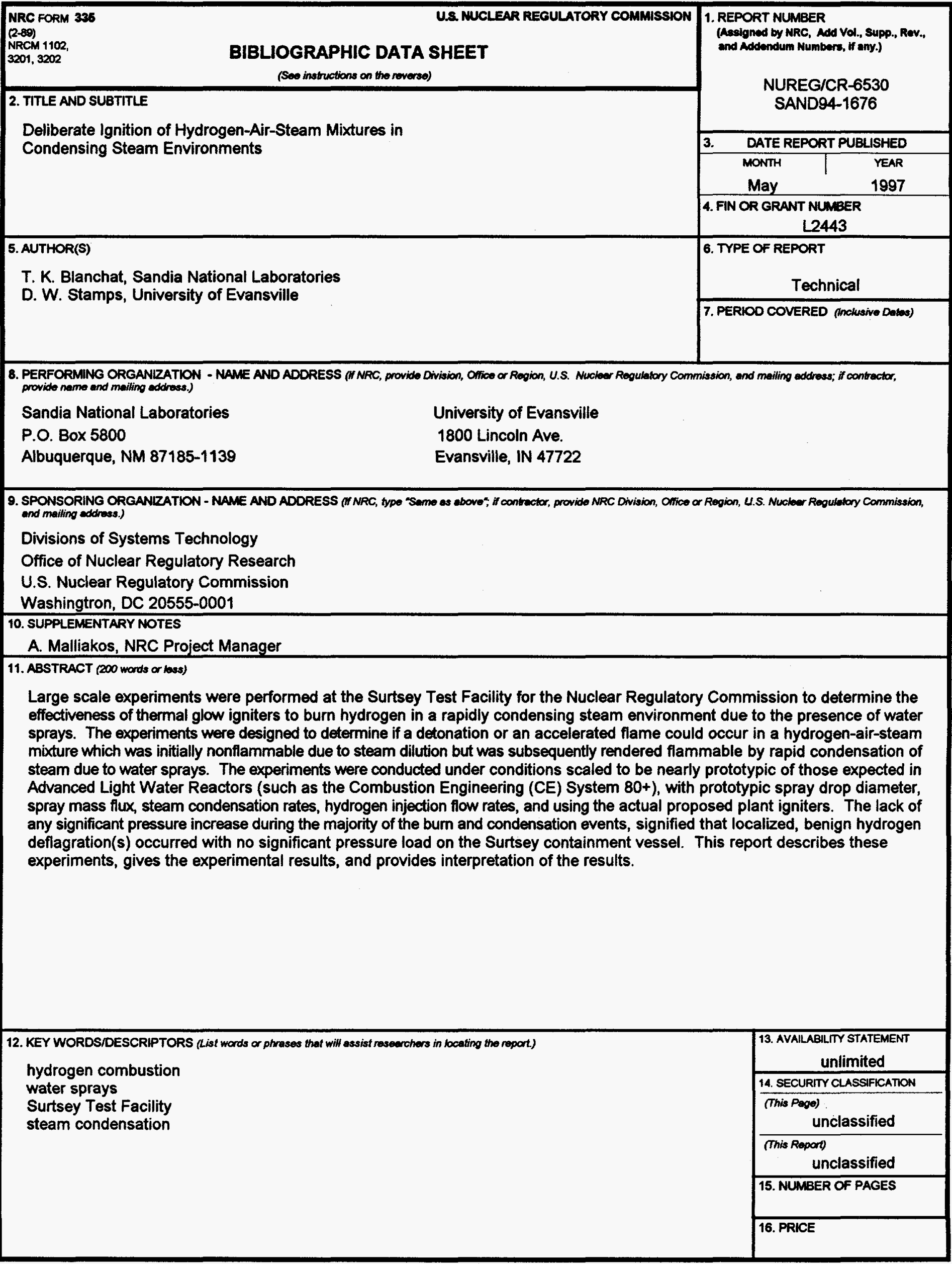

